Shaw" Shaw Environmental, Inc.

Modeling Approach/

Strategy for Corrective

Action Unit 97, Yucca Flat and Climax Mine

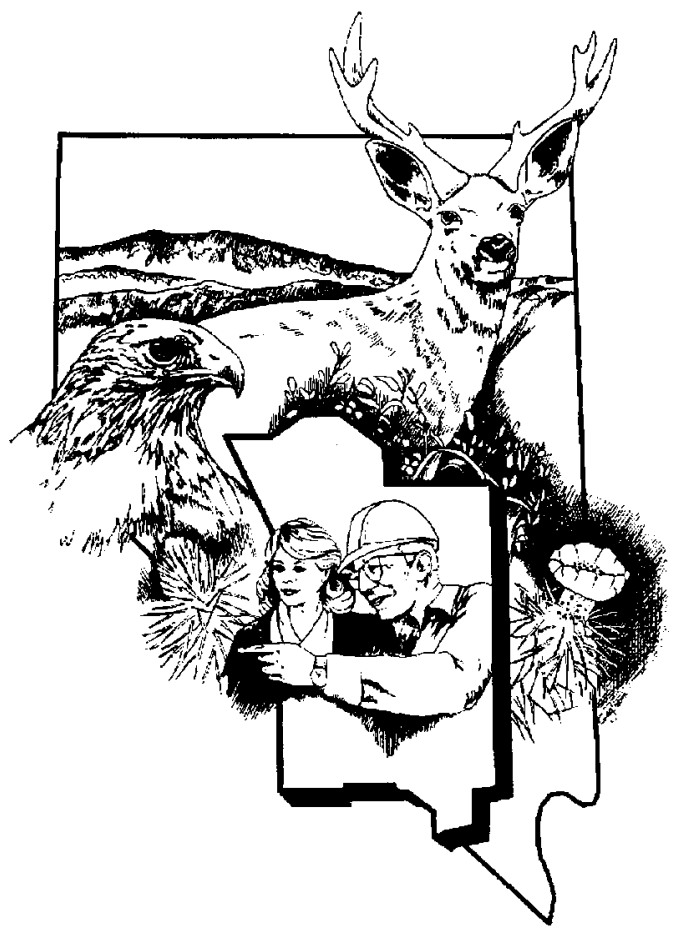

Revision No.: 0

Prepared for U.S. Department of Energy under Contract No. DE-AC08-97NV13052.

Approved for public release; further dissemination unlimited. 
Available for public sale, in paper, from:

U.S. Department of Commerce

National Technical Information Service

5285 Port Royal Road

Springfield, VA 22161

Phone: 800.553 .6847

Fax: 703.605.6900

Email: orders@ntis.fedworld.gov

Online ordering: http://www.ntis.gov/ordering.htm

Available electronically at $\underline{h t t p: / / w w w . d o e . g o v / b r i d g e}$

Available for a processing fee to U.S. Department of Energy and its contractors, in paper, from:

\section{U.S. Department of Energy}

Office of Scientific and Technical Information

P.O. Box 62

Oak Ridge, TN 37831-0062

Phone: 865.576 .8401

Fax: 865.576.5728

Email: reports@adonis.osti.gov

Reference herein to any specific commercial product, process, or service by trade name, trademark, manufacturer, or otherwise, does not necessarily constitute or imply its endorsement, recommendation, or favoring by the United States Government or any agency thereof or its contractors or subcontractors. 


\section{MODELING APPROACH/STRATEGY FOR CORRECTIVE ACTION UNIT 97, YUCCA FLAT AND CLIMAX MINE}

Revision No.: 0

August 2003

Shaw Environmental, Inc.

P.O. Box 93838

Las Vegas, Nevada 89193-3838

Prepared for U.S. Department of Energy under Contract No. DE-AC08-97NV13052.

Approved for public release; further dissemination unlimited. 
MODELING APPROACH/STRATEGY FOR CORRECTIVE ACTION UNIT 97, YUCCA FLAT AND CLIMAX MINE

Approved by: Signature Approved Date: 8/4/03

Ken Wall, UGTA Project Manager

Shaw Environmental, Inc. 


\section{Table of Contents}

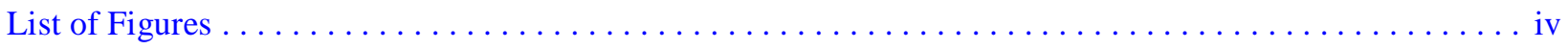

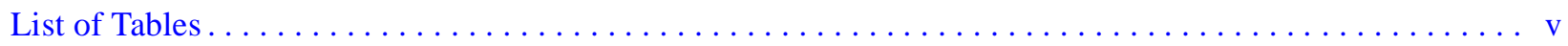

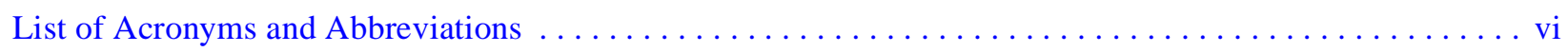

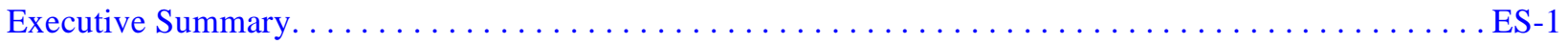

1.0 General Description of the Corrective Action Unit Model Process $\ldots \ldots \ldots \ldots \ldots \ldots \ldots \ldots \ldots$ 1-1

$1.1 \quad$ Role of Modeling in the FFACO Corrective Action Strategy . . . . . . . . . . . . 1-1

1.2 Role of Modeling in Understanding System Behavior . . . . . . . . . . . . . 1-7

1.3 Role of Modeling in a Sparse Data Environment ......................... 1-9

1.4 Overview of Uncertainty and Variability........................ 1-10

$1.5 \quad$ CAU-Specific Aspects . . . . . . . . . . . . . . . . . . . . . . . . . . 1-13

1.6 Quality Assurance ........................................ 1-14

1.7 Modeling Approach for Yucca Flat and Climax Mine $\ldots \ldots \ldots \ldots \ldots \ldots \ldots \ldots \ldots \ldots \ldots \ldots$

2.0 Interpretation of the Yucca Flat/Climax Mine System and Representation in the CAU and Total System Models ...................... 2-1

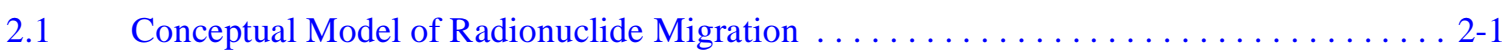

2.2 Development of CAU and Total System Models . . . . . . . . . . . . . . . 2-4

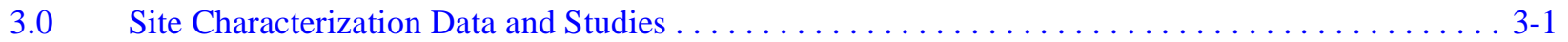

3.1 Site-Specific Historic Data from the Regional Model . . . . . . . . . . . . . . . . . . 3-1

3.2 Relevant Data From Other Sites . . . . . . . . . . . . . . . . . . . . . 3-1

3.3 Documented Models of Components. . . . . . . . . . . . . . . . . . . . . . . 3-2

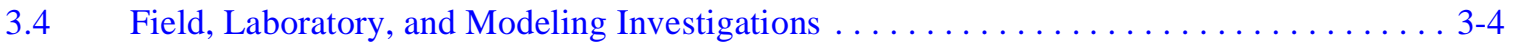

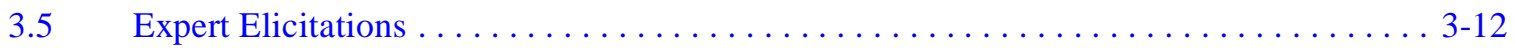

$3.6 \quad$ External Review. . . . . . . . . . . . . . . . . . . . . . . . . . . . . . . 3-13

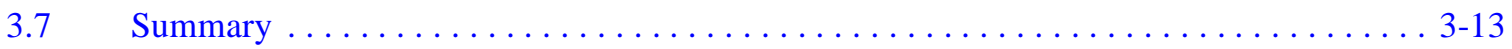

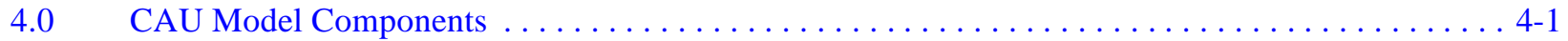

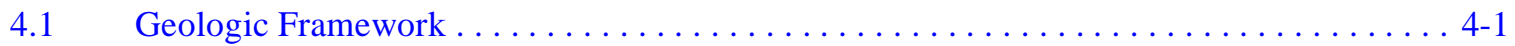

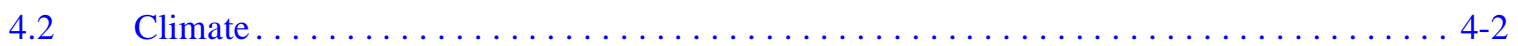

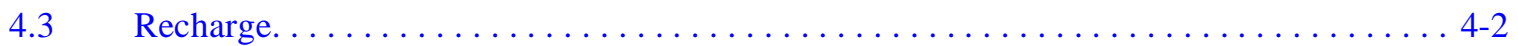

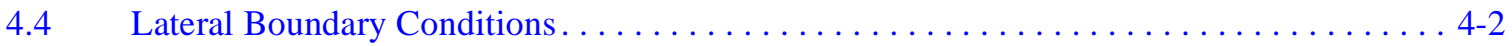

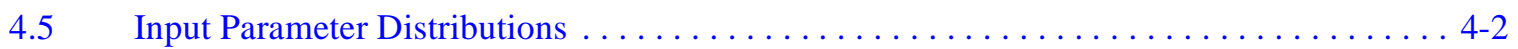

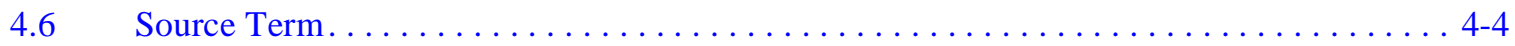

4.6.1 Radiological Source Term.............................. 4-4

4.6.2 Process Scale Modeling of Radionuclide Mobilization in the Exchange Volume and Melt Glass . . . . . . . . . . . . . . . . . . . . . 4-5 


\section{Table of Contents (Continued)}

4.6.3 Abstraction to the CAU Scale . . . . . . . . . . . . . . . . . . . . 4-7

4.6.4 Source Categorization ........................... 4

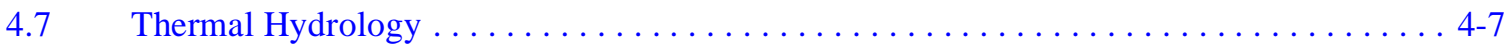

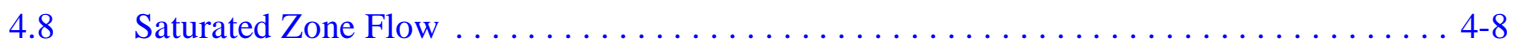

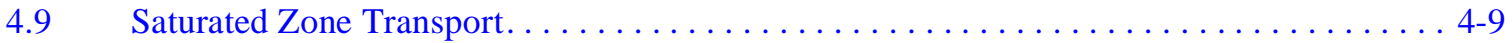

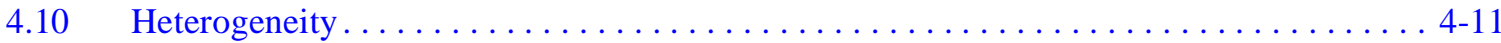

$5.0 \quad$ Implementation of the CAU Model . . . . . . . . . . . . . .

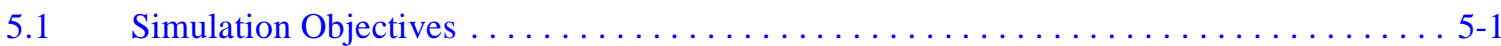

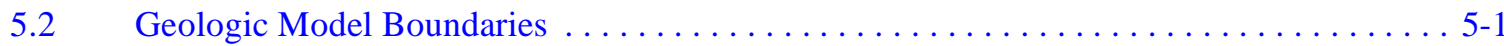

5.3 CAU Model Boundaries and Boundary Conditions ....................... 5-4

$5.4 \quad$ Multiple Alternative Conceptual Models. . . . . . . . . . . . . . . . . . . . . . 5-4

5.5 Sensitivity Analyses for Fault Hydraulic Properties and Recharge. . . . . . . . . . . 5-6

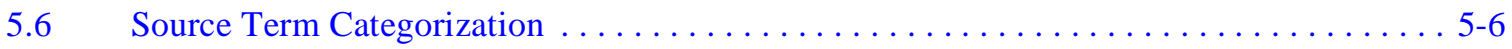

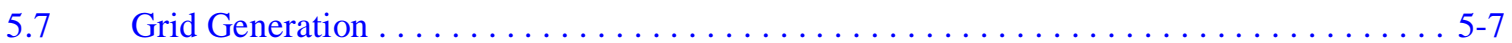

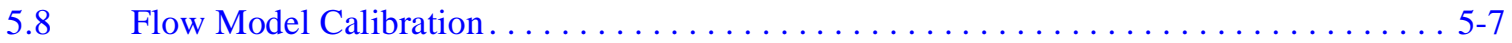

$5.9 \quad$ Local Models . . . . . . . . . . . . . . . . . . . . . . . . . . . . . . . 5-9

5.10 Transport Processes and Parameters Sensitivity Analyses . . . . . . . . . . . . . . . . 5-9

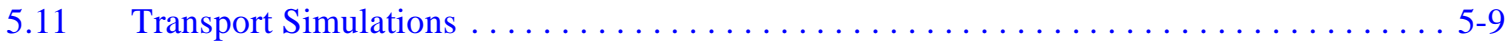

5.12 Model Verification. . . . . . . . . . . . . . . . . . . . . . . . . . . . . . . 5-12

6.0 Total System Model: Components and Implementation $\ldots \ldots \ldots \ldots \ldots \ldots \ldots \ldots \ldots \ldots$ 6-1

$6.1 \quad$ Components . . . . . . . . . . . . . . . . . . . . . . . . . . . . . 6-1

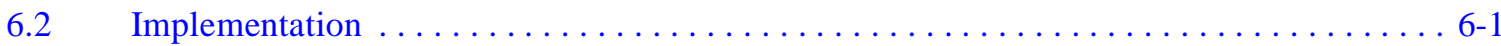

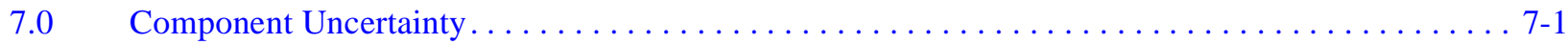

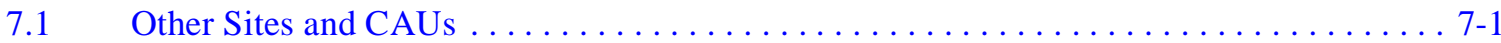

7.2 Parameter and Model Component Uncertainties for Pahute Mesa CAUs............. 7-3

7.3 Treatment of Uncertainty. . . . . . . . . . . . . . . . . . . . .

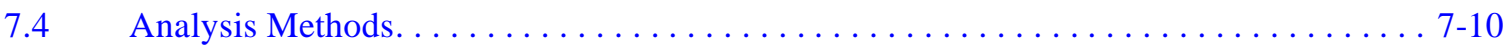

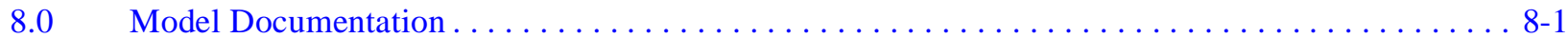

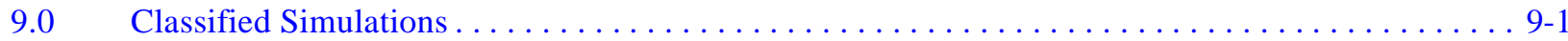

$10.0 \quad$ References . . . . . . . . . . . . . . . . . . .

\section{Appendix A - Code Selection for Yucca Flat/Climax Mine CAU Model}

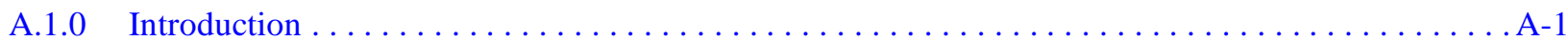

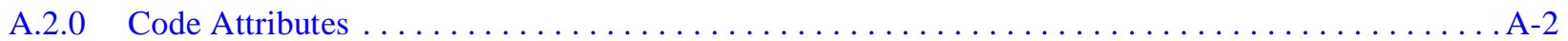

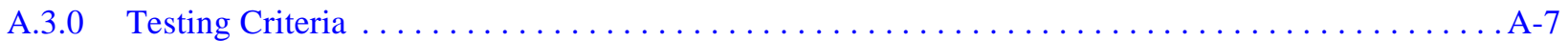




\section{Table of Contents (Continued)}

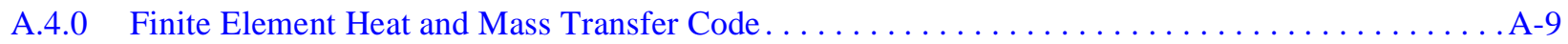

A.5.0 Test Problem Location. . . . . . . . . . . . . . . . . . . . . . . . . . . . . . . . . . . . . . . . . . . . A -10

A.6.0 TYBO-BENHAM Study . . . . . . . . . . . . . . . . . . . . . . . . . . . . . . . . A-12

A.7.0 Performance Evaluation. . . . . . . . . . . . . . . . . . . . . . . . . . . . . . . . . . . . . . . . A A-14

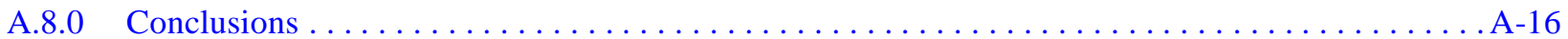

A.9.0 References . . . . . . . . . . . . . . . . . . . . . . . . . . . . . . . . . . . . . A -17 


\section{List of Figures}

Number

Title

Page

1-1 Location of Corrective Action Units on the Nevada Test Site . . . . . . . . . . . . . . . .1-3

1-2 Process Flow Diagram for the Underground Test Area

Corrective Action Units . . . . . . . . . . . . . . . . . . . . . . . . . . . . $1-6$

2-1 Simulated BOURBON Pathline $\ldots \ldots \ldots \ldots \ldots \ldots \ldots \ldots \ldots \ldots \ldots \ldots \ldots \ldots \ldots \ldots \ldots \ldots \ldots \ldots \ldots \ldots \ldots .2$

2-2 Information Flow for the Yucca Flat/Climax Mine CAU Model. . . . . . . . . . . . . . . . .2-5

2-3 Configuration of Codes for the Yucca Flat and Climax Mine CAU Model . . . . . . . . . . . .2-6

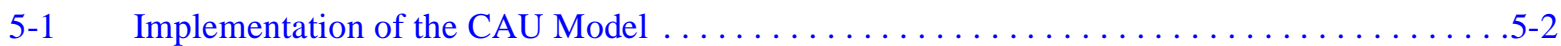

5-2 Location of Yucca Flat/Climax Mine Investigation Area and Potential CAU-Model Area . . . . . . . . . . . . . . . . . . . . . . . . . . . . . . . . . . . .5-5 


\section{List of Tables}

Number

3-1 Numbers of Measurements and Number of Wells Contributing to

Site-Specific Historic Data for Hydraulic Properties . . . . . . . . . . . . . . . . . 3-2

3-2 Numbers of Measurements and Wells Contributing to

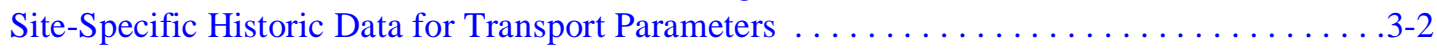

3-3 Modeling Component Supported by the Investigation $\ldots \ldots \ldots \ldots \ldots \ldots \ldots \ldots \ldots \ldots$ 


\section{List of Acronyms and Abbreviations}

AA Alluvial Aquifer

BN Bechtel Nevada

CAI Corrective Action Investigation

CAIP Corrective Action Investigation Plan

CAU Corrective Action Unit

CDF Cumulative Distribution Function

DRI Desert Research Institute

DOE U.S. Department of Energy

EC Equilibrium continuum

ER Environmental Restoration

FEHM Finite Element Heat and Mass Transfer Code

FFACO Federal Facility Agreement and Consent Order

FFCAU Frenchman Flat Corrective Action Unit

FY Fiscal Year

HGU Hydrogeologic Unit

HRMP Hydrologic Resource Management Program

HST Hydrologic Source Term

HSU Hydrostratigraphic Unit

ITLV IT Corporation, Las Vegas

Kd Distribution coefficients

$\mathrm{km} \quad$ Kilometer

Ksat Saturated Hydraulic Conductivity

LaGriT Los Alamos Grid Toolbox

LANL Los Alamos National Laboratory

LCA Lower Carbonate Aquifer

LLNL Lawrence Livermore National Laboratory

m Meter

$\mathrm{m}^{2} / \mathrm{g} \quad$ Square meters per gram

NDEP Nevada Division of Environmental Protection

NNSA/NSO U.S. Department of Energy, National Nuclear Security Administration Nevada Site Office

NTS Nevada Test Site

PDF Probability Density Function 


\section{List of Acronyms and Abbreviations (Continued)}

QA Quality Assurance

QAPP Quality Assurance Project Plan

SDWA Safe Drinking Water Act

THC Thermal-hydrologic-chemical

TSM Total system model

UGTA Underground Test Area

USGS U.S. Geological Survey

1-D One-dimensional

3-D Three-dimensional 


\section{Executive Summary}

The U.S. Department of Energy (DOE), the U.S. Department of Defense, and the State of Nevada have negotiated a Federal Facility Agreement and Consent Order (FFACO, 1996) to address environmental restoration activities at DOE, National Nuclear Security Administration Nevada Site Office (NNSA/NSO) sites. The FFACO sets the framework and contains the requirements for prioritizing and enforcing the environmental restoration activities of contaminated NNSA/NSO facilities and sites including the Underground Test Area (UGTA). The DOE, through the UGTA Project, is responsible for completing corrective actions for five Corrective Action Units (CAUs) associated with historical underground nuclear testing on the Nevada Test Site. The objectives of the UGTA corrective action strategy are to predict the location of the contaminant boundary for each CAU, develop and implement a corrective action, and close each CAU. The process for achieving this strategy includes modeling to define the maximum extent of contaminant transport within a specified time frame. Modeling is a method of forecasting how the hydrogeologic system, including the underground test cavities, will behave over time with the goal of assessing the migration of radionuclides away from the cavities and chimneys. Use of flow and transport models to achieve the objectives of the corrective action strategy is specified in the FFACO.

In the Yucca Flat/Climax Mine system, radionuclide migration will be governed by releases from the cavities and chimneys, and transport in alluvial aquifers, fractured and partially fractured volcanic rock aquifers and aquitards, the carbonate aquifers, and in intrusive units. Additional complexity is associated with multiple faults in Yucca Flat and the need to consider reactive transport mechanisms that both reduce and enhance the mobility of radionuclides. A summary of the data and information that form the technical basis for the model is provided in this document.

Two approaches are proposed for developing the models required to describe these processes. First, detailed numerical process models are developed to represent the processes influencing flow and transport. These models provide the necessary components which are integrated to provide predictions of radionuclide transport. A second modeling approach utilizes simplified representations of the process models to assess the wide range of interactions between model and parameter uncertainty. The extensive groundwater flow system of the Nevada Test Site consists of a large number of heterogeneous aquifers and aquitards. Due to the complexity of the system and the sparse data available, a modeling approach that incorporates the uncertainty in model parameters and model structure is essential.

This document provides an overview of the generic aspects of the UGTA CAU modeling approach. In addition, there are significant differences between CAUs 
that require CAU-specific approaches for particular aspects of the modeling. Approaches specific to the Yucca Flat/Climax Mine CAU are described in this document, with emphasis on the major assumptions, data, inputs, and outputs for each component of the integrated CAU model and an overview of the steps required to implement the integrated CAU model approach. Development and implementation of the system model are described, and the identification and treatment of uncertain processes, and parameters are reviewed. The final sections describe model documentation and constraints imposed on the CAU modeling approach due to the use of classified data for the hydrologic source term. 


\subsection{General Description of the Corrective Action Unit Model Process}

The objectives of the Underground Test Area (UGTA) Project are: (1) evaluate the extent of contamination to the groundwater as a result of past underground nuclear testing on the Nevada Test Site (NTS), (2) develop and implement a corrective action for each Corrective Action Unit (CAU), and (3) close each CAU. A key element of the strategy to meet the UGTA objectives is the development of groundwater flow and radionuclide transport models to predict the migration of contaminants from the underground test locations.

This section provides an overview of the generic aspects of the UGTA CAU modeling approach, a brief review of features and processes that may differ between CAUs, and outlines how the following sections will describe the specific modeling approach for the Yucca Flat/Climax Mine CAU. This overview will address:

- Role of modeling in the Federal Facility Agreement and Consent Order (FFACO) Corrective Action Strategy (FFACO, 1996)

- Role of modeling in understanding system behavior

- Role of modeling in a sparse data environment

- Uncertainty and variability

\subsection{Role of Modeling in the FFACO Corrective Action Strategy}

The U.S. Department of Energy (DOE), the U.S. Department of Defense, and the State of Nevada have negotiated the FFACO to address environmental restoration activities at DOE, National Nuclear Security Administration Nevada Site Office (NNSA/NSO), facilities and sites. The FFACO (1996) is the primary regulatory driver for DOE environmental restoration activities in Nevada. Reference to the FFACO in this document includes amendments to Appendix VI (Corrective Action Strategy), dated December 7, 2000. The FFACO sets the framework and contains the requirements for prioritizing and enforcing the environmental restoration activities of contaminated NNSA/NSO facilities and sites. Technical strategies for these activities are provided in the FFACO. The DOE, through the UGTA Project, is responsible for completing corrective actions for five CAUs associated with historical underground nuclear testing on the NTS. The UGTA Project CAUs (i.e., Frenchman Flat, Western Pahute Mesa, Yucca Flat/Climax 
Mine, Central Pahute Mesa, and Rainier Mesa/Shoshone Mountain) are shown in Figure 1-1. The Yucca Flat and Climax Mine areas were originally designated as two CAUs because the geology of the areas is different. The Climax Mine tests, in northern Yucca Flat, were performed in an intrusive rock body while those conducted in Yucca Flat proper were performed in alluvial, volcanic, and carbonate rocks. During regional modeling efforts, particle-tracking simulations indicated that the Climax Mine groundwater flow system would merge into the Yucca Flat system during the 1,000-year time period of interest; therefore, the two areas were combined into a single CAU (BN, 2001).

Specific requirements established by the FFACO (1996) are to:

II.1.b.ii. "Determine whether releases of pollutants and/or hazardous wastes or potential releases of pollutants and/or hazardous wastes are migrating or potentially could migrate and, if so, identify the constituents, their concentration(s), and the nature and extent of that migration."

The UGTA corrective action strategy, described in Section 3.0 of Appendix VI of the FFACO (1996), was revised in 2000. The UGTA strategy was modified following completion of the DOE review of the Frenchman Flat CAU model. Any subsequent references to the FFACO or its appendices in this document will be made to the FFACO as a whole (i.e., FFACO, 1996). The objectives of the Corrective Action Investigation (CAI) process are specified in the FFACO (1996):

"The objective of the CAI process is to define the boundaries around each UGTA CAU to establish areas that contain water that may be unsafe for domestic and municipal use."

The FFACO (1996) also outlines the objectives of the UGTA Corrective Action Strategy:

"The objective of the strategy is to analyze and evaluate each UGTA CAU through a combination of data and information collection and evaluation, and modeling groundwater flow and contaminant transport. This analysis will estimate the vertical and horizontal extent of contaminant migration for each CAU in order to predict contaminant boundaries."

The FFACO (1996) provides a definition of the contaminant boundary:

"A contaminant boundary is the model-predicted perimeter which defines the extent of radionuclide-contaminated groundwater from underground testing above background conditions exceeding the Safe Drinking Water Act (SDWA) standards. The contaminant boundary will be composed of both a perimeter boundary and a lower hydrostratigraphic unit boundary."

Requirements for modeling results are included in the FFACO (1996):

"The computer model predicts the location of this boundary within 1,000 years and must do so at a $95 \%$ level of confidence. Additional 


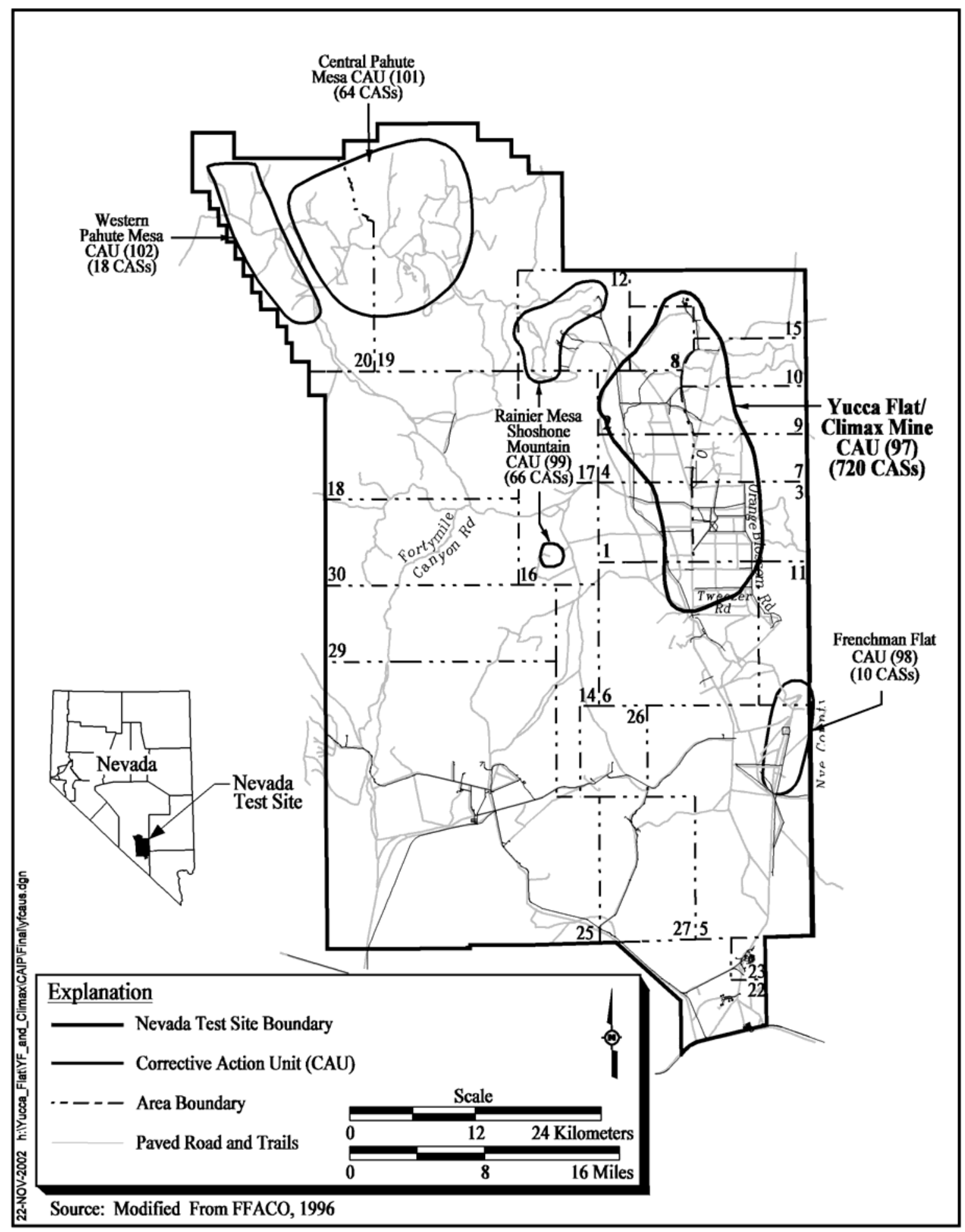

Figure 1-1

Location of Corrective Action Units on the Nevada Test Site 
results showing contaminant concentrations and the location of the contaminant boundary at selected times will also be presented. These times may include the verification period, the end of the five-year proof of concept period, as well as other times that are of specific interest."

The contaminant boundary is the starting point from which a compliance boundary is negotiated between Nevada Division of Environmental Protection (NDEP) and DOE. As defined in the FFACO (1996):

"The compliance boundary will define the area within which the radiological contaminants above the SDWA standards relative to background are to remain. DOE will be responsible for ensuring compliance with this boundary. The compliance boundary may or may not coincide with the contaminant boundary. If the predicted location of the contaminant boundary cannot be accepted as the compliance boundary, an alternative compliance boundary will be negotiated by both parties."

The use of flow models to achieve the objectives of the corrective action strategy is described in the FFACO (1996):

"For saturated conditions, a flow model of each CAU will be constructed to provide local three-dimensional flow, to evaluate the range of flow conditions in the CAU that may be important in determining maximum extent of transport, and to provide boundary conditions for modeling transport. Saturated conditions are planned to be modeled for Frenchman Flat, Yucca Flat/Climax Mine, Western Pahute Mesa, and Central Pahute Mesa CAUs."

The use of contaminant transport models to achieve the objectives of the corrective action strategy is described in the FFACO (1996):

"CAU models utilizing tritium as the source term will be used to establish the contaminant boundary for each CAU. The boundary will be composed of a perimeter boundary and a lower hydrostratigraphic unit boundary. The perimeter boundary will define the aggregate maximum extent of contamination transport at or above the concentration of concern for the CAU. The lower hydrostratigraphic unit boundary will define the lowest aquifer unit affected by the contamination. Long-lived radionuclides, besides tritium, will be included to evaluate the relative extent of migration of different radionuclides in the future. If it is predicted that another radionuclide will migrate farther than tritium at concentrations of concern, the contaminant boundary will include that prediction."

The modeling to predict the locations of the contaminant boundary within 1,000 years requires the integration of multiple individual models, each with a specific purpose. These individual models simulate flow at various scales (regional and CAU), transport, source term, among others. The combination of the individual models is called the CAU model in this document. 
The entire process flow leading to the closure of CAUs, as specified by the FFACO (1996), is shown in detail in Figure 1-2. The upper portion of the figure shows processes designed for the CAI phase. The FFACO requires that several plans and reports be prepared to document the corrective action process. One of these reports is the Corrective Action Investigation Plan (CAIP) that provides or references all specific information for planning and investigation activities associated with corrective action units or sites. The first step in the Corrective Action Strategy for a CAU, as shown in Figure 1-2, is preparation of the CAIP. The use of groundwater models to address the requirements of the FFACO is detailed in the CAIPs for Frenchman Flat (DOE/NV, 1999a), Pahute Mesa (DOE/NV, 1999b), and Yucca Flat/Climax Mine (DOE/NV, 2000a). The CAIP for the remaining $\mathrm{CAU}$ will be written at a later time.

The first steps of the CAI include the evaluation of existing data and the collection and evaluation of new data. In this context, data evaluation may include development of three-dimensional (3-D), CAU-scale flow and transport models. The NDEP then reviews interim and final work products from these activities. The NDEP provides comments to DOE regarding data adequacy and the data evaluation process. From these reviews, DOE and NDEP will make a determination on data adequacy. If either DOE or NDEP determine the data are inadequate, DOE and NDEP will conduct an evaluation of alternatives including determining if the current strategy is achievable. If the strategy is determined to be achievable, DOE will develop and prepare an addendum to the CAIP that will, “....address the identified needs, how these needs are translated into requirements, and what additional work activities will be conducted that are expected to address and/or satisfy these requirements" (FFACO, 1996). As shown in Figure 1-2, following NDEP approval, this action leads to additional data collection and evaluation.

If both DOE and NDEP agree that the data are adequate, DOE will proceed to develop a 3-D groundwater flow and transport model to define the maximum extent of contaminant transport at the CAU scale. A ten-step protocol (DOE, 2000) has been established to demonstrate that a model meets user needs (FFACO, 1996). The ten steps are as follows:

- Establishment of model purpose

- Development of a conceptual model

- Selection of a computer code and verification of code

- Model design

- Model calibration

- Sensitivity and uncertainty analyses

- Model verification

- Predictive simulations

- Presentation of model results

- Post audit

Tritium and other radionuclides that are longer-lived will be evaluated to establish the contaminant boundary for each CAU. The boundary will define the maximum extent of contaminant transport in the horizontal direction as well as the lowest aquifer unit affected, as specified in the FFACO (1996). In addition, CAU 


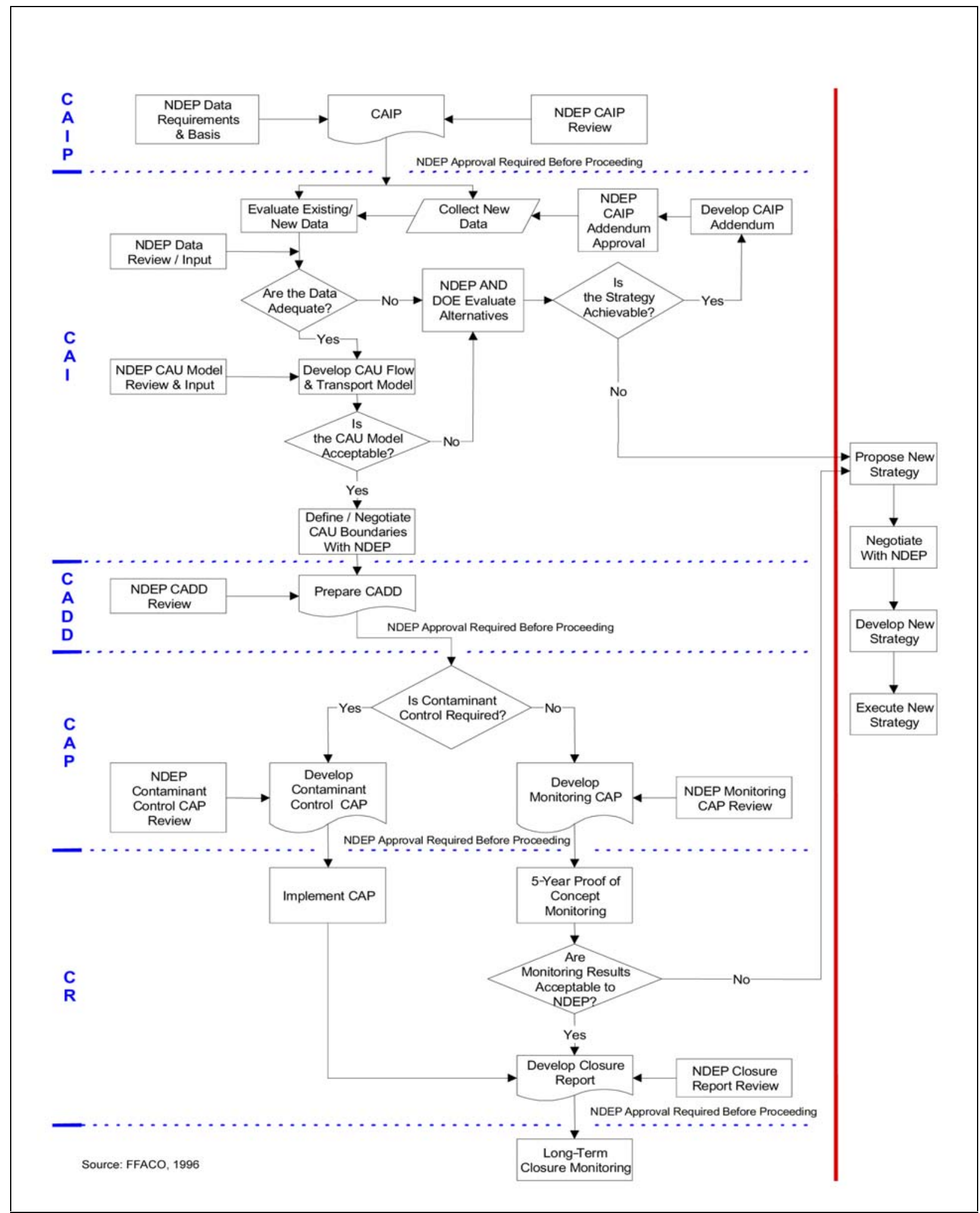

Figure 1-2

Process Flow Diagram for the Underground Test Area

Corrective Action Units 
modeling results will provide the uncertainty associated with contaminant boundary prediction. The DOE and NDEP will review and evaluate the flow and transport modeling to determine if the definition of the contaminant boundary is acceptable. To be accepted, the model must be "fully calibrated and verified." Calibration and verification are defined in the FFACO (1996):

"Calibration refers to the process of refining the model representation of the hydrogeologic framework, hydraulic properties, and boundary conditions to achieve a desired degree of correspondence between the model simulation and observations of the ground-water flow system. Verification is using the set of parameter values and boundary conditions from a calibrated model to approximate acceptably a second set of data measured under similar hydrologic conditions."

The DOE and NDEP review will determine if the CAU model is acceptable. If the model is not acceptable, DOE and NDEP will conduct an evaluation of alternatives including determining if the current strategy is achievable. If the strategy is determined to be achievable, another iteration of development and preparation of an addendum to the CAIP, review, data collection, and evaluation will be conducted to refine the model. If the model is determined to be acceptable, the process will move on to the next step, definition and negotiation of CAU boundaries with NDEP.

\subsection{Role of Modeling in Understanding System Behavior}

Underground nuclear testing at the NTS included a total of 908 detonations in shafts and tunnels with approximately one-third of these tests conducted near or below the water table (DOE/NV, 1997). Groundwater flow away from these sources occurs through diverse and structurally complex rocks

(Laczniak et al., 1996). Given the complexity of the system, sources, and processes controlling transport, computer models will be required as a tool to meet the objectives of the FFACO strategy. The modeling approach used to develop an integrated 3-D model for flow and transport begins with characterization of the system, development of conceptual models based on assumptions of system processes, and representation of these processes mathematically. Mathematical models are then implemented on a computer to represent the system (DOE, 1998).

Following the development of an integrated 3-D model, a total system model will be developed for dynamic probabilistic simulations of mass transport.

\section{Integrated 3-D Model Development}

In developing the Total System Performance Assessment for Yucca Mountain, DOE has successfully addressed many issues in modeling radionuclide migration in a complex natural system (DOE, 1998). Aspects of the modeling approach for Yucca Mountain have been adapted for the UGTA CAU modeling approach as described below. 
Currently, the integrated 3-D flow and transport model is viewed as the model that will provide final decision support for the FFACO Correction Action Strategy. For the purposes of this document, the integrated 3-D flow and transport model will be referred to as the CAU model.

Building the CAU model begins with compiling all site characterization data and relevant information to provide a technical basis for the model. Based on this information, conceptual models are developed that describe how the various system processes work. For particularly complex processes, detailed process models are developed to represent the process in a numerical model. These detailed models are then simplified or "abstracted" to represent the essential aspects of the process in the CAU model. Abstraction in this context is defined as:

"...the development of a simplified mathematical and/or numerical model that reproduces and bounds the results of an underlying detailed process model." (DOE, 1998)

Abstraction is necessary to achieve CAU model objectives for a number of reasons including:

- Without abstraction, models may become so large that they cannot be run efficiently even on large computers.

- The CAU model must be able to utilize probabilistic parameter distributions to adequately account for uncertainty and variability of the system. In order to do this, the model is run many times to explore the impact on predictions of alternative models and ranges of parameters.

- Using overly complex models pose the risk of over representing our actual state of knowledge of system processes because a commensurate amount of data may not be available to characterize the complexity (DOE, 1998).

In the model development process, information flows from the data and information compilation level through conceptual model development, process model development, and abstraction to the level of the CAU model. Moving up the levels from compilations of data, expert elicitations, and reviews, detailed information is synthesized into more distilled forms. For example, stratigraphic and lithologic data from drilling and geophysical logs have been synthesized into a 3-D hydrogeologic model providing the geometry and distribution of hydrostratigraphic units for the Frenchman Flat, and Central and Western Pahute Mesa CAUs. The information contained in these hydrogeologic models is captured using software that allows easy visualization and the ability to export the information to other applications.

The CAU flow and transport models will consist of an integrated set of models, some focused on a small-scale (relative to the CAU) process such as radionuclide release from source regions and some simplifying CAU-scale processes such as reactive transport in fractures to an abstraction for system sensitivity analysis. 
Combined, the models (referred to as component models) constitute the CAU model.

There are two requirements for this integrated model development process to be effective (DOE, 1998). The first requirement is that information moving from level to level must be consistent. Second, essential aspects of the processes described by the detailed process models must be accurately represented in the CAU model. This representation must include the uncertainty associated with the process or parameters.

Multiple component models will be integrated to predict radionuclide migration from underground test locations on the NTS. One-, two-, and three-dimensional numerical models may be used to capture the complex physical and chemical processes of the hydrogeologic system. The integrating numerical model will be a 3-D finite-element flow and transport simulator that captures the complex geologic structure including units of variable thickness, faults, and offsets as well as complex transport processes associated with reactive solutes and fractured rock.

\section{Total System Model}

In addition to the integrated model development, a modeling platform for dynamic, probabilistic simulations will be used to develop simplified abstraction models that will attempt to reduce the description of the system to capture dominant processes and behaviors in one-dimensional (1-D) models of transport. Using this platform, uncertainty in processes and parameters can be explicitly represented. This approach facilitates a more thorough uncertainty analysis of the governing parameters and processes using simplified models. The Total System Model is presented in Section 6.0.

\subsection{Role of Modeling in a Sparse Data Environment}

A major effort of the UGTA Project is to first compile and assess the suitability of the existing data for these models. Modeling of the UGTA CAUs is not a common groundwater contaminant modeling problem. Most groundwater contamination problems consist of migration of contaminants from relatively well-characterized sources over short flow paths through shallow aquifers. There is often some information about contaminant distribution as a result of monitoring and site characterization. In contrast, the Yucca Flat/Climax Mine CAU model, for example, will require prediction of contaminant movement through deep aquifers in a large system (tens of kilometers on a side). Geological observations vary by location, with large amounts of data in the interior of the basin associated with the testing areas and relatively little data on the margins of the basin. The data indicate that geologic units and material properties are heterogeneous in portions of this CAU. Hydraulic head and hydraulic conductivity measurements are limited and unevenly spaced. Of a total of 747 widely distributed contaminant sources that must be considered for Yucca Flat and the Climax Mine, 169 are below or within 100 meters (m) of the water table (DOE/NV, 2000a). Information about sources and radionuclide distribution in the aquifer is sparse. Test cavities in Yucca Flat are as deep as $780 \mathrm{~m}$, making extensive characterization of the 
source and contaminant migration difficult and expensive. Modeling in a sparse data environment requires efforts focused on identifying and reducing key uncertainties. These efforts may include:

- Data from other sites to reduce parameter uncertainty (Freeze et al., 1990)

- Expert interpretive skills to complete or modify models based on knowledge of processes (Morgan and Henrion, 1998)

- Statistical estimation methods to complement process understanding (Kitanidis, 1997)

- System dynamics modeling to assess the impact of data limited uncertainty on the development of transport predictive modeling

\subsection{Overview of Uncertainty and Variability}

The extensive groundwater flow system of the NTS is comprised of a large number of heterogeneous aquifers and aquitards. Due to the complexity of the system, uncertainty will be inherent in the CAU modeling approach. The two major sources of uncertainty in this groundwater model are uncertainty in model parameters and uncertainty in the conceptual models. This section provides an overview of uncertainty that should be considered in the CAU modeling. Specific details are reserved for later in the document.

\section{Parameter Uncertainty and Variability}

Sources of uncertainty in empirical quantities are listed by Morgan and Henrion (1998). Important sources of uncertainty in model parameters for the UGTA CAU models are:

- Random error and statistical variation of direct measurements

- Systematic error and subjective judgement in direct measurements

- Variability

- Inherent randomness and practical unpredictability

- Disagreement

- Numerical model uncertainty introduced by approximations

The first two sources of uncertainty are related to direct measurements of parameters and are treated as part of the data analysis phase.

Many flow and transport parameters are spatially variable. Some parameters such as recharge may also be temporally variable. Where extensive characterization has been conducted, the variability of a parameter may be well specified and can be represented by a frequency distribution with some degree of confidence. In such cases, a model can be developed to include parameter variability. If the variability of a parameter cannot be quantified, the parameter should be treated as uncertain and described using a probability distribution. For the NTS, and Yucca Flat in particular, most parameters will be treated as uncertain. Inclusion of a 
parameter in formal uncertainty analysis will occur after a sensitivity analysis to demonstrate importance of the parameter.

Making a distinction between variability due to sampling from a frequency distribution and parameter uncertainty due to lack of knowledge is important for developing data collection activities. Variability due to inherent randomness or practical unpredictability may be irreducible, while uncertainty due to lack of knowledge may be reduced through data collection and analysis.

Disagreement refers to differences in opinion between informed experts about an uncertain parameter. This is generally treated by first conducting a sensitivity analysis to determine the significance of the disagreement to the results. If the impact is significant, a weighting scheme can be developed to produce an average model, or multiple models can be used to evaluate each opinion.

Numerical models represent simplifications of complex processes. Implementation of models requires approximations such as simplification of mathematical representations, reduction of the dimensionality of the model, representation of fracture flow by equivalent porous media, and choice of spatial and temporal resolution. Additional model complexity comes at the cost of increased computer hardware requirements and increased simulation times. Approximations represent a balance between oversimplification and computational costs. Testing of abstraction models and studies of grid resolution provide information required for achieving an appropriate level of model detail. Validation of any model with laboratory or field data increases the confidence and credibility of the simplifying assumptions associated with the model.

\section{Conceptual Model Uncertainty}

The other source of uncertainty is that which involves the actual model form. For example, the Yucca Flat/Climax Mine CAU model has uncertainty in the hydrogeologic conceptual model, hydrologic conceptual models including lateral boundary conditions, recharge, hydraulic gradients, role of faults, geochemical conceptual models describing fracture-matrix interactions, and source term conceptual models. Uncertainty in the conceptual model(s) is inherently linked to data uncertainty. However, for systems like Yucca Flat and Climax Mine with sparse data, multiple conceptual models may be supported by the same data set.

\section{Propagating Uncertainty}

Since the inputs to the CAU models are uncertain, forecasts of contaminant migration will be uncertain. Once uncertainties in model inputs and model form have been identified, these uncertainties must be propagated through the model to evaluate their impact on the results. Zimmerman et al. (1990) summarize several techniques for propagating data and parameter uncertainty in radioactive water repository performance models. These techniques are: (1) Monte Carlo simulation, (2) response surface methodology, (3) differential analysis, and (4) geostatistical techniques.

The Monte Carlo method can be used for evaluating model input parameter uncertainty. This method consists of randomly selecting a value from the 
distribution for each input parameter. This set of random values is used as input to the model and the position of the contaminant boundary with time is computed. This process is repeated " $n$ " times to produce " $n$ " independent realizations of the contaminant boundary position with time. From these results, the maximum extent of the contaminant boundary during the 1,000-year period is determined for each realization and plotted as a probability distribution. Since in the Monte Carlo method described above each realization is equally likely, the probability associated with any single realization is $1 / \mathrm{n}$.

The response surface method attempts to replace the complex response of the model to various inputs by a system of regression equations that approximate the model response. Conceptually this approach is appealing because the regression equations are computationally simple and allow for rapid calculation. The method is only as good as the ability of the regression model to reproduce system response. In addition, Zimmerman et al. (1990) consider the technique inappropriate for multidimension problems with greater than 50 parameters.

Differential analysis is based on determining a Taylor series approximation for the model in question. Most of the effort is spent determining the partial derivatives of the model response to each of the input parameters. A variety of methods within the differential analysis technique include direct, adjoint, and Green's function techniques. The technique is a local derivative estimator and may not be appropriate for large simulations with large uncertainty where the derivatives are not well represented by local approximations.

The Monte Carlo, response surface, and differential analysis techniques are most easily applied to uncorrelated variables, but can be configured to account for parameter correlation, at least in the rank sense.

Geostatistical techniques allow for the examination of variables that are correlated in space. The geostatistical techniques require the definition of a spatial correlation function, covariance, or variogram. Once defined, the spatial correlation function can be used in conditional or unconditional simulation or stochastic differential equations. Unconditional simulations are multiple realizations of a spatially variable parameter, with each realization having the same statistics. Conditional simulation is the same except that known values are always reproduced in each realization, hence the spatially variable parameter is "conditioned" by the observed values. Stochastic differential equations generally rely upon a linearization of the governing equations and can be applied to analytical models (Gelhar, 1986) or numerical models.

Only parameter uncertainty can be quantitatively implemented by means of the methods described above. Conceptual model uncertainty will be assessed by developing alternative conceptual models representing alternatives in hydrogeologic interpretations and hydrologic and geochemical processes. The process of identifying alternatives cannot enumerate all possible alternatives, nor does it distribute alternatives evenly across the range of all possible alternatives. The impacts of the uncertainties due to alternative conceptual models will be evaluated by examining the sensitivity of the contaminant boundary to the model construct. Uncertainty analyses will be conducted for those alternatives that are 
significantly different. An approach for combining the results of all alternatives to include all system uncertainty is not well defined. Pohll (2003) has suggested that alternatives may be accommodated within the Monte Carlo technique via a

Bayesian approach where the probability of each alternative is determined, in part, by the correspondence of the model results to the observations. In essence, some function of the difference between model predictions and calibration targets would provide a method to weight each alternative relative to the others. This method is computationally feasible, but may be difficult to apply at the CAU scale because the primary model prediction, large-scale contaminant transport, has no corresponding calibration target. One possible solution to this lack of transport calibration targets may come from large-scale geochemical data. Simulation of selected geochemical parameters may provide the necessary data to weight the alternatives. In contrast, assigning probabilities to individual alternatives, while often suggested, is considered inappropriate by some researchers (Morgan and Henrion, 1998). An additional disadvantage of combining all models is that the influence on the combined results of a few cases with large distances to the contaminant boundary may be diluted by a large number of cases showing much less contaminant migration (DOE, 1998). The approach for the UGTA CAUs will be to keep the discrete alternative models separate but the weighting of alternatives will be considered if geochemical simulations prove feasible. Identification and treatment of uncertainty of model components is discussed in detail in Section 7.0.

\subsection{CAU-Specific Aspects}

The previous sections have provided an overview of the generic aspects of the UGTA CAU modeling approach. However, there are significant differences between CAUs that will require CAU-specific approaches for particular elements of the modeling approach. The External Peer Review Report on Frenchman Flat Data Analysis and Modeling Task for the Underground Test Area Project

(IT, 1999b) and an unpublished internal review by the modeling subcommittee of the Technical Working Group listed a number of features and processes that may differ between CAUs. These features and processes included:

- Host geology

- Anticipated mechanisms of transport

- Number of tests in a CAU

- Test yields and their radionuclide inventories

- Depth of burial of tests and relation to the water table

- Nature of the hydrologic source term

- Expected radionuclide attenuation reactions in surrounding rocks

- Location of the tests relative to potential receptors

The review panel concluded that while the underlying scientific and engineering thinking of a modeling approach could be applied consistently for all CAUs, specific codes and modeling strategies would need to be CAU-specific. While this section has provided the generic elements of the modeling approach, specific modeling approach requirements for particular CAUs are addressed later in this document. 


\subsection{Quality Assurance}

A comprehensive Quality Assurance program has been developed for all activities performed under the UGTA Project. That program is documented in the UGTA Quality Assurance Project Plan (QAPP), Revision 3, dated August 2000 (DOE/NV, 2000b). Section 5.1 of the UGTA QAPP addresses the evaluation of data, including existing data. The quality assurance requirements for modeling are specified in Section 5.2 of the UGTA QAPP (DOE/NV, 2000b) and generally consist of software/hardware configuration control, technical evaluation of new codes, code verification and validation activities, and software documentation. Output from modeling runs will be well documented and traceable to the code from which it was generated. Participating organizations' procedures will provide details for the specific methods used for performing these activities.

\section{Software/Hardware Configuration Control}

The primary modeling codes selected for this work were selected, in part, because the codes are maintained by their respective creators under software configuration control. This was done to ensure consistent quality of the codes. To maintain hardware control, selected test problems will be run to ensure the integrity of results.

\section{Technical Evaluation of New Codes}

The code evaluation process presented in Appendix A includes a technical evaluation of the primary modeling codes.

\section{Code Verification and Validation Activities}

The code evaluation and selection process presented in Appendix A ensures that only codes with documented verification and validation are selected.

\section{Software Documentation}

As presented in Appendix A, only codes that are well documented will be selected for the CAU modeling.

\section{Auxiliary Codes}

During the modeling process, auxiliary codes are sometimes required to perform simple tasks such as converting a file from one format to another, or performing simple processing of data to create input values for the model. The contractors have procedures in place that govern the testing, verification, validation, and documentation of each of these auxiliary codes.

\subsection{Modeling Approach for Yucca Flat and Climax Mine}

The remaining sections of this document describe the modeling approach for Yucca Flat and Climax Mine. Section 2.0 is an overview of the current interpretation of the Yucca Flat/Climax Mine groundwater system and a discussion of how the system will be represented in the CAU and total system 
models. It provides the general conceptual model of contaminant migration in Yucca Flat and a description of the component models integrated into a predictive framework for the CAU. The flow of information from data to process models to the CAU model is described and the necessity of including uncertainty and variability is discussed. Section 3.0 provides a summary of the data and information that forms the technical basis for the CAU and total system models. The components of the CAU model are presented in Section 4.0. The implementation of the CAU model is described in Section 5.0. This section also shows how the model components described in Section 4.0 will be linked into an integrated framework to provide decision support for the FFACO Corrective Action Strategy. Section 6.0 describes implementation of the total system model. Section 7.0 describes the identification and treatment of uncertainty of model components due to parameter values, features, and processes. Section 8.0 describes documentation of the CAU and total system models, and Section 9.0 discusses issues associated with classified simulations. 


\subsection{Interpretation of the Yucca Flat/Climax Mine System and Representation in the CAU and Total System Models}

This section presents the current conceptual model of radionuclide migration from test cavities in Yucca Flat and the Climax Mine. Also included is an introduction to the process by which the conceptual model will be represented in the CAU and total system models. The flow of information from data collection through process model development to the CAU model is described. Information flow for the total system model is described and the codes used to provide the required CAU model components and their linkages are presented.

\subsection{Conceptual Model of Radionuclide Migration}

In the Yucca Flat/Climax Mine System, radionuclide migration will be governed by releases from the cavities and chimneys and transport in alluvial aquifers, fractured and partially fractured volcanic rock aquifers and aquitards, the carbonate aquifer, and in intrusive units. The intrusive units are likely fractured, but the degree of fracturing is limited; thus, these units will act as confining units. Additional complexity is associated with the multiple faults in Yucca Flat and the need to consider reactive transport mechanisms that both reduce and enhance the mobility of radionuclides. While a number of UGTA studies are planned for investigating flow and transport processes at multiple scales for the Yucca Flat/Climax Mine System, four completed UGTA investigations help in developing the conceptual model. These four studies include the regional model, CAMBRIC Hydrologic Source Term (HST), CHESHIRE HST, and TYBO/BENHAM intermediate-scale model.

Regional-scale simulations of tritium migration (DOE/NV, 1997) aid in the development of a conceptual model for flow and transport in Yucca Flat and the Climax Mine. Groundwater flow paths from test locations were identified by particle tracking using head and flux distributions from the regional groundwater flow model. Tritium concentrations along selected pathlines were then simulated using a 1-D finite-element model. The test locations and predicted pathline are shown in Figure 2-1. Simulated radionuclide migration begins at each test KANKAKEE, BOURBON, MICKEY, and TORRIDO located along the flow path. The particles were started within the Lower Carbonate Aquifer (LCA) and migrated southward discharging in the Alluvial Aquifer (AA) at the Franklin Lake discharge area.

Two HST modeling studies concerned with underground nuclear tests were conducted and further the development of the conceptual model. The investigation of radionuclide migration in the near-field at the CAMBRIC test 


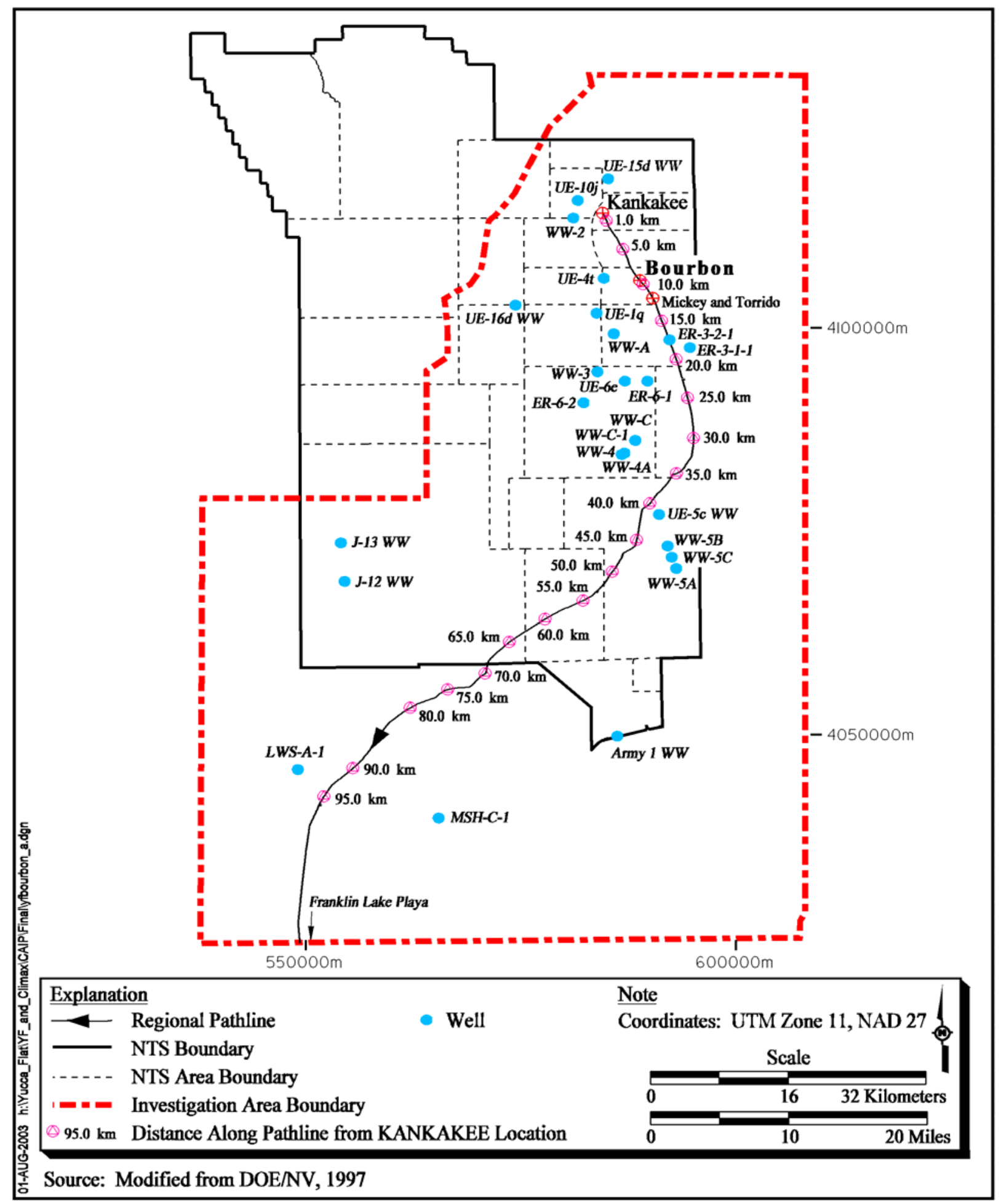

Figure 2-1

Simulated BOURBON Pathline 
(Tompson et al., 1999; Pawloski et al., 2002a) in Frenchman Flat and CHESHIRE test (Pawloski et al., 2001) on Pahute Mesa provide a conceptual model for transport after an underground nuclear test. Further details on these studies can be found in Section 3.4. These authors describe an "exchange volume" consisting of the collapsed cavity, chimney, and sidewalls which contain a significant portion of the radionuclide inventory. The melt glass is the formerly molten material that moved to the bottom of the cavity shortly after detonation. The melt glass contains the majority of long-lived radionuclides and releases them slowly. The exchange volume contains both nonreactive and reactive radionuclides that are released at different rates and via different processes. The rate at which radionuclides are released and transported away from the test location depends on a number of factors including:

- Dissolution rate of the glass

- Form of the released radionuclides

- Reactivity of released radionuclides

- Solubility of the aqueous radionuclides

- Rate of water movement through the exchange volume

- Distribution of reactive minerals

Melt glass dissolution rates were governed by temperature, surface area, silica concentration, $\mathrm{pH}$, and precipitation of secondary minerals. Thermal convection in the chimney due to geothermal and test-related heat was found to influence the initial upward migration of more mobile radionuclides for several decades following the test. The time frame of test-related heat is expected to vary from test to test. The flux of radionuclides in the near-field was also influenced by heterogeneity in the physical and reactive properties of the rock.

An investigation at an intermediate scale focused on the TYBO and BENHAM tests on Pahute Mesa provides a connection between the CAU and source term scale issues (Wolfsberg et al., 2002). A specific objective of this investigation included tracing quantities of plutonium at TYBO observation wells that originated from BENHAM. A three component approach was developed that integrates a sub-CAU flow model, source term models, and site-scale transport models into a predictive framework. Modeling simulations were conducted that:

- Provide estimates of aquifer properties and flow solutions that match head observations

- Predict radionuclide releases from cavity/chimney systems incorporating processes of melt glass dissolution and thermal convection

- Predict radionuclide concentrations consistent with field observations

- Provide sensitivity analysis for uncertain parameters

In general, these studies have captured the complex processes of source release and site-scale migration. These studies provide a conceptual model for hydrologic source term and near-field radionuclide migration applicable to the underground tests in the Yucca Flat/Climax Mine CAU. These completed modeling studies, 
combined with ongoing studies and data evaluation, indicate that the Yucca Flat/Climax Mine CAU transport model will need to account for the following processes:

- Advection

- Dispersion in fractured and porous media

- Solute diffusion from fractures into the matrix

- Solute reactions in the matrix (sorption)

- Solute reactions on fracture minerals (sorption)

- Solute reactions with colloids in fractures

- Colloid filtration on fracture walls

- Solute speciation in fracture and matrix water

- Solute precipitation/coprecipitation

- Radioactive decay

- Influence of faults (e.g., fast paths, barriers) and major geologic features such as stratigraphic offset along structural block boundaries.

\subsection{Development of CAU and Total System Models}

The philosophy underlying modeling approaches for a CAU model and a total system model (TSM) was presented in Section 1.0. Currently, the CAU model is viewed as the model that will provide final decision support for the FFACO Correction Action Strategy. The TSM follows the development of the CAU model and enhances sensitivity and uncertainty analyses. This section describes the information for the modeling approaches, the CAU-specific codes used to provide output for each CAU modeling component, and linkages between the CAU component models.

\section{CAU Model}

A simplified schematic showing information flow for the CAU model is shown in Figure 2-2. This figure shows information inputs from field data, laboratory experiments, and other sources to the process models. Connections are shown between process models and abstractions leading to the prediction of total system behavior. The intent of this figure is to illustrate the character of information flow, not explicitly identify every data type or process model. Data types and subsystem model names represent broad categories. For example, data from field and laboratory investigations and information relating to hydrogeologic processes from process model investigations are combined in the box titled site hydrogeology. Information sources are discussed in detail in Section 3.0.

The configuration of computer codes used for the CAU model is shown in Figure 2-3. The component models are run outside of the main flow and transport model execution so there are no run time linkages between models at the CAU level. The results of the detailed process level runs are provided to the flow and transport model as tables or as simplified expressions. The codes used and the linkages between codes are:

- Hydrologic Source Term Model: The Lawrence Livermore National Laboratory (LLNL) and the Los Alamos National Laboratory (LANL) 


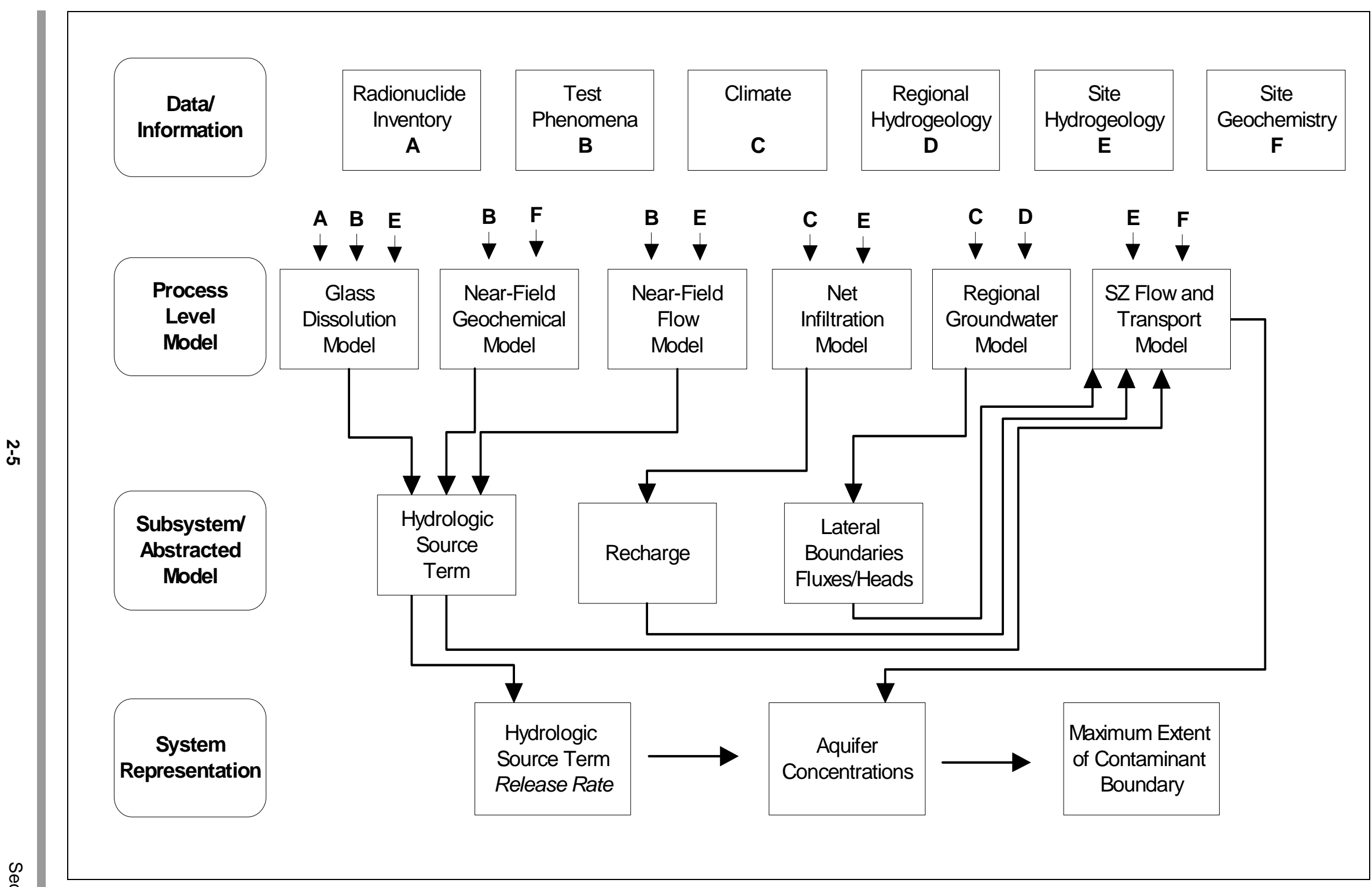

Figure 2-2

Information Flow for the Yucca Flat/Climax Mine CAU Model 


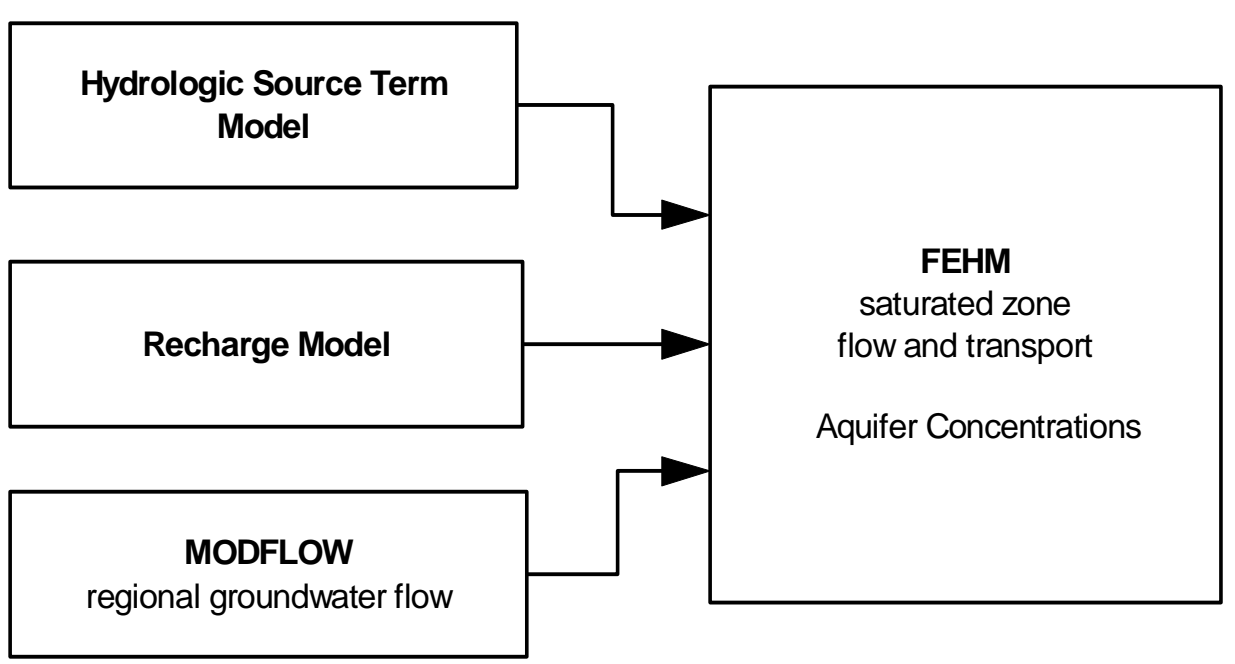

Figure 2-3

Configuration of Codes for the Yucca Flat and Climax Mine CAU Model

have investigated the release of radionuclides from selected source locations. The hydrologic source term provides information on the release from the glass and nearby exchange zone. The overall hydrologic source term process includes steps related to (1) development of phenomenological models for specific geologic environments, (2) categorization of tests, (3) unclassified modeling, (4) classified modeling, and (5) source term simplification, as may relate to TSM models and as may be guided by categorization information.

- Recharge Model: The Desert Research Institute (DRI) and the U.S. Geological Survey (USGS) have been conducting regional recharge studies over an area including the NTS. The results of these studies are estimates of steady-state recharge for the regional domain. These recharge estimates are intended to be input for the Yucca Flat/Climax Mine CAU-scale model.

- Regional-Scale Groundwater Flow Model: Shaw Environmental, Inc. (Shaw) (DOE/NV, 1997) simulated groundwater flow in the Death Valley Basin using MODFLOW (McDonald and Harbaugh, 1988). Subsequent to performing the activities detailed in this report, IT Corporation's contract with the U.S. Department of Energy, National Nuclear Security Administration Nevada Site Office was novated to Shaw Environmental, Inc. (Shaw). As a result of this novation and to standardize reporting, all IT Corporation activities associated with this project are herein referred to as Shaw. This code was developed by the USGS for the numerical simulation of 3-D saturated groundwater flow in porous media, and it was 
designed to simulate flow under both steady-state and transient conditions. Due to the absence of natural physical boundaries to define CAUs, the regional groundwater model will be used to provide hydraulic head and flux conditions to the flow and transport simulator Finite Element Heat and Mass Transfer Code (FEHM) to define the lateral boundary conditions of the CAU model.

- CAU-Scale Flow and Transport Model: The FEHM code (Zyvoloski et al., 1997b) has been selected as the flow and transport simulator for the Yucca Flat/Climax Mine CAU model. The code selection process is documented in Appendix A. The FEHM code simulates 3-D, time-dependent, multiphase, nonisothermal flow, and multicomponent reactive groundwater transport through porous and fractured media. FEHM's finite element formulation provides an accurate representation of complex 3-D geologic media and structures and their effects on subsurface flow and transport. The hydrologic source term, recharge, lateral boundary conditions, and parameter values are inputs to FEHM. FEHM output consists of spatial distribution of head and concentration at specified times and concentration with time through specified boundaries and planes. The transport processes of interest include advection, dispersion, sorption, matrix diffusion, radioactive decay, colloid facilitated transport, and daughter products.

The component models described above represent hydrostratigraphy and structure as well as hydrologic and chemical processes over length scales ranging from tens of kilometers to meters. Time scales range up to 1,000 years. The modeling approach needs to appropriately integrate and represent linkages between these components. As discussed in Section 1.0, requirements for this modeling approach include that information moving from level to level must be consistent and essential aspects of the processes described by the detailed process models must be accurately represented in the CAU model. Measures must be taken through coordination of UGTA modeling groups to ensure consistency on parameter distributions and current views on conceptual models of geology, heterogeneity, and hydrologic and chemical processes.

\section{Total System Model}

The GoldSim modeling platform will be used to develop a TSM. GoldSim was developed by Golder Associates as a tool for conducting dynamic probabilistic simulations of physical systems. Information flow for this modeling approach is described by Golder Associates (2000). Information from field and laboratory investigations as well as from process model studies form the foundation of the approach. Detailed process modeling is required to determine appropriate input parameters and to constrain processes considered and the accuracy of their representation in the TSM. This information is incorporated by model developers to build a conceptual model that represents the features and processes that determine the behavior of the system. The conceptual model is translated to a mathematical model in a form that can be used in a TSM. The downward flow of information from the TSM includes the sensitivity of system performance to processes and parameters. 
Capabilities for specifying contaminant species, method of introduction of contaminant into the system, and the nature and linkage of transport pathways are contained in the GoldSim modeling platform. Uncertainty in processes and parameters can be represented by specifying model inputs as probability distributions. A mass transport model can be developed using the GoldSim program and GoldSim's Contaminant Transport Module. However, since the Contaminant Transport Module is a mass transport model, not a flow model, flow velocities are required input for GoldSim transport simulations. Since GoldSim uses a top-down design, integration and coupling of system components is inherent to the model development process. As new data are obtained or new conceptual models developed from process models, the GoldSim model can be refined.

The calculated contaminant boundary produced by the CAU scale model is the end product of a series of component models: (1) Conceptual model, (2) HSU framework model, (3) recharge model, (4) regional groundwater flow model, (5) CAU groundwater flow model, (6) Hydrologic Source Term Model, and (7) CAU transport model. In the simplest terms, the purpose of the TSM is to replicate the processes and interactions of each of these models into a single, simplified, easy to use modeling tool to allow assessment of the total flow and transport system.

Stakeholders want to know if a wide range of possible scenarios have been examined to provide confidence in the CAU-model predictions. Assessment of the impact of a change (or proposed change) to one of these component models could take months to implement. That is too inefficient to examine a wide range of scenarios. A TSM would allow "what if" scenarios to be assessed quickly.

The TSM is created by replicating the CAU model processes. Each component model becomes a module in the TSM. The module is an abstracted (read simplified) version of the component model that uses a small number of integrated, upscaled, effective parameters to capture the features and processes important to the prediction of the contaminant boundary location. Any of the effective parameters in the TSM may be uncertain, with bounds defined by the data and the underlying component model.

GoldSim is a tool to simplify the creation of the TSM. As such, GoldSim is not a prerequisite for a successful TSM and could be replaced by a different tool. However, the ease of use and flexibility of GoldSim make it a good tool to use. GoldSim is a 1-D transport simulator, but because of its flexibility, can call external modules, as necessary. For example, a 2-D flow simulator (simplified, effective parameters) could be used to generate possible flow paths, which would then be used for transport simulation.

The TSM should be created at the same time as the CAU component models. Initially, the modules will be general, with large uncertainties on the parameters. However, as time progresses, the TSM uncertainties can be reduced based on data, modeling results, and other constraints. 


\section{Role of the TSM}

The role of the TSM is to provide quantitative comparison of different scenarios, alternatives, and parameter sensitivity. The modules in the TSM will not be calibrated, although the component models on which the modules are based, will be calibrated. Nonetheless, the lack of calibration of the TSM modules precludes the TSM from providing quantitative definition of the location of the contaminant boundary. 


\subsection{Site Characterization Data and Studies}

This section provides a description of the data and information that form the technical basis for the model. Data and information for the Yucca Flat and Climax Mine CAU model consist of:

- Site-specific historical data

- Relevant data from other sites

- Documented models of components

- Field investigations conducted by the Environmental Restoration (ER) Program

- Laboratory investigations conducted by the ER Program

- Modeling investigations conducted by the ER Program

- Expert elicitations

- Peer reviews of the Frenchman Flat CAU model

\subsection{Site-Specific Historic Data from the Regional Model}

Site-specific historic data for the Yucca Flat/Climax Mine CAU can be found in the Underground Test Area Subproject Phase I Data Analysis Task Volume I-VIII Data Documentation Package (IT, 1996a to e). The amount and distribution of hydraulic property data collected from the wells in the Yucca Flat study area (see Section 2-1) are summarized in Table 3-1. The amount and distribution of transport parameter measurements are summarized in Table 3-2.

\subsection{Relevant Data From Other Sites}

Extensive site characterization data have been collected in support of the Yucca Mountain Site Characterization program. While Yucca Mountain is located approximately 45 kilometers $(\mathrm{km})$ southwest of Yucca Flat, the transferability of data from Yucca Mountain for use in developing parameter distributions for the Yucca Flat and Climax Mine CAU model has not been evaluated yet. The structural setting of Yucca Mountain is different than Yucca Flat. While the flow field characteristics will be different, the range of rock types present at Yucca Mountain are similar to some of the rock types present in the Yucca Flat/Climax 
Table 3-1

Numbers of Measurements and Number of Wells Contributing to Site-Specific Historic Data for Hydraulic Properties ${ }^{a}$

\begin{tabular}{|c|c|c|}
\hline Parameter & Number of Measurements & Number of Wells \\
\hline \hline Water Elevation & 2,102 & 121 \\
\hline Discharge & 354 & 8 \\
\hline Hydraulic Conductivity & 62 & 9 \\
\hline Transmissivity & 71 & 10 \\
\hline Specific Capacity & 29 & 7 \\
\hline Storage Coefficient & 29 & 1 \\
\hline Total Porosity & 11 & 5 \\
\hline
\end{tabular}

aData from Underground Test Area Subproject Phase I Data Analysis Task Volume I-VIII Data Documentation Package (IT, 1996a to e)

Table 3-2

Numbers of Measurements and Wells Contributing to Site-Specific Historic Data for Transport Parameters ${ }^{a}$

\begin{tabular}{|c|c|c|}
\hline Parameter & Number of Measurements & Number of Wells \\
\hline \hline Diffusion Coefficient & 0 & 0 \\
\hline Longitudinal Dispersivity & 1 & 1 \\
\hline Transverse Dispersivity & 0 & 0 \\
\hline Vertical Dispersivity & 0 & 0 \\
\hline Matrix Porosity & 253 & 25 \\
\hline Effective Porosity & 1 & 1 \\
\hline
\end{tabular}

${ }^{a}$ Data from Underground Test Area Subproject Phase I Data Analysis Task Volume I-VIII Data Documentation Package (IT, 1996a to e)

Mine CAU. Given these similarities, there is a large amount of rock property data that could be integrated into the Yucca Flat/Climax Mine CAU study.

\subsection{Documented Models of Components}

\section{Regional Groundwater Model}

A regional groundwater flow model for the NTS was developed to:

- Provide a basis for predicting movement of contaminants from underground test areas on a regional scale. 
- Evaluate the range of uncertainty of these predictions.

- Provide boundary conditions for CAU models that are consistent with the regional groundwater budget.

This model was peer reviewed, modified in response to peer review comments, and documented in DOE/NV (1997). The regional groundwater system is modeled using MODFLOW. The model grid consists of 68 columns by 76 rows and 20 layers. Model inputs include:

- Hydrogeologic framework (IT, 1996e)

- Potentiometric data (IT, 1996d)

- Hydraulic conductivity/transmissivity data (IT, 1996c)

- Groundwater recharge and discharge data (IT, 1996b)

- Estimates of parameter uncertainties (DOE/NV, 1997)

Model assumptions (IT, 1996a) include:

- The conceptual model used as the basis for the numerical flow model is representative of the NTS regional groundwater-flow system.

- The model represents steady-state conditions representative of natural stresses to the system prior to groundwater development and underground nuclear testing.

- The system is laterally isotropic and vertically anisotropic.

- Each HSU is homogeneous or can be divided into homogeneous zones.

- The hydraulic conductivity in each cell in the coarse MODFLOW model can be assigned by volume averaging the properties of the different HSUs in the high-resolution geologic model that intersect each finite difference cell.

- The hydraulic conductivity of an HSU is assumed to decrease in an exponential manner with increasing depth. The rate of decrease may be different for each HSU.

- At the scale of the regional model, movement of water in fractured rock can be adequately described by an equivalent porous media model.

- Spatial variations in groundwater density due to changes in temperature or chemistry are negligible and are not accounted for in the flow model.

- Because of the steady-state assumption, the volumetric recharge is based on estimates of discharge from the basin.

- Recharge can be adequately simulated by using a technique similar to that used by Maxey and Eakin (1949), modified to account for runoff (recharge redistribution). 


\section{Integrated Radionuclide Migration/Hydrologic Source Term}

The integrated radionuclide migration abstraction which provides the hydrologic source term to the flow and transport model is developed from outputs from a glass dissolution model, a reactive transport model, and a flow simulator. The framework for this approach is documented in Tompson et al. (1999), Pawloski et al. (2001), and Pawloski et al. (2002a), which provided a hydrologic source term for the Frenchman Flat CAU model and Pahute Mesa CAU model. Lawrence Livermore National Laboratory will develop a hydrologic source term for the Yucca Flat/Climax Mine CAU. This hydrologic source term is based on a radiological source term from all Yucca Flat/Climax Mine tests located near or below the water table. Significant improvements were required for the Pahute Mesa models that can now be applied to the Yucca Flat/Climax Mine CAU. Some of the major improvements include:

- Simulations addressing evaluation of the hydrologic source term in fractured volcanic rock. The flow and transport processes in fractured rock are much more complex than in the porous alluvium considered at Frenchman Flat.

- Expanded list of radionuclides to be considered. The additional radionuclides reflect concerns with daughter product ingrowth and a need for a differing selection process than was previously used.

- Geochemical speciation, ion exchange, and surface complexation model improvement with an overall greater appreciation for sensitivity and the influence of the glass dissolution model on the overall release of radionuclides from the melt glass.

- Physical and chemical effects associated with residual, test-related heat have been addressed in current simulations. Particularly with the incorporation of how the residual heat influences groundwater flow and the nature of glass dissolution.

- Improved estimation of uncertainty in results based upon incorporation of geostatistical methods used to generate multiple realizations with realistic spatial variability of permeability and mineralogy.

\subsection{Field, Laboratory, and Modeling Investigations}

The following is a summary of Yucca Flat or NTS-specific investigations that provide information to the CAU modeling. Table 3-3 lists each investigation and the model component it supports. A summary of each investigation is then provided. 
Table 3-3

Modeling Component Supported by the Investigation

\begin{tabular}{|c|c|c|}
\hline \multirow{2}{*}{ Investigation } & \multicolumn{2}{|c|}{ Modeling Component } \\
\hline & Flow & Transport \\
\hline Core Fracture Analysis & & $\mathrm{x}$ \\
\hline Yucca Flat/Climax Wells & $x$ & $x$ \\
\hline Geology & $x$ & $x$ \\
\hline Yucca Flat EarthVision ${ }^{\circledR}$ & $x$ & $x$ \\
\hline BULLION Forced-Gradient Experiment & $\mathrm{x}$ & $\mathrm{x}$ \\
\hline Water Wells C and C-1 & & $x$ \\
\hline ER-6-1 Tracer Test & $x$ & $x$ \\
\hline NTS Recharge & $x$ & \\
\hline Source Term Studies & & $x$ \\
\hline Glass Dissolution & & $\mathrm{x}$ \\
\hline Colloids & & $x$ \\
\hline CAMBRIC Hydrologic Source Term & & $x$ \\
\hline CHESHIRE Hydrologic Source Term & & $x$ \\
\hline TYBO-BENHAM & $x$ & $x$ \\
\hline Geochemical Models & $\mathrm{x}$ & $\mathrm{x}$ \\
\hline Boundary Conditions & $x$ & \\
\hline Faults & $x$ & \\
\hline Geochemical Data & $\mathrm{x}$ & $x$ \\
\hline Hydrologic Resource Management Program & & $\mathrm{x}$ \\
\hline
\end{tabular}

\section{Core Fracture Analysis}

Conventional core samples from four drill holes located in Yucca Flat were analyzed to obtain information on:

- Fracture type

- Fracture density

- Aperture

- Orientation

- Secondary mineral coatings

This information is reported in Analysis of Fractures in Cores from the Tuff Confining Unit Beneath Yucca Flat, Nevada Test Site (Prothro, 1998).

\section{Yucca Flat/Climax Mine Hydrogeologic Investigation}

Five wells have been drilled and completed in fiscal year (FY) 2003. When the development and testing of these wells is completed, they will provide information on geology, hydrogeology, and water chemistry. Field activities consist of borehole drilling, cuttings sample collection and description, geophysical logging, 
well completion, well development, and groundwater sample collection. In addition, hydraulic testing is conducted to obtain information on vertical gradients, flow, and proportional water production.

\section{Geologic Investigation}

The geology of Yucca Flat has previously been described in Volume I of the regional evaluation documentation package (IT, 1996e). Geologic data used include borehole data, geophysical data, gravity data, and published geologic maps and cross sections. This existing data will be further augmented with new data obtained during the corrective action investigation to develop the Yucca Flat/Climax Mine Hydrogeologic Model. Of particular interest will be the Climax stock, a Cretaceous granitic body, exposed at the north end of Yucca Flat. This body is of low permeability and may contribute to the steep hydraulic gradient in the area.

\section{Yucca Flat/Climax Mine Hydrogeologic Model}

The Yucca Flat/Climax Mine hydrogeologic working model is planned to be developed in EarthVision ${ }^{\circledast}$ in conjunction with Bechtel Nevada (BN) prior to the start of flow modeling. The model will likely be connected to the northern boundary of the Frenchman Flat CAU model. Outside of the CAU model areas, the regional hydrostratigraphic unit (HSU) model (DOE/NV, 1997) will provide hydrogeologic control.

\section{BULLION Forced-Gradient Experiment}

The BULLION experiment was conducted in a fractured lava aquifer on Pahute Mesa. Although outside of the Yucca Flat study area, insights gained in this study are applicable to fractured volcanic aquifers in Yucca Flat. Work on this experiment had field, laboratory, and modeling components. This experiment (IT, 1998) was designed to obtain site-specific information about the transport of radionuclides in saturated fractured volcanic rock. The specific objectives were:

- Observe the transport process

- Characterize transport parameters

- Characterize the hydrologic source term for an underground nuclear test

- Obtain information on the relative mobility of mobile radionuclides

Three wells were installed downgradient from the location of the BULLION test. The well furthest from the test was pumped to produce a hydraulic gradient while tracers were injected into the other two wells. Tracer breakthrough curves were obtained for three different flow path segments. Radionuclide transport from the BULLION test cavity was not detected in any of the wells.

Simulation of drawdown response provided estimates of hydraulic conductivity. Estimates of transport properties were obtained by calibrating the transport model to the observed breakthrough curves. This produced three estimates of fracture spacing, matrix porosity, matrix diffusion coefficient, dispersivity, and effective porosity. 
Laboratory experiments at LANL were conducted to support and constrain the interpretation of the BULLION results. Matrix diffusion coefficients were obtained from cores representing the six lithologies identified at the BULLION site. Fourteen diffusion cell tests were conducted, with 8 of the 14 tests being replicates. These tests provided estimates of effective matrix porosity and estimates of matrix diffusion coefficients for two tracers. Laboratory-scale, fractured rock, and column transport experiments were conducted in four fractured cores representing different lithologies. These tests provided estimates of fracture aperture, dispersivity, and matrix diffusion coefficients for two tracers. Both field and laboratory results support a dual-porosity conceptual model for transport.

\section{Water Wells $C$ and $C-1$}

In May of 1962, a tracer test was performed between Water Wells C and C-1 in southern Yucca Flat. This experiment was quickly conceived to determine if drilling muds being used in Well C-1 may interfere with the pump in operation at Water Well C. These wells are $29.3 \mathrm{~m}$ apart at depth and are completed in a carbonate aquifer that transmits water primarily through fractures. Sodium fluorescein was injected into Well C-1 and was clearly seen in Water Well C after 252 minutes. The concentration of fluorescein in Water Well $\mathrm{C}$ gradually increased to a maximum after about 8 hours. The velocity of the first arrival was about $0.12 \mathrm{~m}$ per minute (Winograd and West, 1962). The dispersivity was estimated from the limited data to be about $1.4 \mathrm{~m}$.

\section{ER-6-1 Tracer Test}

A tracer test at the ER-6-1 well site, within Yucca Flat, is planned for FY 2004. This will be a multiwell tracer test designed to help characterize the hydrogeology of southeastern Yucca Flat and, in particular, the hydrogeology of the lower carbonate aquifer.

\section{NTS Regional Recharge Study}

The DRI and USGS have recently completed regional studies of recharge over an area including the NTS. The DRI study looked at the chloride distribution within alluvium. This information combined with precipitation data and an estimate of chloride input are being used to calculate recharge fluxes for the region. In addition, recharge fluxes were calculated from measurements of chloride concentrations in water samples from springs. The results of this study are estimates of steady-state recharge for their regional domain (Russell and Minor, 2002). The USGS study involved creating a numerical model using parameters such as precipitation, topography, geology, vegetation, and others to obtain preliminary estimates of net infiltration and recharge for the Death Valley region (Hevesi et al., 2002). The results of these studies are likely to be used as input for the Yucca Flat/Climax Mine CAU-scale model. The strategy for treating uncertainty in the recharge model is discussed in Section 6.0. 


\section{Glass Dissolution Investigations}

Laboratory measurements of physical and reactive surface areas of natural and man-made silicate glasses and nuclear melt glasses were conducted by DRI and LLNL (Bourcier et al., 2000). These measurements are required to reduce the uncertainty in reactive surface area, an important parameter in the glass dissolution model. Based on these measurements, a reactive surface area ranging from 0.001 to 0.01 square meters per gram $\left(\mathrm{m}^{2} / \mathrm{g}\right)$ was recommended for models of nuclear melt glass dissolution. An improved glass dissolution model is provided in Pawloski et al. (2001).

\section{Colloid Transport Experiments}

The migration of colloids and colloid-facilitated transport of actinides in fractured rock has been studied at both the laboratory scale in column experiments and at the field scale in multi-well tracer tests. For the assessment of colloid transport properties, synthetic microspheres have been used due to the ease (or at least feasibility) of controlling the source concentration in feed solutions and measuring their concentration in extracted solutions. Application of synthetic microspheres in the BULLION Forced-Gradient Experiment on Pahute Mesa (IT, 1998) and in the $\mathrm{C}$-wells experiments at Yucca Mountain has led to an assessment of the range of attachment and detachment rates colloids undergo in fractured flow systems. Similar experiments are planned for the ER-6-1 tracer test in Yucca Flat. Recent experiments in laboratory columns have used actual clay, silica, and zeolite colloids to investigate their role in enhancing the mobility of plutonium. These experiments have led to additional useful data for parameterizing colloid retardation due to filtration, as well as the reactions between plutonium and colloids. To date, the reactive transport model used in the TYBO/BENHAM study has been applied to the experiments involving clay colloids and is currently being used for silica colloids.

\section{CAMBRIC HST Investigation}

In support of the Frenchman Flat CAU model, Tompson et al. (1999) developed a process model of the unclassified CAMBRIC hydrologic source term. The objective of this model was to provide a modeling framework to quantitatively forecast the hydrologic source term within the near-field environment of an underground nuclear test (Tompson et al., 1999).

The radionuclides tritium, strontium-90, cesium-137, europium-155, plutonium-239, and americium-241 were selected for the CAMBRIC source term modeling because their inventories are unclassified and available, they have a varied initial distribution in the glass, chimney, and cavity areas, and they represent a cross section of geochemical behavior in the subsurface environment.

The source term model incorporates available information on the distribution and release of radionuclides. Radionuclides are partitioned among the glass, rubble zone, and water. The model assumes that essentially the entire inventory of potential radioactive contaminants in the rubble zone is available for leaching or dissolution and subsequent transport. The model also assumes the tritium 
inventory in the form of tritiated water is available for transport. A glass dissolution model is included to predict the release of potential contaminants from the melt glass. Geochemical reactions (e.g., aqueous and surface complexation, ion exchange, and precipitation/dissolution) are modeled to assess the influence of these reactions on release rates from the glass (Tompson et al., 1999).

Release rates include radioactive decay, but do not include the presence of reactive minerals in the near-field flow path. The absence of reactive minerals is a conservative assumption with regard to the release rates of radioactive contaminants because reactions that could potentially attenuate dissolved contaminant concentrations (e.g., surface complexation or ion exchange) will not occur (Tompson et al., 1999). Pawloski et al. (2002a) developed a classified source model for Frenchman Flat based in part upon Tompson et al., 1999. The classified report will be of assistance for classified simulations in Yucca Flat.

\section{CHESHIRE HST Investigation}

Pawloski et al. (2001) conducted an evaluation of the hydrologic source term of CHESHIRE as part of the data analysis activities for the Pahute Mesa CAUs. The purpose of this evaluation was to develop a basic understanding of how radionuclides move from the radiologic source term of underground nuclear tests into groundwater. As stated by Pawloski et al. (2001), the objectives of this evaluation were "to develop, summarize, and interpret a series of detailed unclassified simulations that forecast the nature and extent of radionuclide release and near-field migration in groundwater away from the CHESHIRE test over the next 1,000 years. Collectively, these results are called the CHESHIRE Hydrologic Source Term."

The approach included the development of a conceptual model of the near-field environment, a groundwater flow model, geochemical models, and reactive transport models of radionuclides. The models were used to simulate radionuclide release into groundwater and migration away from the near-field of the CHESHIRE test on Pahute Mesa.

The unclassified residual inventory is the summed unclassified inventory for saturated tests on Pahute Mesa, averaged and applied at the CHESHIRE site (Smith, 2001).

A protocol for selecting radionuclides for HST modeling was developed. The near-field model list of radionuclides was derived from three sources: a report on the unclassified radiologic source term (Smith, 2001), recommendations by the UGTA Source Term Subcommittee (Smith, 1997), and a set of reports containing radionuclide measurements in groundwater near CHESHIRE (Finkel et al., 1992; Daniels et al., 1993; Smith et al., 1998, 1999, and 2000; and Thompson, 2000). A total of 52 radionuclides were identified from these three sources.

Thirty-seven of the 52 radionuclides were selected for incorporation into the unclassified CHESHIRE HST model. Radionuclides were excluded from consideration either (1) because they had no inventory, or (2) they did not satisfy criteria related to their abundance (Pawloski et al., 2001). 
The CHESHIRE flow model was based on the NUFT code. The flow model was designed to account for the influence of test-related and geothermal heat. Model results indicated a strong tendency for rapid upward and dynamic movement of groundwater (mobile radionuclides) away from the cavity area for a period lasting several decades. Several models were evaluated; however, the geostatistically heterogeneous model was able to reproduce all measured temperature profiles and observed tracer pathways (Pawloski et al., 2001).

Mechanistic models were used to describe the geochemical interactions controlling the radionuclide release from the melt glass and the exchange volume, as well as the radionuclide-rock interactions along the flow path. These models were designed to simulate kinetically-controlled glass dissolution and radionuclide precipitation and equilibrium-controlled aqueous speciation, surface complexation, and ion exchange.

Two models were used to simulate the transport of radionuclides in groundwater. A reactive streamline model and a more efficient particle-based model were used to develop reactive transport simulations of radionuclide migration away from the CHESHIRE cavity and melt glass region.

The main conclusions of this evaluation were as follows:

- A protocol for selecting radionuclides for HST modeling was developed.

- The release of radionuclides from the melt glass, although proportional to temperature, is generally slow and long lasting regardless of their retardation characteristics in the geologic medium.

- The release of radionuclides from the exchange volume is generally quicker and more short-lived, although significant radionuclide retention in the near-field occurs for the more sorptive radionuclides.

- The flux of radionuclides past the UE-20n\#1 control plane is affected by heterogeneity in the physical and reactive properties of the geologic medium.

\section{TYBO-BENHAM Modeling Investigation}

The detection of plutonium in the groundwater $1.3 \mathrm{~km}$ from the BENHAM subsurface nuclear test motivated the TYBO-BENHAM modeling investigation by Wolfsberg et al. (2002). This investigation had the following four major components:

- Reactive colloid-facilitated solute transport model development

- Subregional groundwater flow model development and calibration

- Heterogeneous site-scale flow and transport model development

- Model abstraction development

Although the model domain associated with this study is smaller than the Yucca Flat and Climax Mine CAU, this study may provide insights into CAU-scale 
simulation issues. The finite-element grid is constructed with the same tools as will be used for the CAU-scale model and the flow and transport simulator FEHM is used for the calculations. The steady-state flow model is calibrated with the FEHM-PEST software suite on a grid with about the same resolution as is expected for the CAU model. Transport is simulated on an embedded high resolution subdomain to utilize geostatistical realizations of heterogeneous hydrologic attributes.

\section{Modeling of Geochemical Transport in the Vicinity of Yucca Flat and Climax Mine}

Geochemical modeling techniques were applied to groundwater flow paths from the southern regions of Yucca Flat to the Amargosa Desert (Hershey and Acheampong, 1997). The objective of this study was to calculate groundwater flow velocities from Yucca Flat to the Amargosa Desert, taking into account the mixing of different groundwater inputs. This work demonstrated that interpretation of geochemical data combined with transport modeling can provide a tool for characterization of the groundwater system.

\section{Boundary Conditions}

A modeling study was conducted to provide a strategy for specifying boundary conditions for CAU models with boundaries that do not extend to the natural limits of the aquifers and account for associated uncertainties. Coupled PEST-FEHM simulation developed in the TYBO-BENHAM modeling investigation was demonstrated as a method for matching specified fluxes through CAU-model faces while calibrating to observed hydraulic heads. This method will be used as part of a process for determining the impact of CAU model boundary condition uncertainty on contaminant transport predictions. Additional refinements to geochemical modeling have been provided in Rose et al. (2003) for the Pahute Mesa flow system. Similar work could be performed for the Yucca Flat flow system.

\section{Assessment of Fault Characteristics}

LANL is conducting a study during FY 2003 to assess fault characteristics for the Pahute Mesa-Oasis Valley region and determine importance of faults to CAU model development. This study includes the compilation and analysis of geologic descriptions of faults from the literature. Graphic analysis of faults and hydraulic head contours will be used to identify hydrologically significant faults within the model domain. Site-specific information on vertical hydraulic head gradients, permeability, groundwater geochemistry and isotopic concentrations, and groundwater temperature will be used to infer likely fault characteristics. This information will be used to develop a classification system for faults based on length, offset, genesis, and mineralization. This classification system will allow the numerous faults in the region to be grouped into a small number of categories for which appropriate hydraulic properties can be assigned. This study will be applicable to the Yucca Flat/Climax Mine CAU. 


\section{Geochemistry, Hot Well, and HRMP Migration Data}

Selected site-specific geochemical data are summarized in the Corrective Action Investigation Plan for Corrective Action Unit 97: Yucca Flat/Climax Mine, Nevada Test Site, Nevada (DOE/NV, 2000a). The geochemical data within the report include general chemistry, environmental isotopes, and radiochemistry for selected wells within the Yucca Flat/Climax Mine CAU. The data used in this study were obtained from the UGTA geochemical database (IT, 1999a).

Site-specific data is also available from hot well sampling as well as the Hydrologic Resources Management Program (HRMP). Since the mid 1970s, the radiochemistry of Yucca Flat groundwater has been investigated as part of the HRMP. The following objectives of the HRMP are pertinent to the Yucca Flat/Climax Mine CAU:

- Behavior of radionuclides in the NTS underground environment

- Geologic and hydrologic consequences of nuclear testing

- Factors controlling transport of radionuclides by groundwater (Thompson, 1998).

Results from HRMP groundwater investigations in Yucca Flat were described in the Yucca Flat/Climax Mine CAIP (DOE/NV, 2000a).

\subsection{Expert Elicitations}

As part of the Value of Information Analysis for Corrective Action Unit 97: Yucca Flat, Nevada Test Site, Nevada (IT, 1999c), an expert panel was asked to provide information on distributions of several hydrologic parameters for Yucca Flat. The panel provided 5 and 95 percent fractiles for the distributions, and then specified the mathematical forms. Distributions were developed for:

- Groundwater flux into Yucca Flat from the north determined from groundwater flow and cross-sectional area considerations

- Hydrologic source term

- Effective porosity in the LCA

- A diffusion parameter, for the LCA, that combined effective diffusion coefficient, matrix porosity, and fracture half-spacing

- Path length from the volcanic confining unit to the lower carbonate aquifer

These distributions were obtained prior to detailed analysis of data from Yucca Flat and will be superseded as necessary. 


\subsection{External Review}

An external peer review group (IT, 1999b) provided a review of the data analysis and modeling components of the Frenchman Flat CAU model. The review highlighted key issues of concern, provided detailed comments on model components, and suggested actions for developing a more defensible prediction of radionuclide migration. In addition, the group addressed the issue of transferability of the modeling strategy used for the Frenchman Flat CAU to other CAUs on the NTS.

\subsection{Summary}

The CAU model will first seek to simulate flow by matching observed heads, then simulate transport to predict the location of the contaminant boundary. The site characterization data and studies that will support the CAU model were summarized in Table 3-3 and described in Section 3.4. One task of the modeling process is to integrate this diverse set of information, which will provide greater confidence in the model predictions. 


\subsection{CAU Model Components}

This section presents the components of the CAU model and describes the major assumptions, data inputs, and outputs for each component.

\subsection{Geologic Framework}

The geologic framework will consist of a 3-D hydrogeologic model providing the thickness, distribution, and geometric relationships of hydrostratigraphic units and faults. Migration pathways are strongly dependent on the hydrostratigraphy and structure represented in the model. The digital geologic framework model will provide input to the finite-element grid generation software that produces grids for flow and transport calculations.

Producing this framework will include the following steps:

- Compilation of stratigraphic, lithologic, and alteration data for all drill holes in the study area

- Compilation of existing geologic cross sections

- Development of a hydrostratigraphic system

- Development of a HSU database

- Adoption of a structural model for the study area

- Construction of unit-extent and structure contour maps for each HSU

- Development and integration of HSU surface and geologic structure models using EarthVision ${ }^{\circledR}$

EarthVision ${ }^{\circledR}$ is a suite of software applications used for geospatial analyses. EarthVision ${ }^{\circledR}$ integrates representational models with data and can generate various representations of the spatial data and models including contour maps, cross sections, and 3-D shaded models. Since the hydrogeologic framework developed is an interpretive product, multiple alternative models are possible, each consistent with field data. The strategy for treating uncertainty in the geologic framework is discussed in Section 7.0. 


\subsection{Climate}

Climate describes the prevailing meteorological conditions at a site and includes frequency and duration of precipitation and the conditions that determine the amount of water transferred back to the atmosphere through evapotranspiration. Climate is an important component of the CAU model since it influences recharge, the amount of water flowing through the unsaturated zone to the water table. Climate data for Yucca Flat and the Climax Mine are sparse and represent only a relatively short-term period. Uncertainty in transport predictions may increase with the time frame considered because uncertainty in climate predictions increases with time into the future. The USGS has conducted some climate modeling and predictions for the Yucca Mountain Project which may be useful to the UGTA Project in constraining precipitation inputs to the recharge model. Temporally variable climate scenarios will not be considered as part of the CAU modeling because considerable uncertainty in the recharge rate is already planned for the CAU modeling (see Section 4.3).

\subsection{Recharge}

Climate data, in particular precipitation, provides input to the recharge model.

The output to the flow and transport model FEHM is recharge flux. The recharge model is empirical and has large uncertainties associated with its predictions. For example, recharge is modeled as a diffuse process and focused recharge in washes may, or may not be included. The strategy for treating uncertainty in the recharge model is discussed in Section 7.0.

\subsection{Lateral Boundary Conditions}

Ideally, model boundaries are chosen such that natural physical boundaries of the aquifers are used. This approach is difficult to implement at the NTS since natural boundaries are distant from the CAUs. One of the objectives of the Regional Groundwater Model is to provide boundary conditions to CAU models consistent with regional mass-balance information (DOE/NV, 1997). The regional groundwater model provides necessary information about hydraulic heads and total fluxes to provide boundary conditions for the CAU model.

Outputs from the model are hydraulic heads and fluxes and are used as boundary conditions and constraints for the CAU flow model calibration. Since there are uncertainties in the conceptual models and parameters used for the regional model, there will be uncertainties in prediction of heads and fluxes. Sources of uncertainty and its propagation will be discussed in Section 7.0.

\subsection{Input Parameter Distributions}

The development of input data parameter distributions includes consideration of the number, location, quality, and representativeness of the data. Each parameter will be described by a central tendency and variability about that central tendency as represented by a probability density function (PDF) or a cumulative distribution function $(\mathrm{CDF})$. The process of describing variable data with a probability 
distribution begins with the compilation of the data and an examination of the data. A histogram or analogous method is a tool to examine the variability in the dataset. These tools are one way to portray the distribution of parameter values and much can be learned about the nature of the variability. A decision point occurs after the initial examination of the distributions of parameter values. If the number of data is small, the limits of possible values are assessed based on the data or on physical/chemical laws. For example, most aquifer parameters are non-negative. In some cases, the best that can be done is to assign lower and upper bounds to the data. In these cases, it may also be necessary to examine data from other locations outside the study area; therefore, the range of variability will be quite large. As more information becomes available, more detail about the distribution can be assigned.

An additional important issue is the scale of the measurement and whether that scale is appropriate to the scale of the model. Two factors that need to be considered are (1) the physical-chemical processes of the measurement the same as the physical-chemical processes of interest at the model scale, and (2) the statistics calculated from the data appropriate at the model scale.

Some measurements do not represent the same physical-chemical processes as at the model scale. Consider for example, laboratory measurements of the hydraulic conductivity of core samples. In porous media, one might be able to use core data if a large number of samples were available to allow calculation of the mean and variance. In fractured media, cores are usually recovered from the least fractured portions of the units. Flow is primarily through the fracture network; therefore, the small-scale cores do not sample the appropriate portions of the unit. In this case, core-scale data are at too small of a scale to be applicable to the CAU-scale modeling because the physical process of flow through fractures is not measured.

A second example of a different physical-chemical process is the adsorption of radionuclides onto rock material (Zavarin et al., 2002). At the small scale of laboratory measurements, adsorption is recognized as interactions, governed by thermodynamic processes, between specific radionuclides and specific reactive minerals. The CAU model scale is too coarse to simulate these detailed physical-chemical processes. Rather, the CAU model utilizes bulk representations of sorption processes in the form of $\mathrm{Kd}$ (distribution coefficient) or retardation coefficients. In this case, it appears possible (Zavarin et al., 2002) to scale the small-scale measurements up to the CAU model scale and define approximate bulk parameters applicable to the physical-chemical processes at the model scale.

Scale of measurement is also a consideration with respect to statistics of the data. Even if the physical-chemical processes of the measurement and CAU model are the same, issues of scale arise. Vanmarke (1983) presents examples of spatially variable data characterized by covariance functions in which the data are averaged inside regions of various sizes. As the size of the averaging volume increases, the variance decreases and the mean value of the block trends toward the geometric mean for parameters characterized by a log normal distribution and exponential covariance. This suggests that the variability in the average value of a parameter, applied to an entire HSU, would be much smaller than the variability of the data itself. This general concept, analogous to the central limit theorem, would apply 


\subsection{Source Term}

to datasets where the number of measurements is large (generally greater than 25) and the data adequately represent the entire HSU. If the number of measurements is small, or spatially unrepresentative, then it will be difficult to quantitatively reduce the uncertainty of the mean value.

The underground nuclear tests in Yucca Flat are the sources of radionuclides in the groundwater system. To simulate radionuclide migration, the source term must be defined at each of the source locations. Definition of the source term is a complex process that includes: (1) definition of the radiological source term, (2) process scale simulation, (3) abstraction to the CAU scale, (4) source categorization, and (5) calculation of the hydrologic source term for each source location.

There are important differences between the radiological source term and the HST. At each test location, the radiological source term is the total inventory of residual radioactivity resulting from an underground nuclear explosion (Pawloski et al., 2001). The HST describes the nature and extent of radionuclide release and near-field migration in the groundwater away from the test. The HST provides the source term input to the CAU-scale transport model.

\subsubsection{Radiological Source Term}

The radiological source term is the total inventory of radionuclides remaining in the subsurface following an underground nuclear explosion. These radionuclides are distributed in three zones: the melt glass zone, cavity zone, and the disturbed zone. The cavity and disturbed zones are referred to as the exchange volume. This inventory is important information for forecasting contaminant migration. The radiological source term is classified for most tests. An approach for identifying a representative unclassified inventory for the CHESHIRE flow and transport modeling was developed by LLNL (Pawloski et al., 2001). This approach consisted of assembling a list of candidate radionuclides from the following unclassified information:

- The mean of the total radionuclide inventory for all tests detonated below or within $100 \mathrm{~m}$ of the water table in Areas 19 and 20

- $\quad$ Radionuclides identified by the UGTA Source Term Subcommittee as significant for environmental restoration activities at the NTS

- Radionuclides measured in groundwater near the test of interest

A screening process was applied to this list with radionuclides being retained if:

- $\quad$ There was a test-related inventory for the radionuclide

- The inventory equalled or exceeded the natural inventory of the rock

- The ratio of activity or amount of radionuclides decaying by $\alpha$ and $\beta$ electron capture/isomeric transition processes to the total activity or 
amount of radionuclides decaying by these processes exceeded 0.1 percent

- The radionuclide was detected in groundwater from or near the test of interest

Radioactive decay and ingrowth processes were also considered for the listed radionuclides to account for increased daughter product activity during the 1,000-year simulation period. Once radionuclides meeting the criteria were determined, they were segregated into 13 simplified classes of radionuclides that had similar partitioning and chemical reactivity characteristics. This approach is considered to be conservative, comprehensive, and transferable to the Yucca Flat/Climax Mine CAU.

Other issues regarding classification of source terms are discussed in Section 9.0.

\subsubsection{Process Scale Modeling of Radionuclide Mobilization in the Exchange Volume and Melt Glass}

The process scale modeling simulates: (1) the release of radionuclides from the melt glass and exchange volume, and (2) the chemical interaction of the radionuclides as they migrate in the cavity and the surrounding groundwater system. The release of radionuclides from the melt glass is defined by a glass dissolution model. The release of radionuclides from the exchange volume is defined by a geochemical model that is a function of the radionuclide, the chemistry of the water, and the mineralogy. The migration of the released radionuclides in the cavity and near-field environment is defined by a near-field flow and transport simulator that is a complex function of coupled reactive transport and groundwater flow dependent on radionuclide, groundwater chemistry, mineralogy, and groundwater velocity. The assumptions, inputs, and outputs for each model are described below.

\section{Glass Dissolution Model}

A glass dissolution model developed for the CHESHIRE test is described in Pawloski et al. (2001). Assumptions include:

- Dissolution rates of radioactive melt glass can be estimated using previous experimental studies of natural, man-made silicate glasses and nuclear melt glasses (Bourcier et al., 2000).

- Effects of small amounts of contaminants including radionuclides have negligible effects on dissolution rates.

Inputs to the glass dissolution model are:

- Surface area of the melt glass

- Rate coefficient

- Activity of each species in solution

- Affinity (saturation) term 
- Final rate

- Ambient groundwater chemistry

- Temperature

The model output is the rate of glass dissolution. Future improvements may include precipitation reactions.

\section{Geochemical Model}

The geochemical model simulates radionuclide precipitation and equilibrium controlled speciation, ion exchange, and surface complexation. Radionuclide sorption to iron oxide, calcite, and aluminosilicates was simulated with a nonelectrostatic surface complexation model. Ion exchange reactions among radionuclides and sodium, calcium, potassium, and magnesium on smectite, ilite/mica, and zeolite was modeled with a Vanselow ion exchange formalism (Pawloski et al., 2001).

\section{Coupled Reactive Transport and Groundwater Flow Model}

The Coupled Reactive Transport and Groundwater Flow model uses information from the radiological source term and the glass dissolution model to estimate the concentration of radionuclides in the pore water of the exchange volume and radionuclide fluxes into the aquifers. These radionuclide fluxes are the HST needed for the CAU model. Whereas the assumption of steady-state flow is appropriate at the CAU scale, complex thermal circulation cells in cavity-chimney systems require transient simulations. In addition to the transient thermal effects, complex chemical processes govern the dissolution of melt glass, release of radionuclides, and transport in the rubblized chimney. Therefore, the release of radionuclides for individual sources to the CAU flow system needs to be considered as a complex process which feeds the CAU assessment. One strategy for simulation of radionuclide migration in a cavity chimney system is to extract a large number of streamlines from a simulated flow field and conduct independent 1-D reactive transport simulations. Information from the 1-D simulations would then be used to produce an integrated flux through a downstream boundary face (into a CAU aquifer). Another strategy involves a fully coupled thermal-hydrologic-chemical (THC) model, which allows for mixing during the transient flow simulation. Each of these approaches have strengths and weaknesses and should be compared to develop confidence and credibility in hydrologic source term models, for which there are little data for validation.

Due to the small spatial scale associated with individual cavity simulations, boundary conditions for process models will be derived either from local data (heads) or fluxes from CAU-scale flow models as they are developed. Hydraulic conductivities will either be developed from measurements in wells near the source of interest or from the calibrated CAU flow model. The HST-specific inputs include melt glass temperature, estimations of mineralogic distributions, thermodynamic databases for reactions, other laboratory data including kinetic rate measurements, and Kd's of radionuclides, and local geochemical conditions derived from field sampling (e.g., major and trace chemical composition of water, $\mathrm{pH}$, Eh, ionic strength, colloid concentration estimates). 


\subsubsection{Abstraction to the CAU Scale}

The process models are very detailed and provide valuable insights into the release and transport mechanisms in the near-field environment of an underground test. The result of the process modeling is radionuclide flux exiting the near-field environment into the ambient groundwater system. The purpose of the abstraction is to generalize the process level simulations for use in the CAU-scale transport model. Pawloski et al. (2001) identified the following issues that must be considered during the abstraction of the process model.

- The effective flow rates in the process model and the CAU model must be the same, or fluxes must be scaled to account for the different flow rates

- Heterogeneous hydraulic conductivity must be scale to provide effective larger scale hydraulic conductivity

- Dispersion at the process scale caused by heterogeneous hydraulic conductivity must be scaled to produce a macrodispersivity at the CAU scale

- Chemical heterogeneity must be scaled to produce effective retardation coefficients at the CAU scale

- Care must be taken to address a potential dilution effect as the radionuclide flux is introduced into a larger volume of the CAU model, thus artificially reducing concentrations

\subsubsection{Source Categorization}

Transient, nonisothermal, reactive transport modeling of each source in the Yucca Flat/Climax Mine CAU is impractical. Therefore, a strategy will be developed for categorization and grouping sources, thus yielding a small subset of source locations for which simplified hydrologic source term modeling is required. The categorization will be based on local geology, proximity of working points to aquifers, proximity of working points to faults, proximity of working points to other tests, and other characteristics to be determined (Pawloski et al., 2002b).

\subsection{Thermal Hydrology}

The temperature of groundwater beneath the NTS can vary significantly from location to location. Some of these temperature variations are due to residual heat from underground tests while others are due to natural geothermal processes.

\section{Chimney Scale}

Modeling results from LANL and LLNL (Pawloski et al., 2001;

Wolfsberg et al., 2002) have shown that heat from underground tests significantly affects local fluid flow for several hundred years after the test. The period of time that heat impacts are important may be quite variable from test to test depending on the local flow system. As described above, successful simulation of 
radionuclide transport at the chimney scale may require the ability to model temperature-dependent flow. Detailed process models have been completed for the Pahute Mesa CAU that may be applicable to the Yucca Flat/Climax Mine CAU. An approach for abstracting process models to CAU models has been developed using GoldSim, but is not yet verified. This very simplified approach allows radionuclides to enter overlying aquifers for a fixed period of time (for example, 200 years). The appropriateness of this assumption will be assessed during the modeling process.

\section{CAU Scale}

Differences in water temperature will lead to differences in saturated hydraulic conductivity, a parameter dependent on both rock and fluid properties. Rather than simulating fully transient nonisothermal flow at the CAU scale, the CAU flow model may take advantage of a new capability in FEHM for specifying water temperature as a function of the elevation of an HSU. Although the approach will not capture such processes as thermal upwelling and other local phenomena, it will be suitable for regional prescription of a geothermal gradient. A second approach would be to convert the hydraulic conductivity for temperature prior to input to the model. The impact of thermal processes at the CAU scale is discussed further in Section 7.0.

\subsection{Saturated Zone Flow}

The FEHM code (Zyvoloski et al., 1997b), developed by LANL, was chosen for the Yucca Flat/Climax Mine CAU-scale flow and transport model. The code selection process is documented in the Appendix A. FEHM simulates 3-D, time-dependent, multiphase, nonisothermal flow and multicomponent, reactive groundwater transport through porous and fractured media. FEHM's finite element formulation provides an accurate representation of complex 3-D geologic media and structures and their effects on subsurface flow and transport. Specific capabilities include:

- 3-dimensional

- Flow of air, water, and heat

- Multiple chemically reactive and sorbing tracers

- Colloid transport

- Finite element/finite volume formulation

- Coupled stress module

- Saturated and unsaturated media

- Preconditioned conjugate gradient solution of coupled nonlinear equations 
- Double-porosity and double-porosity/double-permeability capabilities

- Complex geometries with unstructured grids

- Two different reactive, dual-porosity, particle-tracking modules

- Coupled to PEST (Watermark, 2000) parameter estimation software

- $\quad$ Linked with Los Alamos Grid Toolbox (LaGriT) (George, 1997) grid generation software

- Supported on SUN, SGI, ALPHA, and Intel (windows)

Documentation includes a description of the mathematical models and numerical methods used by FEHM (Zyvoloski et al., 1997a), the user's manual (Zyvoloski et al., 1997b), documentation of the functional and performance requirements for FEHM, description of the FEHM software, and verification and validation reports (Dash et al., 1997; Dash, 2000 and 2001). Further, the software is maintained in configuration management at LANL. With each new release, the software is subjected to a rigorous verification test to ensure accuracy and functionality of all capabilities.

Assumptions for the flow and energy transport models in FEHM include fluid flow governed by Darcy's law, thermal equilibrium between fluid and rock, immovable rock phase, and negligible viscous heating. Specific assumptions are discussed further by Zyvoloski et al. (1997a).

Inputs to the flow model include the finite-element grid, initial conditions, lateral boundary conditions, recharge, and material properties for HSUs and faults.

For application to isothermal groundwater flow, the calibrated FEHM model produces values of hydraulic head or pressure for each node in the grid.

\subsection{Saturated Zone Transport}

Saturated zone transport can be simulated with continuity equations on a finite-element grid, with discrete particle-tracking techniques, or with continuity equations along 1-D grids, mapped to coincide with particle pathways in a 3-D flow field.

Solving the continuity equations in 3-D or along 1-D pathways allows for the greatest flexibility in specifying reactive processes. Fully coupled kinetic and equilibrium reactions describing multicomponent, aqueous-aqueous, and aqueous-solid reactions can be accommodated with a dual-porosity methodology suitable for capturing fracture-matrix interactions. However, such simulations are computationally demanding and may not be appropriate for CAU-scale simulations, particularly when parameter uncertainty is addressed with Monte Carlo-type simulations. Although more limited in the reactions that can be addressed, the 3-D streamline particle-tracking transport algorithm is significantly more efficient than finite-element solutions of the continuity equations. The 
particle-tracking model is a full, dual-porosity methodology for simulating transport in fractured rock. It can be used to simulate dual-porosity transport with: (a) diffusion into the matrix, (b) solute retardation on fracture minerals, and (c) solute reaction with matrix minerals. Fracture properties such as aperture, spacing, and reactivity can vary spatially as can matrix reactivity.

The limitation of the particle-tracking solver compared to the continuity equation solver is that solute-solute reactions cannot be simulated with the particle-tracking model. This means that an abstraction of complex processes such as solute-colloid reactions must be developed prior to the simulations. Such an abstraction can be developed with a limited number of simulations of the complete set of continuity equations. It involves identifying the transport parameters associated with a new species, such as plutonium-colloid. The parameters govern the retardation and the maximum aqueous concentration. Then the new species can be simulated independently, and somewhat conservatively relative to the fully coupled model. Another limitation of the particle-tracking model is that it is incapable of considering kinetic sorption processes and filtration of colloids. Thus, the fully coupled process model will be used to justify equilibrium retardation factors for such processes as colloid attachment and detachment to fracture walls, while maintaining conservatism.

In summary, the strategy for simulating transport of radionuclides at the CAU scale will include both a fully coupled reactive transport methodology, and an abstraction model based on streamline particle tracking. The fully coupled model will be used to investigate process sensitivity and to design parameter ranges for the more efficient particle-tracking model. The particle-tracking model will be suitable for the multiple simulations needed to investigate multiple geologic interpretations and ranges of uncertainty of all other flow and transport parameters. Variants on this coupled approach using fully reactive transport and particle tracking algorithms were applied by Pawloski et al. (2001) and Wolfsberg et al. (2002).

The source for the CAU transport model will be abstracted release functions representative of the 169 underground tests that have been identified as at or below the water table. These will be in the form of mass flux versus time at either: (a) the working point of the tests, or (b) the intersection of aquifers with the cavity/chimney systems associated with the tests. For the tests which are studied in greater detail in the Yucca Flat/Climax Mine CAU, such as CHESHIRE and BENHAM were in the Pahute Mesa CAU, the process models should produce mass fluxes into specific aquifers. For tests that are "categorized" based on geologic or other background information (see Section 4.6.2), it is likely that the resolution of the source mass flux will not be as high as for those tests which are studied in detail. The mass flux at each test will be a function of the local groundwater conditions. In addition, a limited number of simulations will address the potential impact of tests located above the water table. The initial approach will be to transfer the vadose zone test to the water table and simulate them as saturated zone tests.

The CAU transport model will be used to assess radionuclide concentrations in the aquifer. The methods described above will be used to calculate mass flux and 
concentration at specified locations downgradient from the tests of interest. These computed concentrations will then be used to estimate the maximum extent of the contaminant boundary.

\subsection{Heterogeneity}

The physical and chemical properties of the geologic materials that affect groundwater flow and solute transport are spatially variable, or heterogeneous. The heterogeneity of parameters in the various component models of the CAU model must be adequately represented in the groundwater flow and radionuclide transport models to effectively serve the process of defining the maximum extent of the contaminant boundary.

How heterogeneity is represented in the models depends on the parameter in question and the scales of the variability and the model. For example, some forms of heterogeneity may be adequately represented by the average value defined over an HSU, some may be represented adequately at the nominal grid scale used in the simulations, and other may require additional consideration of sub-grid scale considerations.

Other considerations include assumptions that constrain heterogeneity later in the modeling. For example, the assignment of stratigraphic units to HSUs (a necessary step in the modeling process) places constraints on heterogeneity that may cross HSU boundaries.

Heterogeneity is also important in the scaling of data from the measurement scale to the model scale. In some cases, such as the effective porosity of porous units, the scaling process generally retains the mean value but reduces the variability. Other parameters, such as the log-normally distributed hydraulic conductivity, may be modified both in mean and variability by the scaling process. Thus, heterogeneity must be considered during the data analysis and modeling phases. 


\subsection{Implementation of the CAU Model}

This section describes how the component process models presented previously will be linked to forecast system behavior. The CAU model will integrate mathematical and numerical modeling of each process including uncertainty through a prescribed flow of information. An overview of the steps to implement the CAU model approach described in this section is shown in Figure 5-1.

\subsection{Simulation Objectives}

The role of modeling in the FFACO Corrective Action Strategy was discussed in Section 1.0. Simulation objectives are defined in the FFACO (1996). Briefly, the objective is to develop a tool for predicting contaminant migration from source locations through the hydrogeologic units of Yucca Flat/Climax Mine to forecast locations of specified contaminant concentrations for assessment of the contaminant boundary and to provide a basis for risk assessment, design, and siting of monitoring wells.

The objectives of the FFACO will be met via a multistep modeling process defined in Figure 5-1. The process includes definition of model boundaries, analysis of geologic, hydrologic, and geochemical data, definition and screening of alternative models, specialized analyses related to faults and source term, and generation of the flow model grids. The flow model is calibrated to observed data which may include water levels, groundwater fluxes, and geochemistry constraints. If necessary, local models will be developed to support the creation of transport models. The transport models use information related to sources, transport parameters, and heterogeneity. Finally, the transport simulations forecast system behavior and associated uncertainty, both of which contribute to the definition of the location of the contaminant boundary. Following the simulations, a model verification will be conducted to enhance confidence in the model results.

\subsection{Geologic Model Boundaries}

The next step in the implementation of the CAU model is to define the geologic model domain. Boundaries will be chosen based on a number of considerations. The boundaries will be chosen such that: (a) they coincide with perceived geologic and hydrologic domains, (b) the contaminant source areas and discharge areas will be included with some buffer regions, and (c) practical constraints on model size will be considered. The Yucca Flat/Climax Mine CAU flow and transport models will be developed within the boundaries of the geologic model. 


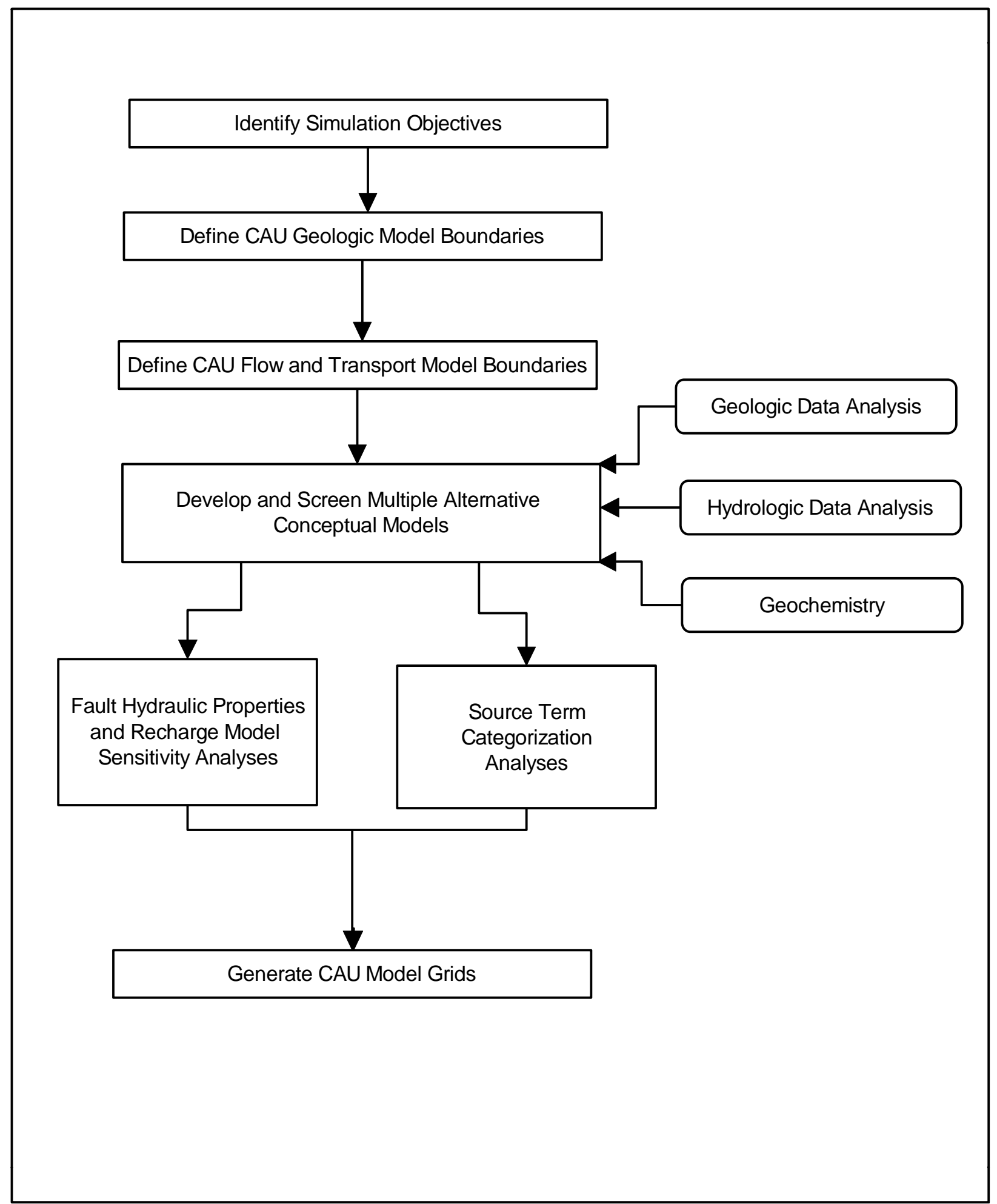

Figure 5-1

Implementation of the CAU Model

(Page 1 of 2) 


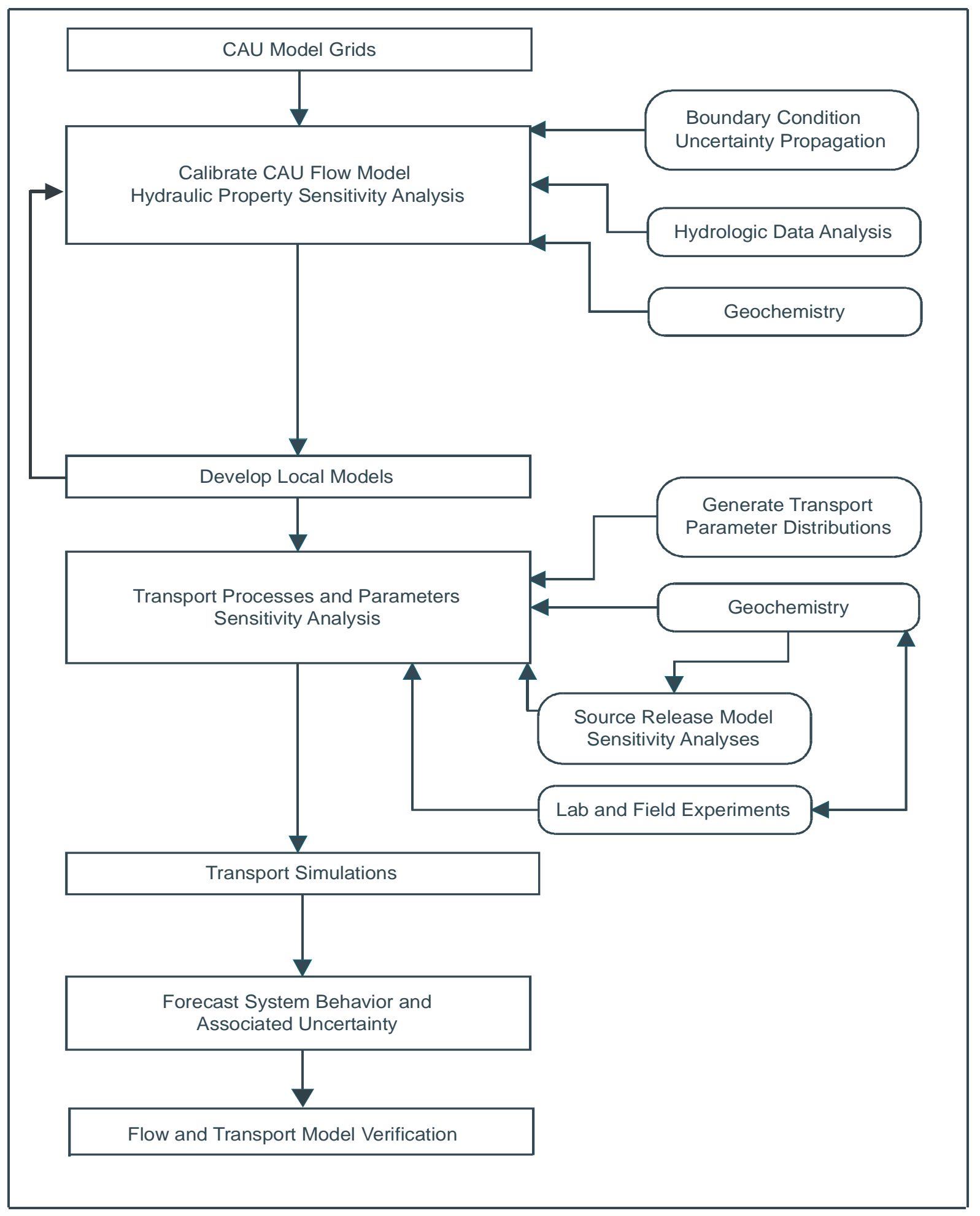

Figure 5-1

Implementation of the CAU Model

(Page 2 of 2) 


\subsection{CAU Model Boundaries and Boundary Conditions}

The next stage of the process shown in Figure 5-1 is identification of the CAU model boundaries and boundary conditions. When selecting boundaries for a flow and transport model, natural physical boundaries of the aquifer system such as recharge and discharge zones, impermeable rock, or aquifer connections with surface water bodies are preferred because they provide easily described hydraulic boundary information. The characteristics of the Yucca Flat/Climax Mine CAU are such that natural physical boundaries are too distant to be used for the lateral boundaries of the flow and transport model. The CAU boundaries will be selected to incorporate all relevant sources, important hydrogeologic features, and wells providing hydrologic and geologic information. Potential CAU model boundaries encompassing the Yucca Flat/Climax Mine CAU as described in the Corrective Action Investigation Plan for Corrective Action Unit 97: Yucca Flat/Climax Mine, Nevada Test Site, Nevada (DOE/NV, 2000a) are shown in Figure 5-2. The model boundaries are shown as potential because they could be as large as the study area, or as small as the CAU boundary. Lateral boundary conditions will be obtained from the regional groundwater model. Details of this approach are described in Section 7.0. The recharge model will provide fluxes for the model surface and the bottom of the model will be considered impermeable. The bottom of the model will be no deeper than the regional model (4,000 $\mathrm{m}$ below sea level). If the bottom is the same as the regional model, then the bottom of the CAU model will be treated as "no flow" as was the case in the regional model. Recent evaluations of the regional groundwater flow model have shown that little flow occurs deep in the model because of the small values of hydraulic conductivity. The deepest underground test conducted in the Yucca Flat/Climax Mine area has a working point elevation of about $490 \mathrm{~m}$ above sea level. The CAU-model bottom may be significantly shallower than $4,000 \mathrm{~m}$ below sea level, if it can be shown that very little flow occurs at the larger depths. If so, the regional flow model will be used to define bounds on the fluxes through the bottom of the CAU model.

\subsection{Multiple Alternative Conceptual Models}

With the objectives and boundaries of the analysis defined, the next step incorporates uncertainty about structure and processes. As shown in Figure 5-1, analysis of geologic, hydrologic, and geochemical data will be used to develop multiple alternative conceptual models of CAU model components that potentially have large uncertainty. For example, alternative conceptual models of the hydrogeologic framework, boundary conditions, source release, and transport in fractured rock will be identified and evaluated through sensitivity analysis. Whereas, flow and transport parameter uncertainty will be addressed on all of the computational grids created for this process; uncertainty in the hydrogeologic framework model will be treated as a set of equally likely discrete cases, each one potentially leading to a unique model grid for simulation. Following initial hydrogeologic model development, opinions of experts will be elicited to develop and prioritize alternative hydrogeologic models. Each model will be a deterministic representation of the complex geologic system. The alternative models will incorporate interpretations related to stratigraphy and structural features such as faults. Initially, alternatives will focus on conceptual models having a geographically extensive impact on the hydrostratigraphic framework. 


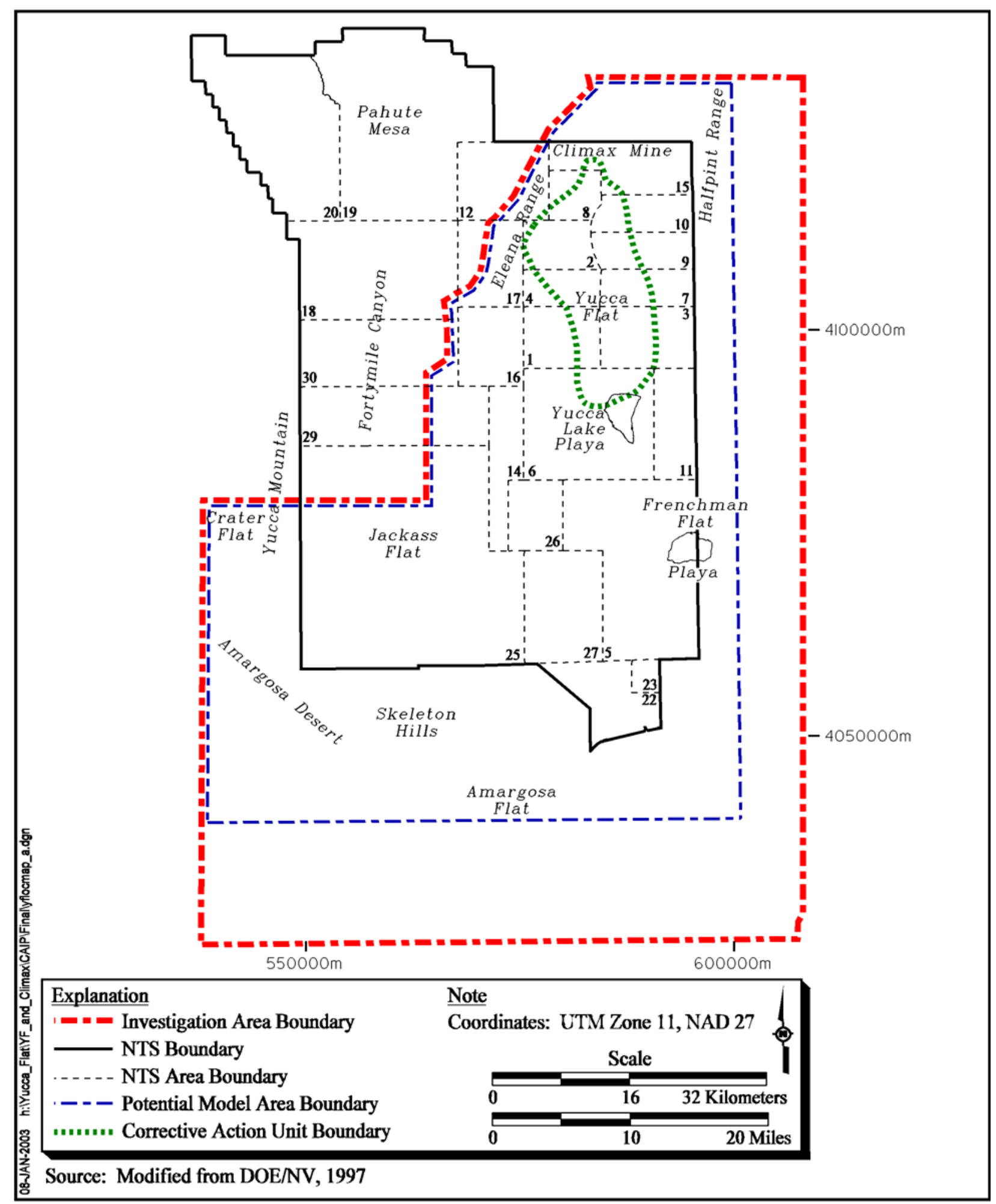

Figure 5-2

Location of Yucca Flat/Climax Mine Investigation Area and Potential CAU-Model Area 
These alternative framework models will be screened using particle-tracking simulations. The base model will be partially calibrated to ensure rough correspondence to observed conditions. Then alternatives will be simulated with the same parameter sets to determine which models lead to significantly different transport results. These significantly different alternative hydrogeologic framework models will be taken through the remaining steps in the CAU model implementation. This includes transport simulations to provide a basis for determining uncertainty in model predictions due to uncertainty in the hydrogeologic framework model.

This screening activity will also allow for initial identification of "failure modes" for additional consideration. The objective of the CAU modeling step within the UGTA approach is to define the maximum extent of contaminant transport for the CAU. Unlike applications in areas, such as waste management, a regulatory performance standard for the CAU is not defined. There is no defined compliance boundary for the CAUs at which contaminants cannot exceed some maximum concentration. Neither is there a regulatory minimum travel time for contaminants to reach a specified boundary. Without some measure of performance, failure cannot be defined in a regulatory context. Thus, "failure modes" will need to be contrived to provide a measure of performance for the purposes of the sensitivity analysis. For example, for the Yucca Flat/Climax Mine CAU, the predicted extent of contaminants with respect to the southern and western boundaries of the NTS could be used to evaluate performance. Failure modes may relate to pathways through HSUs or faults that lead to transport in the carbonate to the basin boundaries.

\subsection{Sensitivity Analyses for Fault Hydraulic Properties and Recharge}

Two key uncertainties can be investigated without requiring a calibrated, CAU-scale flow model. These are uncertainties in fault hydraulic properties and recharge. Although very little data currently exists for fault zone properties, end-member considerations include properties which cause the fault to behave as a conduit or a barrier. An additional consideration is one in which the fault acts as a barrier to flow across it, but acts as a conduit for flow within the fault. Further, the role fault zones play in connecting aquifers at different elevations may be significant, particularly in failure scenario studies. Recharge fluxes provide the boundary condition for the top of the flow and transport model. Recharge models in arid regions characteristically have a large associated uncertainty. Sensitivity analyses for these processes are described in Section 7.0.

\subsection{Source Term Categorization}

Of the 744 underground detonations conducted in shafts and tunnels in Yucca Flat and 3 conducted in the Climax Mine, 169 were below or within 100 meters above the water table (DOE/NV, 2000a). The large number of sources adds to the complexity of modeling transport. There are several options for incorporating multiple sources. The first is to treat each source individually. This option would increase computational burden-making simulation times much longer. The second is to combine nearby tests to form integrated source terms. The third option is to evaluate data for tests in the Yucca Flat/Climax Mine CAU to determine if 
categories of tests can be created based on geologic and hydrologic setting (e.g., proximity to faults and aquifers), test-specific information, and phenomenological data. In this manner, the number of sources may be reduced. The fourth option, which can be combined with any of the above, is to develop a convolution of source release with the CAU-scale transport simulation to provide an efficient time history simulation of radionuclide concentration at specified locations.

\subsection{Grid Generation}

Simulations of flow and transport, including particle tracking, in 3-D domains representing the complex hydrostratigraphy described in the hydrogeologic models will be conducted on finite-element grids. The grids are discrete interconnected tetrahedra that, when connected together, capture the structure of the hydrostratigraphy. The flexibility of finite-elements allows for the resolution of the grid to vary spatially so as to capture source areas and complex structures such as faults with higher resolution than other areas where coarser discretization is sufficient.

With multiple hydrogeologic models to consider, multiple grids must be generated. The method developed for the flow of information from hydrogeologic interpretation through grid generation has the following steps. The process begins with incorporation of a given alternative hydrogeologic digital model using EarthVision ${ }^{\circledR}$. Elevations describing the surface of each HSU and traces of each fault are extracted from the EarthVision ${ }^{\circledR}$ model and become inputs to the grid generation software, LaGriT (George, 1997), which is composed of a suite of grid generation tools. This software provides an integrated system for all grid generation steps. Unique properties can be assigned to each HSU and fault in the grid. Grid generation will require decisions on the location of high-resolution areas. Possible candidates for high resolution include fault zones and thin HSUs. Calibration efficiency can be increased by keeping the flow model grids coarse, then adding higher resolution to source regions and plume pathways for the transport simulations. A process for transferring hydrogeologic framework model information from an EarthVision ${ }^{\circledR}$ model to inputs required by LaGriT has been developed and tested.

\subsection{Flow Model Calibration}

Each alternative hydrogeologic model identified after screening will require calibration (Figure 5-1). Calibration consists of determining model parameter values such that simulated heads and fluxes are consistent with observed or target values. The model parameters for a CAU flow model will include the permeabilities of the HSUs and faults in the model. Specified observations for a CAU model will include hydraulic heads measured in wells within the model domain and fluxes through lateral model boundaries calculated from the regional model. These data provide "targets" for the calibration process. Recharge is defined by a recharge model and may be adjusted during calibration. Data required for calibration includes information from hydrologic data analysis including well locations, locations of open intervals, HSUs represented by open intervals, transient head measurements in wells, and fluxes from the Regional 
Groundwater Model. Methods for propagating uncertainty in boundary conditions from the Regional Groundwater Model are discussed in Section 7.0.

It is known that some water levels in Yucca Flat have been impacted by testing. Initial calibration will include these transient effects, but they will need to be examined before calibration is complete.

PEST (Watermark, 2000), a commercially available software package developed by Watermark Computing, provides a nonlinear parameter estimation routine that can be used to automatically calibrate a flow model. PEST can be used with any existing computer modeling program for model calibration. However, FEHM was recently modified to efficiently provide data needed by PEST in each iteration with no additional post-processing. PEST runs the model initially and calculates the weighted sum of squared differences between model-generated heads and observed heads and between simulated flux values and regional model fluxes. This sum is referred to as the objective function. PEST then repeatedly runs the flow model to guide the adjustment of parameters until the objective function is minimized. In principle, PEST can be set up to adjust permeabilities until simulated fluxes on the CAU model boundary match those calculated by the regional model and simulated heads match measured heads within the CAU model domain. Due to random and systematic errors, there will always be some discrepancy between modeled and measured values. The PEST routine attempts to minimize this discrepancy and provides estimates of uncertainty in the results. Since the flow model must be run many times during calibration, this part of the process requires heavy usage of computing resources. A model calibration will be specific to the hydrogeologic model, parameter zonation, and recharge specified and the lateral boundary fluxes and hydraulic heads used as calibration targets. Alternative geologic models, alternative recharge models, or changes in calibration targets will require new calibrations.

The PEST optimization process will produce expected values, 95 percent confidence limits, and a measure of sensitivity for HSU and fault hydraulic properties used as parameters. It is recognized that parameter sensitivity in PEST is with respect to the calibration objective function. Broader sensitivity analyses will also need to examine parameter sensitivity with respect to predicted location of the contaminant boundary.

For complex models with sparse data, calibration is generally nonunique. That is, more than one set of parameter values provided to the flow model could result in the observed hydraulic heads and fluxes. Analysis of geochemical data will be integrated into the calibration process to provide independent lines of evidence to support parameters leading to the prediction of groundwater flow paths and travel times. Recent work by Rose et al. (2003) for Pahute Mesa is an example of the types of constraints that can be placed on the flow system.

Thermal effects may need to be considered during calibration. Sources of heat in the Yucca Flat/Climax Mine area include flow of heat from deeper layers toward the surface and residual thermal pulses from underground nuclear tests. Since warm water is more buoyant than cooler water, hot water injected into the aquifer from nuclear test cavities will tend to rise towards higher layers. Natural 
temperature gradients may lead to large-scale thermal upwelling in some areas. The significance of these processes must be evaluated as calibration assuming either a steady state, or an isothermal domain, will ignore their effects. The saturated hydraulic conductivity (Ksat) is dependent on both rock and water properties. Therefore, Ksat may be larger in deeper systems where the water is warmer. Even for steady-state flow fields, FEHM accounts for thermal variation effects based either on elevation in the model or HSU in the model. However, if thermal upwelling is determined to be a significant alternative conceptual model, then transient nonisothermal simulations will be required to assess the impacts of such processes.

\subsection{Local Models}

Local-scale models may need to be developed to address specific issues that must be resolved at an intermediate scale before developing the CAU-scale model. The local models may be 3-D, of limited extent, and would feature finer resolution than can be achieved with a model at the CAU scale. The local models are calibrated to local heads, but may use boundary conditions derived from the CAU model.

The purpose of the local models is to assess small-scale processes in more detail than is possible with the CAU model. For example, the local models may be used to assess the role of faults in local groundwater flow, the uncertainty due to spatial variability, the impact of alternative hydrostratigraphic framework interpretations, and alternative hydrologic conceptual models (primarily the direction of flow).

The local models will assess numerous sources of uncertainty such as uncertainty in local parameter values, boundary flux uncertainty, source uncertainty, and conceptual model uncertainty. The local models will provide input to the CAU model. The local models will help to determine if the CAU model must be made more detailed to capture certain features of the flow system or whether the local processes can be scaled up to the CAU scale via effective parameters. The need for local models will not be established until after the CAU flow model is calibrated.

\subsection{Transport Processes and Parameters Sensitivity Analyses}

Each transport parameter will be described by a central tendency and variability about that central tendency as represented by a PDF or CDF. This process is described in Section 4.5. Results of sensitivity analyses from source term and site-scale modeling studies, such as Pawloski et al. (2001) and Wolfsberg et al. (2002), will be used to identify significant transport processes and parameters for the Yucca Flat/Climax Mine CAU.

\subsection{Transport Simulations}

Transport simulations will be conducted to predict the movement of contaminants in the groundwater and determine the associated uncertainty. The primary tool for "production run" process model simulations will be the dual-porosity, streamline, particle-tracking module of FEHM. However, additional simulations will be 
conducted with the finite-element, dual-porosity, reactive transport module (1-D and 3-D). These simulations will be used to condition and validate parameters used in the particle-tracking simulations. They will also be used to condition and validate conceptual models and model parameters used in GoldSim simulations of the CAU system.

Important inputs for transport simulations are:

- Groundwater fluxes

- Transport parameter distributions

- Grid resolution improvements

- Integrated source release model

- Natural geochemical system

\section{Groundwater Fluxes}

For each alternative hydrogeologic model, at least one calibrated steady-state groundwater flow field will be simulated. As uncertainty in boundary conditions is considered, multiple flow models will be developed for each hydrogeologic model. Further, the strategy at this time is to consider only steady-state flow at the CAU scale. However, there may be reasons that surface later to investigate transient or quasi-transient flow fields at the CAU scale. For example, the current strategy is to consider a 1,000-year time frame. If it becomes necessary to consider longer time frames, then the transient effects of climate change will need to be assessed. Also, the source term models predict radionuclide releases from the cavity/chimney systems with transient simulations. Although it is unexpected, integration of source term and CAU models may require some simulations in the transient mode as well. Thus, there will be at least one and probably more flow fields per alternative geologic model. Radionuclide transport will be simulated upon these flow fields.

\section{Transport Parameters}

Distributions for transport parameters such as effective porosity and radionuclide sorption coefficients are required input. For each transport simulation, multiple processes must be considered. Some will be simplified based on other detailed process models. Some will be represented as accurately as possible with the CAU transport model. Fundamentally, the CAU transport model will attempt to capture the processes of:

- Advective and dispersive solute transport

- Diffusion of solutes from fractures into matrix material

- Retardation of solutes on fracture minerals

- Retardation of solutes on matrix minerals

- Enhanced mobility of solutes due to colloids

- Retardation of colloids via filtration and attachment to fracture walls

Each of these processes, treated isothermally, is captured with parameterized equations in the transport model. The parameters (e.g., diffusion coefficients, matrix porosity, fracture aperture, fracture spacing, sorption coefficients, filtration coefficients) are derived either from laboratory or field studies and have 
uncertainty associated with them (see Section 7.0). Further, some of the processes listed above are affected by environmental conditions such as $\mathrm{pH}$, redox potential, and ionic strength. The effect on the processes, also uncertain, will be accounted for in the parameter distributions, developed prior to the CAU simulations. Doing so requires assuming unvarying conditions with time in local water chemistry and mineral composition. Another significant assumption in the CAU simulations will be that solute-solute reactions are either negligible or that they can be captured in the abstracted specification of source species and their concentrations. For example, if species A and $\mathrm{B}$ tend to react to form species $\mathrm{C}$, which is more mobile than $\mathrm{A}$ or $\mathrm{B}$, then a conservative assumption may be to allow all $\mathrm{A}$ and $\mathrm{B}$ to go to $\mathrm{C}$ instantaneously. However, that may reduce the residence time of dose-contributing solutes in the system. Therefore, these assumptions will be tested and refined with more rigorous process-level models.

Using a set of simplifying assumptions (justified with data and/or rigorous process models), the processes listed above will be accounted for in the CAU simulations of radionuclide migration. The source term (possibly abstracted for each test) will provide time varying input functions to the CAU transport model. The model will then be used to simulate concentrations and mass fluxes in the groundwater system.

\section{Grid Resolution}

A smaller model area and a higher grid resolution may be required for the transport simulations than for the flow simulations. Increased resolution may be needed near sources and in the plume migration domain. Further, portions of the grids may need to be structured in source regions to accommodate geostatistical attribute simulations and source term abstraction integration. The strategy involves a coupled link between the EarthVision ${ }^{\circledR}$ hydrostratigraphic modeling software and the LaGriT grid generation software. The process will allow for appropriate grids to be developed for the specific flow and transport needs of the CAU model.

\section{Integrated Source Release Models}

The integrated source release models will provide the hydrologic source term including uncertainty for transport simulations. These models involve fully coupled process models or abstractions of them that capture the complex thermal flow and reactive transport processes associated with radionuclide release from cavity/chimney systems into the CAU aquifers. Since all of the tests in the Yucca Flat/Climax Mine CAU will not be simulated individually with full process models, abstractions of the release process will involve, in part, a source term categorization process. Source term categorization will utilize geologic and source-related information to group different tests into like categories. This should reduce the number of detailed studies needed to develop appropriate, unclassified source functions for the Yucca Flat/Climax Mine CAU.

\section{Natural Geochemical System}

An understanding of the natural geochemical system may provide constraints on the contaminant transport model for the Yucca Flat/Climax Mine CAU. Modeling 
of geochemical transport in the vicinity of Yucca Flat and the Amargosa Desert demonstrated that interpretation of geochemical data combined with transport modeling can provide a tool for characterization of the groundwater system and information required to understand the movement of radionuclides. Further work will revise this flow path analysis incorporating the additional geochemical data obtained from wells drilled as part of the Yucca Flat hydrogeologic investigation.

\subsection{Model Verification}

Model verification is defined as the testing of predictions of the calibrated model against available data not used in the model construction and calibration. For the steady-state groundwater flow model, it is expected that all the available steady-state data will be used. Transient hydraulic head response data from the water supply wells located within Yucca Flat and/or transient water level declines in the "high pressure zone" in north central Yucca Flat will be used to verify the flow model calibration.

It may also be necessary for additional data to be collected for purposes of model verification. However, until the CAU modeling is complete, it is not possible to state what type of data should be collected and whether new wells will need to be installed. The new data collection types and locations will be determined from the model response to the uncertainty and sensitivity analyses. After completion of the model, a verification plan will be prepared and submitted to the NNSA/NSO and the NDEP for approval. This plan will identify what data are to be collected, where they will be collected, and the acceptable range of data uncertainty. Data representing both model inputs and model outputs will be collected. These new data may potentially include water levels, model parameters, geochemistry parameters, and contaminant concentrations. These data will be compared against the results of the model predictions consistent with the time period in which the verification data are collected. The data collected for model verification will be designed to provide positive comparison to model inputs and outputs and will be compared with the range of values corresponding to the 5 percent and 95 percent bounds of the specific parameter.

One of several approaches may be used to determine if the new data verify the model predictions. In the case of data for which the number of values are sufficient to determine a probability distribution function, the new data will be shown to be consistent with the previously defined PDF by comparing mean and standard deviation values before and after inclusion of the new data. If the new data do not significantly change the mean and standard deviation, that parameter will be considered verified. In other cases, for which upper and lower bounds have been defined, the new data will be compared with the bounds. The new data will be considered to be verified if the results fall within the 5 percent and 95 percent ranges defined for that data.

If the data significantly modifies the PDF, or if it falls outside of the 5 percent and 95 percent ranges, the model will not have been verified. In this case, NNSA/NSO and NDEP will initiate discussions to identify the appropriate path forward. 


\subsection{Total System Model: Components and Implementation}

This section describes the components of the total system model and how they are implemented in the GoldSim Contaminant Transport Module.

\subsection{Components}

\subsection{Implementation}

The GoldSim modeling platform will be used to develop models for simulation of dynamic behavior for the total system. This capability is promising in that the uncertainty in the input parameters may be able to be propagated through the entire system through a series of simplified GoldSim models to represent source release, transport, and impact to the groundwater. An abstraction model for the hydrologic source term will need to be developed that, while simple enough for use in the GoldSim model, preserves the parameters that most influence the resulting mass flux into the system. This abstraction model and the associated uncertainty in the model parameters are used to describe source release in the GoldSim model.

The GoldSim Contaminant Transport Module is a mass transport model, not a flow model. Fluid fluxes either from the Regional Groundwater Model, the CAU-scale Yucca Flat/Climax Mine flow model, or some other source will be required for all media in every transport pathway of the GoldSim model. The GoldSim modeling platform contains capabilities for all other required components such as specifying contaminant species, source release, media characteristics, and transport pathways.

This section describes the steps required to conduct environmental simulations using the GoldSim Contaminant Transport Module. The steps for developing the system model are outlined in Golder Associates (2000).

\section{Define Simulation Objectives and Measures of Performance}

The objective of flow and transport modeling for the corrective action strategy is defined in the FFACO (1996) as determining the maximum extent of the contaminant boundary. This objective defines the performance measure for evaluating the performance of the system. The FFACO (1996) defines the contaminant boundary as "...the model-predicted perimeter which defines the extent of radionuclide-contaminated groundwater from underground nuclear testing above background conditions exceeding the Safe Drinking Water Act (SDWA)." Although a 1-D model cannot produce predictions of concentrations 
along a perimeter, a possible model output to be used as a performance measure would be the ratio of model predicted radionuclide concentrations to SDWA standards at a specified distance from the source. While this model output would be adequate for qualitatively evaluating uncertainty in parameters and processes, designing GoldSim models to produce output consistent with the performance measure specified by the FFACO is not straightforward. The GoldSim Contaminant Transport Module produces values of mass flux or concentration at a particular location. The FFACO objectives require predicting the location of a particular concentration.

\section{Develop the Conceptual Model}

The conceptual model and alternative conceptual models have already been addressed in Section 5.4. The total system model will use the conceptual models developed as described in Section 5.4.

It is not expected that additional conceptual models will be identified for evaluation during the total system modeling. However, if additional conceptual models are developed, these additional conceptual models will be carefully documented. In addition, any additional conceptual model incorporated into the total system model and shown to yield significant consequences with respect to radionuclide transport will need to be evaluated with the CAU model as well.

\section{Build the Mathematical Model}

In this step, the conceptual model(s) described in Section 5.4 is represented in a mathematical model. The mathematical model includes the assumptions and approximations on which the conceptual model was based. For the Yucca Flat/Climax Mine area, these processes will include those listed in Section 2.1. The mathematical model may include abstractions from more detailed process level models.

\section{Quantify Model Inputs}

Model inputs include geometry of the system, media composing the flow paths, fluid fluxes in the respective media, source species and source fluxes, and physical and chemical properties of the media and contaminant species. Parameter inputs are defined by specifying their values or specifying a probability distribution for uncertain parameters. Multiple alternative conceptual models can be represented in two ways. In some cases, multiple alternative models can be represented by assimilating all models into a single metamodel that contains the alternative models as special cases determined by the value of one or more parameters (Morgan and Henrion, 1998). Uncertainty about model form is thus translated to uncertainty about parameter values and can be easily evaluated in a GoldSim model. Alternatively, multiple alternative models may require investigation of discrete models. In this case, multiple GoldSim models, each representing a specific alternative conceptual model, would need to be developed.

Steps for building a contaminant transport model for an environmental system using GoldSim are described by Golder Associates (2000): 
- Define the relevant contaminant species.

- Define the characteristics of the transport and storage media.

- Define the transport pathways.

- Define the linkages between transport pathways.

- Define the contaminant source terms.

- Define the receptors that may be impacted.

\section{Implement Computational Model}

Simulations are conducted by specifying simulation control values and output.

\section{Evaluate Results}

In GoldSim, transport processes can only be described with 1-D pathways. However, such simplification may be supported and justified with a limited number of full 3-D process model simulations using the CAU model in FEHM. Comparison of GoldSim and 3-D process model results will be an important step in the evaluation process.

Simulation results will be evaluated to determine the importance of alternative conceptual models and parameters in controlling contaminant transport. The impact of parameter uncertainty and uncertainty due to alternative conceptual models will be evaluated by quantifying the sensitivity of contaminant transport to parameter values and model constructs. Results of GoldSim simulations will be used in decisions regarding which alternative models must be considered for the CAU model to fully incorporate uncertainty in the results. Any of the above steps can be revisited to refine the model as new information becomes available.

The benefit of the GoldSim model to the FFACO corrective action strategy is that this relatively simpler approach to system simulation allows a much wider range of uncertainty analysis of hydrologic source term, hydrogeologic framework, and flow and transport processes to be performed. While a suite of 1-D abstraction models developed specifically for UGTA could serve the same purpose, using GoldSim has a number of advantages. GoldSim is maintained in a software configuration management system that facilitates quality assurance and GoldSim is highly graphical, including convenient intrinsic model presentation capabilities.

\section{Interaction of the TSM with the CAU Model}

The TSM complements the CAU model by providing the ability to assess a variety of scenarios in an efficient manner. Conclusions drawn from TSM simulations need to be verified with the CAU model and its components. The precise interaction of the models for Yucca Flat cannot be defined at this time because the data analysis, HSU model development, and conceptual model development are not complete. However, an example of how the TSM can be used is provided by the application of the TSM in Frenchman Flat.

\section{Frenchman Flat Application of TSM}

The Frenchman Flat CAU (FFCAU) model was completed and submitted for peer review in 1999 (IT, 1999b). The FFCAU model predicted essentially horizontal flow and radionuclide transport away from underground nuclear tests in the 
Alluvial Aquifer of northern Frenchman Flat toward a large fault located east of the NTS. The peer review expressed concern that other alternative conceptual models leading to radionuclide migration to the Lower Carbonate Aquifer such as horizontal flow to the north or south, flow vertical through the confining unit, or vertical flow through faults were not addressed. To address these alternatives with the FFCAU model would have required modifications to the flow model and boundary conditions, and in some cases modifications to the underlying HSU model. This would have been a very time consuming and expensive process.

To assess these alternative models, in the context of overall uncertainty, a TSM was created using GoldSim as the platform. In the TSM, the groundwater flow away from a selected underground test was defined by a vector that had horizontal and vertical direction components. For any realization, the horizontal and vertical angles were random variables, the choice of which led to the calculation of flow path geometry parameters. For example, given a horizontal direction to the east, and a vertical angle of 45 degrees, the distance through the alluvium to the confining unit could be calculated as well as the distance through the confining unit to the LCA. In most cases, the HSU geometry is uncertain, so pipe length was also treated as uncertain. The amount of flow through the path was defined by the parameters of the materials along the path.

The path is composed of several pipes, each representing an HSU, or portion of an HSU. Within each pipe, material properties can be defined to be HSU- and radionuclide-specific. If the pipe represents flow through a fault, it has different parameters than if the pipe represents flow through a porous confining unit.

The starting location is always an underground test, with its source release function also represented by a module that includes release from an exchange volume and glass dissolution. The source module is a simplified representation of the source model of Tompson et al. (1999). The TSM was extended to include the full suite of radionuclides from Pawloski et al. (2001), and many of the parameters in the source model were assigned probability distributions to assess a wide range of uncertainty.

The hydraulic conditions along each pipe, defined by hydraulic conductivity and hydraulic gradient, were varied according to constraints provided by site data. Transport parameters such as effective porosity, dispersivity, and reactivity were also varied in accordance with observed data.

The TSM simulations allow the simultaneous assessment of conceptual model uncertainty, source module uncertainty, HSU geometry uncertainty, and flow parameter and transport parameter uncertainty. For each realization, the concentration of radionuclides entering the carbonate aquifer is recorded for later analysis. The TSM allows for an assessment of the relative importance of various sources of uncertainty on the predicted transport of radionuclides to the LCA. As key parameters or processes are identified, they can be targeted for additional analysis. This will focus resources on the CAU model where they will be most beneficial. 
The TSM does not provide the final answer, rather it is a tool to focus attention on key parameters and processes. Additionally, by focused data collection, it is possible to limit previously widely varying parameter values, thus limiting the range of acceptable scenarios. Consider the Frenchman Flat example again. At the time of the FFCAU model, no water-level data was available at depth in the alluvium, thus the vertical gradient through the alluvium and through the confining units were unknown. They were constrained only by water table elevations in the alluvium and LCA, and by conservation of mass principles. Thus, the TSM was initially allowed to define almost any head value at the base of the alluvium that fell between the alluvium and LCA measured heads. After the drilling of well cluster ER-5-3, the water level at the base of the alluvium was measured. This then became an additional constraint on the TSM and modified the possible outcomes of simulation. This assessment was accomplished very quickly.

The TSM is a tool to assess the transport of radionuclides through a complicated flow and transport system under uncertainty. 


\subsection{Component Uncertainty}

This section describes the identification and treatment of uncertainty of model components due to parameter values, features, and processes. Uncertain model components identified at other sites are reviewed and a list of uncertain components for the Yucca Flat/Climax Mine area is proposed. An approach is described for determining which uncertain parameters or conceptual models are most significant to model results and for propagating this uncertainty in the CAU model.

Some flow and transport model parameters are naturally variable, leading to uncertainty in their input values for the CAU models. Other parameters are uncertain because of lack of knowledge. Many parameters are both naturally variable and uncertain because there are few measurements to characterize them. Another source of uncertainty is in the form of geologic, hydrologic, and geochemical conceptual models. For example, in portions of Yucca Flat there is uncertainty in the occurrence, depth, thickness, and continuity of many HSUs. The level of uncertainty is spatially variable, with less uncertainty in areas of greater data density. Since the inputs describing the system are uncertain, predictions of contaminant transport will be uncertain. To properly represent the uncertainty in model predictions, the modeling strategy must include means to propagate all uncertainty through the Yucca Flat/Climax Mine model.

Uncertainty in parameters is treated by developing distributions of values for the parameter rather than using a single value for the model. The distribution represents the likelihood of a particular value occurring. The method used to develop the distribution varies depending on the availability of relevant data or other knowledge.

One approach to treating uncertainty in conceptual models proposed by Gorelick et al. (1999) is to identify alternative model components, and for each component assess the importance of uncertainty on predicted transport.

Assessment consists of hypothesis testing and sensitivity analysis to determine if uncertainties have a significant effect on predictions.

\subsection{Other Sites and CAUs}

Evaluations of conceptual model uncertainties for groundwater systems have been conducted at a number of sites in the arid western United States. The Peer Review Panel reporting on the proposed Hanford Site-Wide Groundwater Model (Gorelick et al., 1999) listed uncertain conceptual model components including:

- Flow-through faults 
- Vertical flow

- Chemical processes

- Focused recharge

- Boundary conditions

Experts involved in the Saturated Zone Transport Expert Elicitation (Geomatrix Consultants and TRW, 1998) listed uncertainties associated with aspects of the saturated zone hydrologic system at Yucca Mountain including:

- Presence, depth, and lateral continuity of key hydrogeologic units

- Hydraulic properties

- Hydraulic properties of faults and fault zones

- Large apparent hydraulic gradient

- Vertical flow

- Recharge estimates

- Focused recharge

- Discharge estimates

- Magnitudes and directions of ambient groundwater fluxes in areas of small hydraulic gradient

- Mixing and dilution

- Field-scale matrix diffusion

- Sorption processes

- Porosity estimates

- Colloid transport

- Thermal effects due to repository heating

The External Peer Review Report on Frenchman Flat Data Analysis and Modeling Task for the Underground Test Area Project (IT, 1999b) listed uncertainties including:

- Hydrostratigraphic framework

- Vertical flow

- Boundary conditions

- Recharge

- Groundwater-level measurements

- Hydraulic properties

- Partitioning of radionuclides between rubble and melt glass

- Reactive surface area of melt glass

- Porosity, retardation coefficients, and dispersivity

The three reviews reflect a number of common issues. All uncertainties listed for the Hanford Site are included in the lists for Yucca Mountain and Frenchman Flat and would be applicable to the Yucca Flat/Climax Mine CAU. These are conceptual model uncertainties concerning flow-through faults and fault zones, the occurrence of vertical flow, flow model boundary conditions, recharge, and transport processes and parameters. Other uncertainties associated with Yucca Mountain and Frenchman Flat are related to the characteristics of the sites. These are uncertainty in the presence, depth, and lateral continuity of key hydrogeologic units (hydrostratigraphic framework) and hydraulic properties. These would also be applicable to the Yucca Flat/Climax Mine. Other uncertainties are particular to 
the nature of the contaminant source for the Frenchman Flat CAU model and would apply to the Yucca Flat/Climax Mine area. These uncertainties are partitioning of radionuclides between rubble and melt glass in the exchange volume, reactive surface area of the melt glass, and the current contaminant distribution. Panel members (Geomatrix Consultants and TRW, 1998) were divided on the importance of thermal effects on the saturated zone due to repository heating. Thermal effects on the saturated zone are a source of uncertainty for the Yucca Flat/Climax Mine CAU.

\subsection{Parameter and Model Component Uncertainties for Pahute Mesa CAUs}

Based on the above reviews and insight gained from modeling activities for the TYBO-BENHAM and CHESHIRE sites, a preliminary list of uncertain model components for the Yucca Flat/Climax Mine CAU would include:

- Hydrostratigraphic framework

- Hydraulic properties of faults

- Vertical flow (flow-through faults)

- Boundary conditions

- Groundwater discharge

- Recharge

- Focused recharge

- Groundwater-level measurements

- Hydraulic properties of HSUs

- Thermal effects

- Porosity, retardation coefficients, dispersivity

- Matrix diffusion

- Colloid transport

- Partitioning of radionuclides between rubble and melt glass

- Reactive surface area of melt glass

\subsection{Treatment of Uncertainty}

Treatment of uncertainty consists of identifying parameters or model constructs in which uncertainty most affects the results, quantifying uncertainty, then calculating uncertainty in model predictions induced by uncertainty in model inputs. Both sensitivity and uncertainty must be examined to establish how uncertainty will be treated. Sensitivity refers to the amount predictions change when an input parameter or model construct changes. Uncertainty relates to how much change is reasonable (DOE, 1998). The combination of sensitivity and uncertainty is important to an efficient strategy. For example, the model may be very sensitive to a parameter, but that parameter may be exactly known. In this case, the parameter would not be important to the uncertainty analysis. Another parameter may be highly uncertain but its value may have little effect on model results. Again, this parameter would not be important in the uncertainty analysis.

Evaluation of uncertain model components begins with sensitivity analysis to assess the range of resulting model predictions. For sensitive parameters determined to be a significant source of uncertainty, probability distributions are developed for the parameter, and a Monte Carlo analysis (see Section 2.0) is used 
to determine the expected value of the model prediction and its uncertainty. For conceptual models found to be significant sources of uncertainty, multiple alternative conceptual models combined with Monte Carlo analysis of uncertain parameters will be used to determine a set of expected values and their uncertainty. The following subsections provide details of the approach proposed for evaluating the impact of uncertainty for each model component listed above.

\section{Hydrostratigraphic Framework}

The development of the hydrostratigraphic framework was described in Section 4.0. Since there is uncertainty in the interpretation of data and the appropriate level of detail, multiple alternative conceptual models may be considered. Uncertainty in the hydrogeologic framework model is treated as a set of equally likely discrete cases. Following initial model development, opinions of experts are elicited to develop and prioritize alternative hydrogeologic models. Each model will be a deterministic representation of the complex geologic system. The different models will incorporate interpretations related to hydrostratigraphy and structure. For example, alternatives that may be considered are increasing the number of faults or fault zones, or varying the depth to basement. Initially, alternatives will focus on conceptual models having a geographically extensive impact on the hydrostratigraphic framework.

Each alternative hydrogeologic model chosen for assessment will be incorporated into a representational model using the geospatial analysis software EarthVision ${ }^{\circledR}$ (Dynamic Graphics, Inc., 2002). Information from this model is provided to produce a 3-D finite element grid for computation. To evaluate the impact of the hydrogeologic alternatives, the influence on transport must be assessed. Values of boundary conditions, fault permeabilities, and other parameters will be chosen to maximize the sensitivity of the model for these hypothesis testing simulations. Each alternative requires modification of the EarthVision ${ }^{\circledR}$ model, development of a new 3-D grid, development of a new flow model, and transport simulations before the effect of the alternative model can be evaluated. Due to the large commitment of staff and computational resources required, only a limited number of alternative hydrogeologic models can be considered.

\section{Hydraulic Properties of Faults}

The Yucca Flat and Climax Mine area is extensively faulted. To date, no field testing has sought to address flow and transport properties and parameters in fault zones in Yucca Flat. However, migration pathways from many tests toward the accessible environment cross fault zones. Therefore, an understanding of the range of possible effects the fault zones may play on pathways and velocities will be necessary to evaluate the impact of this uncertain model component.

Understanding of faults on the NTS can be improved with an analysis of existing data, field observations, and published literature. Improvements in incorporating faults into flow and transport models have been made. A method has been developed to incorporate dipping faults in layered 3-D models. Fault geometry as described in the hydrostratigraphic model is honored and each fault can be assigned unique properties. Sensitivity to fault properties will be investigated using high resolution 3-D grids that include a large portion of Yucca Flat and the Climax Mine. The testing will examine end-member properties ranging from 
hydrologic barrier properties to hydrologic conduit properties for the fault zones. Modeling results and data review will be used to develop probability distributions for fault hydraulic properties. If significant, uncertainty in fault properties will be treated in the CAU-scale model using Monte Carlo analysis.

\section{Vertical Flow}

The extent to which vertical flow contributes to contaminant migration is uncertain. Modeling studies of the BENHAM and CHESHIRE tests indicate upward movement of contaminants due to thermal effects for a period following the test. The impact of this process has been evaluated using high-resolution, local-scale models for TYBO-BENHAM and CHESHIRE. Results of these studies will be incorporated in the CAU model.

Vertical flow through fault zones may allow movement of contaminants through confining units to an aquifer. With the ability to include dipping faults with unique hydraulic properties in the 3-D grid and the development of credible probability distributions for fault permeabilities, the influence of vertical flow in faults will be explicitly included in the CAU model.

\section{Groundwater Discharge}

Groundwater discharge does not occur anywhere in the Yucca Flat basin, but does occur within the investigation area (Figure 2-1). If the CAU model area extends to the discharge areas, then uncertainty in discharge will be included in the CAU model. If the CAU model area does not extend to the discharge areas, then uncertainty in discharge will be included in the boundary flux uncertainty derived from the regional model.

\section{Boundary Conditions}

The CAU-model boundaries do not correspond with natural physical boundaries of the aquifers. Since these natural boundaries are not available to provide boundary conditions, boundary conditions for the CAU model are taken from the Regional Groundwater Model. There is uncertainty associated with fluxes and heads calculated by the Regional Groundwater Model. Since the Regional Model is used to provide boundary conditions for the CAU model, a means for propagating that uncertainty through the CAU model is required. The method proposed for the Yucca Flat/Climax Mine CAU model is to develop steady-state hydraulic heads and boundary fluxes from multiple alternative calibrations of the Regional Model. For example, different alternative HSU models or recharge models are applied to the regional model, each requiring a new calibration. A range of fluxes through the CAU boundaries and discrete values of head would be obtained. Heads and fluxes obtained from the Regional Model calibrations would be used for boundary conditions and constraints for the CAU model calibration. These Regional Model simulations are done outside of the main flow and transport model execution, so there are no run time linkages between models at the CAU level. The results of the Regional Model simulations are provided to the flow and transport model as tables. This approach accounts for uncertainty introduced by the Regional Model and decouples the Regional and CAU models. 


\section{Recharge}

Recharge is an important component of the CAU model, and also a component with large uncertainty. The External Peer Review Report on Frenchman Flat Data Analysis and Modeling Task for the Underground Test Area Project (IT, 1999b) stated: "There is very little that can be done to accurately quantify recharge over extensive areas in arid and semiarid settings where recharge amounts may be only a small fraction of precipitation." Given this assessment of irreducible uncertainty, it is important to quantify the sensitivity of transport to recharge and the uncertainty in the recharge model. The DRI and USGS have developed regional recharge estimates that include the Yucca Flat and Climax Mine area. The assumptions and inputs for the models used to develop the estimates will be evaluated to develop an associated recharge uncertainty. Using this information in a CAU-scale process model, the sensitivity of model predictions to recharge uncertainty can be determined. If uncertainty due to recharge is significant, uncertainty in recharge could be included in the CAU model as a set of discrete cases; possibly the $5^{\text {th }}$ percentile, expected value, and $95^{\text {th }}$ percentile from the recharge model. Alternatively, recharge could be treated as an unknown parameter field to be evaluated by model calibration as suggested by the External Peer Review Report on Frenchman Flat Data Analysis and Modeling Task for the Underground Test Area Project (IT, 1999b).

\section{Focused Recharge}

The focusing of runoff into surface depressions, channels, and high permeability fault zones has been cited as a mechanism for enhanced local recharge fluxes. If uncertainty due to focused recharge is considered to be significant, it has not been determined at this time how, recharge maps will be modified to include this process and its associated uncertainty.

\section{Groundwater-Level Measurements}

Limitations of groundwater-level measurements include emplacement holes which are open except for a short length of surface casing; consequently, water levels generally represent a composite value for the units penetrated. Uncertainty exists as to whether water levels from these holes represent perched or semiperched water rather than regional water levels. Limited accessibility to the holes meant that, in most cases, measured water levels cannot be shown to represent equilibrium conditions. Additional uncertainty in groundwater-level measurements is due to effects from underground testing. Both short-term and long-term water level changes due to underground tests have been documented for the Yucca Flat/Climax Mine area. The adequacy of available groundwater-level measurements will be assessed prior to calibration of the CAU-scale flow model.

\section{Hydraulic Properties of HSUs}

Information about hydraulic properties for the Yucca Flat and Climax Mine area is limited. The lack of information on properties of faults was discussed in the Hydraulic Properties of Faults subsection above. The approach to uncertainty of hydraulic properties of HSUs will be to conduct a sensitivity analysis to evaluate the range of model predictions. If transport results are found to be sensitive to the 
permeability of an HSU, a probability distribution will be developed for that parameter and used in a Monte Carlo analysis for the CAU model.

There is additional uncertainty regarding the depth dependence of Ksat. A conceptual model describing increasing Ksat with depth due to the geothermal gradient was proposed in Section 5.7. Another model suggests decreasing Ksat with depth due to increasing lithostatic stresses. Increasing lithostatic stress with depth may act to decrease fracture apertures and, thus, significantly decrease Ksat with depth. Existing data from the Yucca Flat/Climax Mine CAU will be evaluated to determine Ksat-depth relationships.

\section{Upscaling Fracture Properties}

Water in volcanic rocks primarily flows through fractures. Modeling of the quantity of water moving through the rock using an equivalent continuum (EC) model, such as MODFLOW and FEHM, has been successful. However, modeling the transport of contaminants through fractured rock using these models, even dual-porosity formulations, involves many simplifications and assumptions that may not be valid. The continuum models do not consider important aspects of fractures, such as orientations and variable apertures (which impacts hydraulic conductivity, effective porosity, and diffusion coefficients). These must be considered explicitly in a fracture network model and the results upscaled for use in an EC model. Upscaling fracture properties for the CAU models will include:

- Summarizing available information on the role of fractures in radionuclide transport at the NTS

- Developing techniques for upscaling spatially variable fracture properties to homogeneous single-fracture models

- Developing techniques to incorporate the properties of fracture networks into equivalent continuum models

\section{Thermal Effects}

Sources of heat in the Yucca Flat and Climax Mine area include flow of heat from deeper layers toward the surface and residual thermal pulses from nuclear weapons tests. Uncertainties related to thermal effects due to residual heat from nuclear tests were discussed in the Vertical Flow subsection above. While thermal gradients are not considered to contribute to head differences with depth, there is an observed relationship between the magnitude of the thermal gradient and the stability of the measured water level. Thermal effects due to geothermal gradients will be evaluated in a sensitivity analysis.

\section{Porosity, Retardation Coefficients, and Dispersivity}

The velocity of the groundwater and of solutes relative to groundwater has a first order effect on migration rate predictions. Whereas, a calibrated flow model generally matches observations of head, and in some cases flux, it generally provides little or no information about groundwater velocities. The porosity directly affects the estimation of groundwater velocity. In fractured systems, the 
porosity of concern is actually the fracture volume fraction (often called the fracture porosity) because most of the groundwater movement occurs in the fractures. The fracture porosity is a function of the fracture apertures, the fracture spacing, and fracture connectivity. This term can be estimated either from measurements of fracture spacing, fillings, and apertures in boreholes or from multi-well solute tracer tests. Either method leads to significant uncertainty in the fracture porosity for CAU-scale simulations. Therefore, distributions bounding uncertainty in fracture porosity will be developed using all available borehole and tracer test data. Porosity in fractured systems may also be anisotropic, at least at small to intermediate scales.

The matrix porosity has the same impact on groundwater velocity estimates in nonfractured rock. However, the range of uncertainty on matrix porosity is significantly less and it is a parameter that is easier to measure than fracture porosity. The matrix porosity, in fractured rock systems, does have an impact on the retardation of solutes due to diffusion. Similarly, retardation coefficients describing the reactions of solutes with fracture minerals and matrix minerals serve to reduce the velocity of solutes relative to the groundwater velocity. Retardation factors are generally either estimated from batch experiments involving solutes and crushed rock or they are estimated using thermodynamic reaction coefficients for the solutes and the individual minerals associated with the rock material of interest. In either case, there is uncertainty in the parameters because the methods for estimating the retardation factors do not perfectly assess the actual reactive surface area on the rock with which the solutes will come in contact. Local geochemical conditions may also impact retardation factors. Further, retardation factors are a simplified abstraction of a much more complex reactive process. They inherently assume instantaneous reactions. For fractures, estimating retardation factors is further complicated by the need to estimate fracture apertures, fracture mineral thicknesses and distributions, and reactive surface areas. Therefore, for the CAU model parameter uncertainty distributions, results from fully coupled reactive transport models and all available databases on solute-rock reactions will be compiled.

Dispersivity is another model parameter that affects solute velocity relative to that of the groundwater. It also affects the degree to which concentrated plumes are diluted with uncontaminated groundwater. Essentially, dispersivity parameters describe how much mixing and spreading of contaminants occur at scales smaller than the resolution of the computational grid. The Yucca Flat/Climax Mine CAU transport model will conservatively operate with small transverse dispersion parameters but evaluate the sensitivity of this assumption.

\section{Matrix Diffusion}

Matrix diffusion is the process by which solutes move out of fast-moving fracture water and into essentially immobile matrix water. Not only does this reduce the net velocity of the solutes, it brings them into contact with reactive matrix minerals. The UGTA Project has supported the development of a matrix diffusion database using laboratory diffusion cell experiments and a limited field-scale test. The data from all available sources, including the Yucca Mountain Project, will be compiled and utilized in the development of uncertainty distributions of diffusion coefficients for use in the transport models. 


\section{Colloid Transport}

Colloid-facilitated transport of plutonium has been implicated at the BENHAM site on Western Pahute Mesa. Although the process appears to provide a mechanism for transport of reactive radionuclides, the mass of radionuclide actually transported was very small. It is not clear how important colloid-facilitated transport will be for the contaminant boundary calculation.

The TYBO-BENHAM study (Wolfsberg et al., 2002) has specifically examined the process and modeling options for simulating colloid-facilitated solute transport. A site-scale reactive transport model was developed that included: (1) plutonium speciation, (2) kinetic plutonium-colloid reactions, (3) filtration of colloids on the fracture walls, (4) solute diffusion into the matrix, and (5) surface complexation and ion exchange of radionuclides with fracture and matrix minerals. An abstraction was developed from the site-scale process model to allow more efficient simulation of colloid transport in a particle-tracking model. Uncertainty in the parameters describing this process includes representing uncertainty in the ambient colloid concentration, colloid filtration processes, solute-colloid reactions, background groundwater chemistry, and all of the other parameters affecting transport of solutes in fractures discussed above. Uncertainty distributions for the governing parameters will be developed by integrating results from the TYBO-BENHAM study, compiling field-test results that used synthetic colloids, and compiling field measurements of ambient colloids in wells throughout the NTS.

\section{Partitioning of Radionuclides Between Rubble and Melt Glass}

Current hydrologic source term models at CHESHIRE, CAMBRIC, and BENHAM require as input an assumption of how source term radionuclides are initially partitioned between the chimney rubble and the melt glass. This assumption may significantly affect the rate at which radionuclides initially enter the CAU aquifers. Therefore, these ratios will be varied in hydrologic source term models using expert elicitation to represent the uncertainty in the assumption.

\section{Size of Exchange Volume}

The exchange volume consists of the collapsed cavity, chimney, and sidewalls. For tests conducted in different host rock, such as volcanics, fracturing induced by the test may lead to greater uncertainty in the geometry and size of the exchange volume.

\section{Interactions Between Tests}

The large number of underground tests in Yucca Flat gives rise to the possible interaction between tests. The hydrologic effects of testing in Yucca Flat include increases in the water table elevation and the increase in hydraulic pressure in some confined units (Laczniak et al., 1996). Preliminary numerical simulations using FEHM were conducted by LANL to evaluate the effects of underground nuclear testing in Yucca Flat on hydraulic head. Results indicated that for tests located in low permeability zones, the initial pressurization created by the test may induce a persistent and extensive elevated hydraulic head response. For deeper tests, this zone of elevated hydraulic head may extend to the regional aquifer. 
When the disturbed zone extends into high permeability rock, the overpressure dissipates rapidly. The occurrence and influence of high pressure zones must be dealt with as an uncertain process. There are several alternative conceptual models that can be implemented with any or all of the CAU flow and transport model grids. These involve modification of hydrologic attributes such as permeability, porosity, and fracture properties in the phenomenologically impacted region around tests (estimated by maximum announced yield), and transient simulations to account for mounding and infilling directly after tests which fall in the pathway or may impact plumes from other tests. Results from these sensitivity simulations will be used to determine specifically which simulations are required for CAU model uncertainty analyses.

The potential impact of the tests appears to be most noticeable in the low permeability units. The units of most concern, those that will transmit water most rapidly, will be less impacted because the changes in hydraulic head dissipate most rapidly. The CAU model will be calibrated to pretesting water levels, but as noted in Section 5.12, the transient response may be used as part of the model verification.

\section{Reactive Surface Area of Melt Glass}

Estimations of the reactive surface area of melt glass dominate the estimates of melt glass dissolution rates. Different methods for estimating this parameter at LLNL and DRI have led to many orders of magnitude differences in dissolution rates. Recently, analog vitric field samples were collected and analyzed by both DRI and LLNL, using their different methods, respectively. Results from these studies will be used to develop distributions of surface area uncertainty for use in hydrologic source term models.

\subsection{Analysis Methods}

Methods for investigating sensitivity include scatter plots and stepwise linear regression. Scatter plots are visualizations of the relationships between model results and input parameter values that provide a qualitative indication of sensitivity. Regression analysis provides a quantitative ranking of input parameters according to their affect on the model results. While the sensitivity of alternative models cannot be ranked quantitatively, qualitative comparisons of changes in model results can be used to determine sensitivity. 


\subsection{Model Documentation}

Model documentation required for quantitative investigations supporting policy decisions has been reviewed by a number of authors (Boak and Dockery, 1998; Morgan and Henrion, 1998). Model documentation for the Yucca Flat/Climax Mine CAU models will include:

- Identification of all components, inputs, and assumptions of the analysis

- Justification of assumptions, simplifications, and parameter ranges and distributions used

- Description of all uncertainties

- Identification of the results of sensitivity analysis

- Description of major alternative model formulations and sensitivity of results to alternatives

- Documentation of final model sufficiently detailed to allow replication of modeling and calculations

- Identification of all significant limitations of the model

- Description of all significant conclusions, limitations, and insights 


\subsection{Classified Simulations}

This section describes constraints imposed by using classified data for the hydrologic source term. A procedure for producing unclassified CAU-model results for review is outlined.

Data related to test-specific radionuclide inventories, yield, cavity radius, and geometry are mostly classified. Test-specific hydrologic source term inputs derived from classified inventory data must be treated as classified. The inclusion of this information within the CAU model will make the entire model and subsequent interpretations classified. In the absence of any potential declassification process, some procedure must be designed to deal with this information.

One possible procedure is to develop all simulations related to flow in an unclassified manner since hydrologic flow is independent of radionuclide concentration or classified source term configuration. Unclassified source terms associated with specific tests could be used in place of the classified ones. The unclassified source term usually represents averaged inventories for selected regions. Alternatively, hypothetical source terms constrained to meet the unclassified total CAU inventory data (if available) could be used in place of the classified source terms. The former approach was used for the Frenchman Flat CAU model with the unclassified CAMBRIC source term (Tompson et al., 1999) being used at all ten of the underground test locations. While the results and interpretations of unclassified simulations would be limited, it was believed that they would be adequate for review of the CAU modeling. A classified version of the source term in Frenchman Flat has been created by Pawloski et al., 2002a. This source term uses test-specific data to provide a more representative assessment of local conditions. Once the Frenchman Flat CAU model is accepted, the final calculations may be performed using the classified source.

To the extent that classified source term inventories involve radionuclides whose hydrologic and geochemical behavior can be determined from the above described unclassified simulations, their inclusion in a classified flow and transport model might be accomplished by rerunning the unclassified model with accurate but classified hydrologic source terms. This will require numerical model choices at the outset that are compatible with users and classified and unclassified computing environments at NNSA/NSO, the ER contractor, and the national laboratories. Accordingly, the results of the classified simulations would be more specific with respect to the exact results of radionuclide concentration and contaminant boundary extent distributions, but otherwise similar to the previous unclassified version. 
To the extent that specific classified source term radionuclides affect transport or cannot be understood from analog studies, specific analyses related to these radionuclides and their impacts on transport would have to be considered separately. The External Peer Review Report on Frenchman Flat Data Analysis and Modeling Task for the Underground Test Area Project (IT, 1999b) considered this potential outcome likely:

"The exclusion from the study of radionuclides, with classified source term data compromises the representativeness of the transport calculations, and causes the panel to question whether the predicted doses are either meaningful or conservative."

The panel reiterated their concerns later in the review:

"We consider features of radionuclide transport (most notably contaminant release rates from the source, and retardation rates due to sorption and diffusion) to be strongly dependent on detailed information about the actual source. We are therefore not convinced that reviewing the current model allows us to assess the adequacy of the modeling process that will ultimately be used to predict the spatial and temporal extent of the regulatory contaminant boundary at Frenchman Flat."

If the predicted location of the contaminant boundary is found to be sensitive to the hydrologic source term, classified simulations will be essential in estimating the location of the contaminant boundary. If an unclassified review process is to be used for the CAU model, confidence in the ability of the unclassified source term to capture relevant processes and uncertainties must be increased. 


\subsection{References}

BN, see Bechtel Nevada.

Bechtel Nevada. 2001. Nevada Test Site Annual Site Environmental Report for Calendar Year 2000, DOE/NV/11718--605. Las Vegas, NV.

Boak, J.M., and H.A. Dockery. 1998. "Providing valid long-term projections of geologic systems for policy decisions: Can we succeed? Should we try?" In A Paradox of Power: Voices of Warning and Reason in the Geosciences, v. 12, pp.177-184. Edited by C.W. Welby and M.E. Gowan. Boulder, CO: Geological Society of America Reviews in Engineering Geology.

Bourcier, W., S. Roberts, D.K. Smith, S. Hulsey, L. Newton, A. Sawvel, C. Papelis, W.Y. Um, C.E. Russel, and J. Chapman. 2000. Determination of Reactive Surface Area of Melt Glass, UCRL-ID-145181. Livermore, CA: Lawrence Livermore National Laboratory.

DOE, see U.S. Department of Energy.

DOE/NV, see U.S. Department of Energy, Nevada Operations Office.

Daniels, J.I., R. Andricevic, R. Anspaugh, and R.L. Jacobson. 1993. Risk Based Screening Analysis of Ground Water Contaminated by Radionuclides Introduced at the Nevada Test Site (NTS), UCRL-LR-113891. Livermore, CA: Lawrence Livermore National Laboratory.

Dash, Z.V. 2000. Validation Test Report (VTR) for the FEHM Application Version 2.10, Yucca Mountain Project Identification Numbers SAN: LANL-1999-046; STN: 10086-2.10-00. Los Alamos, NM: Los Alamos National Laboratory.

Dash, Z.V. 2001. Validation Test Report (VTR) for the FEHM Application Version 2.12, Yucca Mountain Project Identification Numbers SAN: LANL-2001-133; STN: 10086-2.12-00. Los Alamos, NM: Los Alamos National Laboratory.

Dash, Z.V., B.A. Robinson, and G.A. Zyvoloski. 1997. Software Requirements, Design, and Verification and Validation for the FEHM Application - A Finite-Element Heat- and Mass-Transfer Code, LA-13305-MS. Los Alamos, NM: Los Alamos National Laboratory.

Dynamic Graphics, Inc. 2002. EarthVision 7: Software for 3-D Modeling and Visualization. Alameda, CA. 
FFACO, see Federal Facility Agreement and Consent Order.

Federal Facility Agreement and Consent Order. 1996 (as amended). Agreed to by the State of Nevada, the U.S. Department of Energy, and the U.S. Department of Defense.

Finkel, R.C., M.W. Caffee, K.V. Marsh, and J.H. Rego. 1992. Accelerator Mass Spectrometry Measurements of I129 in CHESCHIRE Site Groundwater, UCRL-52779-88: 11-12. Livermore, CA: Lawrence Livermore National Laboratory.

Freeze, R.A., J. Massmann, L. Smith, T. Sperling, and B. James. 1990. "Hydrogeological Decision Analysis: 1. A Framework." In Ground Water, Vol. 28, pp. 738-766.

Gelhar, L.W., 1986. "Stochastic Subsurface Hydrology from Theory to Applications." In Water Resources Research, 22(9), P. 135S-145S.

Geomatrix Consultants and TRW Corp. 1998. "Saturated Zone Flow and Transport Expert Elicitation Project" from the U.S. Department of Energy, Office of Civilian Radioactive Waste Management, Yucca Mountain Project Natural Systems and Process Models Web Page. As accessed at http://domino.ymp.gov/va/support/szfteep.nsf on March 1, 2001.

George, D. 1997. Unstructured 3D Grid Toolbox for Modeling and Simulation, LA-UR-97-3052. Los Alamos, NM: Los Alamos National Laboratory.

Golder Associates, Inc. 2000. GoldSim Contaminant Transport Module. Redmond, WA.

Gorelick, S., C. Andrews, and J. Mercer. 1999. "Report of the Peer Review Panel on the Proposed Hanford Site-Wide Groundwater Model" from the Groundwater/Vadose Zone Integration Project Web Page as accessed at http://www.bhi-erc.com/vadose/peer.htm\#GWPanel on March 1, 2001.

Hershey, R.L., and S.Y. Acheampong. 1997. Estimation of Groundwater Velocities from Yucca Flat to the Amargosa Desert Using Geochemistry and Environmental Isotopes, 45157. Reno, NV: Desert Research Institute.

Hevesi, J.A., A.L. Flint, and L.E. Flint. 2002. Preliminary Estimates of Spatially Distributed Net Infiltration and Recharge for the Death Valley Region, Nevada-California, WRIR 02-4010. Sacramento, CA: U.S. Geological Survey.

IT, see IT Corporation.

IT Corporation. 1996a. Groundwater Flow Model Documentation Package (Phase I - Data Analysis Documentation, Volume VI), ITLV/10972-181. Prepared for the U.S. Department of Energy, Nevada Operations Office. Las Vegas, NV. 
IT Corporation. 1996b. Groundwater Recharge and Discharge Documentation Package (Phase I - Data Analysis Documentation, Volume III), ITLV/10972-181. Prepared for the U.S. Department of Energy, Nevada Operations Office. Las Vegas, NV.

IT Corporation. 1996c. Hydrologic Parameter Data Documentation Package (Phase I - Data Analysis Documentation, Volume IV), ITLV/10972-181. Prepared for the U.S. Department of Energy, Nevada Operations Office. Las Vegas, NV.

IT Corporation. 1996d. Potentiometric Data Documentation Package (Phase I - Data Analysis Documentation, Volume II), ITLV/10972-181. Prepared for the U.S. Department of Energy, Nevada Operations Office. Las Vegas, NV.

IT Corporation. 1996e. Regional Geologic Model Documentation Package (Phase I - Data Analysis Documentation, Volume I), ITLV/10972-181. Prepared for the U.S. Department of Energy, Nevada Operations Office. Las Vegas, NV.

IT Corporation. 1998. Report and Analysis of the BULLION Forced-Gradient Experiment, ITLV/13052-042, DOE/NV/13052-042. Prepared for the U.S. Department of Energy, Nevada Operations Office. Las Vegas, NV.

IT Corporation. 1999a. A User's Guide to the Comprehensive Chemistry Database for Groundwater at the Nevada Test Site, ITLV/13052-070. Prepared for the U.S. Department of Energy, Nevada Operations Office. Las Vegas, NV.

IT Corporation. 1999b. External Peer Review Group Report on Frenchman Flat Data Analysis and Modeling Task, Underground Test Area Project, ITLV/13052-077. Prepared for the U.S. Department of Energy, Nevada Operations Office. Las Vegas, NV.

IT Corporation. 1999c. Value of Information Analysis for Corrective Action Unit 97: Yucca Flat, Nevada Test Site, Nevada, ITLV/13052--079. Las Vegas, NV.

Kitanidis, P.K. 1997. Introduction to Geostatistics: Applications in Hydrogeology. New York, NY: Cambridge University Press.

Laczniak, R.L., J.C. Cole, D.A. Sawyer, and D.A. Trudeau. 1996. Summary of Hydrogeologic Controls on Ground-Water Flow at the Nevada Test Site, Nye County, Nevada, USGS-WRIR-96-4109. Denver, CO: U.S. Geological Survey.

Maxey, G.B., and T.E. Eakin. 1949. Groundwater in White River Valley, White Pine, Nye and Lincoln Counties, Nevada, Water Resources Bulletin No. 8. Carson City, NV: State of Nevada, Office of the State Engineer. 
McDonald, M.G., and A.W. Harbaugh. 1988. "A Modular Three-Dimensional Finite-Difference Ground-Water Flow Model.” In U.S. Geological Survey Techniques of Water-Resources Investigations, Book 6, Chapter A-1.

Morgan, M.G., and M. Henrion. 1998. Uncertainty. New York, NY: Cambridge University Press.

Pawloski, G.A., A.F.B. Tompson, and S.F. Carle, eds. 2001. Evaluation of the Hydrologic Source Term from Underground Nuclear Test on Pahute Mesa at the Nevada Test Site: CHESHIRE Test, UCRL-ID-140723. Livermore, CA: Lawrence Livermore Laboratory.

Pawloski, G.A., A.F.B. Tompson, C.J. Bruton, and M. Zavarin, eds. 2002a. Evaluation of the Hydrologic Source Term from Underground Tests in Frenchman Flat at the Nevada Test Site (U), UCRL-ID-138007-DR. Livermore, CA: Lawrence Livermore National Laboratory.

Pawloski, G.A., T.P. Rose, and J. Meadows. 2002b. Categorization of Underground Nuclear Tests on Pahute Mesa, Nevada Test Site, for use in Radionuclide Transport Models, Draft. Livermore, CA: Lawrence Livermore National Laboratory.

Pohll, G. 2003. Communication to J. Wille (Shaw E \& I) entitled, "Technical Review of the Draft Document Modeling Approach for Corrective Action Unit 97, Yucca Flat and Climax Mine." Reno, NV: Desert Research Institute.

Prothro, L.B. 1998. Analysis of Fractures in Cores from the Tuff Confining Unit Beneath Yucca Flat, Nevada Test Site. Las Vegas, NV: Bechtel Nevada.

Rose, T.P., F.C. Benedict, J.M. Thomas, W.S. Sicke, R.L. Hershey, J.B. Paces, I.M. Farnham, and Z.E. Peterman. 2003 (In Production). Geochemical Data Analysis and Interpretation of the Pahute Mesa - Oasis Valley Groundwater Flow System, Nye County, Nevada. Livermore, CA: Lawrence Livermore National Laboratory.

Russell, C.E., and T. Minor. 2002. Reconnaissance Estimates of Recharge Based on an Elevation-dependent Chloride Mass-balance Approach, Report No. 45164. Las Vegas, NV: Desert Research Institute.

Smith, D.K., Lawrence Livermore National Laboratory. 1997. Communication to J. Wille (IT Corporation), entitled, "Radionuclides Recommended by the Underground Test Area-Source and Transport (UGTA-S\&T) Subcommittee of Significance for Remedial Investigations at the Nevada Test Site," 2 April. Livermore, CA.

Smith, D.K. 2001. Unclassified Radiologic Source Term for Nevada Test Site Areas 19 and 20, UCRL-ID-141706. Livermore, CA: Lawrence Livermore National Laboratory. 
Smith, D.K., A.B. Kersting, J.M. Kenneally, J.H. Rego, and J.L. Thompson. 1997. Hydrologic Resources Management Program FY 1996 Progress Report, UCRL-ID-126886. Livermore, CA: Livermore National Laboratory.

Smith, D.K., A.B. Kersting, T.P. Rose, J.M. Kenneally, G.B. Hudson, G.F. Eaton, and M.L. Davisson. 1998. Hydrologic Resources Management Program and Underground Test Area Operable Unit FY 1997 Progress Report, UCRL-ID-130702. Livermore, CA: Lawrence Livermore National Laboratory.

Smith, D.K., A.B. Kersting, T.P. Rose, J.M. Kenneally, G.B. Hudson, G.F. Eaton, M.L. Davisson, F.C. Benedict, Jr., and R.E. Criss. 1999. Hydrologic Resources Management Program and Underground Test Area, FY 1998 Progress Report, UCRL-ID-135170. Lawrence, CA: Lawrence Livermore National Laboratory.

Smith, D.K., G.F. Eaton, T.P. Rose, J.E. Moran, A. Brachmann, J.E. McAninch, A.B. Kersting, V.V. Romanovski, R.E. Martinelli, and J.K. Werner, Jr. 2000. Hydrologic Resources Management Program and Underground Test Area FY 1999 Progress Report, UCRL-ID-139226. Livermore, CA: Lawrence Livermore National Laboratory.

Thompson, J.L., ed. 2000. Laboratory and Field Studies Related to Radionuclide Migration of the Nevada Test Site, October 1, 1998-September 30, 1999, LA-13701-PR. Los Alamos, NM: Los Alamos National Laboratory.

Tompson, A.F.B., C.J. Bruton, and G.A. Pawloski, eds. 1999. Evaluation of the Hydrologic Source Term from Underground Nuclear Tests in Frenchman Flat at the Nevada Test Site: The CAMBRIC Test, UCRL-ID-132300. Livermore, CA: Lawrence Livermore National Laboratory.

U.S. Department of Energy. 1998. Viability Assessment of a Repository at Yucca Mountain, Vol 3: Total System Performance Assessment, DOE/RW-0508. Washington, DC: Office of Civilian and Radioactive Waste Management.

U.S. Department of Energy, Nevada Operations Office. 1997. Regional Groundwater Flow and Tritium Transport Modeling and Risk Assessment of the Underground Test Area, Nevada Test Site, Nevada, DOE/NV--477. Las Vegas, NV.

U.S. Department of Energy, Nevada Operations Office. 1999a. Corrective Action Investigation Plan for Corrective Action Unit 98: Frenchman Flat, Nevada Test Site, Nevada, DOE/NV--478. Las Vegas, NV.

U.S. Department of Energy, Nevada Operations Office. 1999b. Corrective Action Investigation Plan for Corrective Action Units 101 and 102: Central and Western Pahute Mesa, Nevada Test Site, Nevada, DOE/NV--516. Las Vegas, NV. 
U.S. Department of Energy, Nevada Operations Office. 2000a. Corrective Action Investigation Plan for Corrective Action Unit 97: Yucca Flat/Climax Mine, Nevada Test Site, Nevada, DOE/NV--659. Las Vegas, NV.

U.S. Department of Energy, Nevada Operations Office. 2000b. Underground Test Area Quality Assurance Project Plan, Nevada Test Site, Nevada, Rev. 3, DOE/NV-341. Las Vegas, NV.

Vanmarcke, E. 1983. Random Fields: Analysis and Synthesis. Cambridge, MA: The MIT Press.

Watermark Numerical Computing and Waterloo Hydrogeologic. 2000. Visual PEST User's Manual (Includes PEST2000 and WinPEST) - Graphical Model-Independent Parameter Estimation. Ontario, Canada, and Tampa, FL: Waterloo Hydrogeologic.

Winograd, I.J., and L.R. West. 1962. Preliminary Tracer Experiment to Demonstrate Hydraulic Continuity Between Water Wells C and C-1, Yucca Flat, Nevada Test Site, Technical Letter NTS-20. Denver, CO: U.S. Geological Survey.

Wolfsberg, A., L. Glascoe, G. Lu, A. Olson, P. Lichtner, M. McGraw, T. Cherry, and G. Roemer. 2002. TYBO/BENHAM Model Analysis of Groundwater Flow and Radionuclide Migration from Underground Nuclear Tests in Southwestern Pahute Mesa, NTS, LA-13977. Los Alamos, NM: Los Alamos National Laboratory.

Zavarin, M., S.F. Carle, and R.M. Maxwell. 2002. Upscaling Radionuclide Retardation - Linking the Surface Complexation and Ion Exchange Mechanistic Approach to a Linear Kd Approach. Prepared for the Underground Test Area Project, U.S. Department of Energy, National Nuclear Security Administration Nevada Operations Office. Livermore, CA: Lawrence Livermore National Laboratory.

Zimmerman, D.A., K.K. Wahl, A.L. Gutjahr, and P.A. Davis. 1990. A Review of Techniques for Propagating Data and Parameter Uncertainties in High-Level Radioactive Waste Repository Performance Assessment Models, SAND89-1432 (NUREG/CR-5393). Albuquerque, NM: Sandia National Laboratories.

Zyvoloski, G.A., B.A. Robinson, Z.V. Dash, and L.L. Trease. 1997a. Summary of Models and Methods for the FEHM Application - A Finite-Element Heatand Mass-Transfer Code, LA-13307-MS. Los Alamos, NM: Los Alamos National Laboratory.

Zyvoloski, G.A., B.A. Robinson, Z.V. Dash, and L.L. Trease. 1997b. User's Manual for the FEHM Application - A Finite-Element Heat- and Mass-Transfer Code, Report LA-13306-M. Los Alamos, NM: Los Alamos National Laboratory. 


\section{Appendix A}

Code Selection for Yucca Flat/Climax Mine CAU Model 


\title{
A.1.0 Introduction
}

\begin{abstract}
A traceable code selection procedure builds confidence in CAU model results by ensuring that code attributes are consistent with key physical and chemical processes that must be simulated by the CAU model. The CAIP for the Yucca Flat/Climax Mine CAU (DOE/NV, 2000a) outlines a procedure for code selection that depends on completion of the Pahute Mesa CAU model and creation of a specific Yucca Flat/Climax Mine test problem. This procedure consists of assessing the performance of the code FEHM (Zyvoloski, 1997a) in the Pahute Mesa CAU using selected testing criteria. If the performance is considered acceptable, creation of a test problem for the Yucca Flat/Climax Mine area for further assessment of the performance of FEHM is planned. Currently, flow model development for the Pahute Mesa CAU model is just beginning and similarities between the Pahute Mesa and Yucca Flat/Climax Mine areas in potential contaminants, release and discharge processes, characteristics of migration routes, geologic media, and exposure pathways make creation of a specific Yucca Flat problem redundant. Given these considerations, an alternative procedure for code selection is proposed. While the same code attributes and testing criteria as described in the Yucca Flat/Climax Mine CAIP (DOE/NV, 2000) will be applied, this alternative procedure will differ in that the sub-CAU scale and site-scale models developed to investigate contaminant migration from the TYBO and BENHAM tests on Pahute Mesa (Wolfsberg et al., 2002) will be used as the test problem.
\end{abstract}




\section{A.2.0 code Attributes}

A number of attributes or capabilities of the CAU model were defined to satisfy the modeling objectives (DOE/NV, 2000). The first objective requires the CAU model to have the ability to represent the important physical and chemical features of the CAU groundwater flow system. The features include faulting, stratigraphy, sources and sinks of water, the distribution of contaminants and their rates of introduction into the groundwater flow system, and other physical or chemical features unique to the CAU. The second objective requires the CAU model to simulate the movement of a variety of contaminants for which their distribution and abundance serve to define the contaminant boundary. The third objective requires flexibility in the CAU model to allow grid changes, placement of additional wells, and boundary condition variations. The required code attributes that were defined consistently with the three modeling objectives were categorized under "general," "flow model," and "transport model." Each of these attributes will be described and assessed with respect to importance for the CAU modeling. In addition, six non-essential but desirable attributes were identified. These include: finite-element formulation, steady-state capability, double-porosity/ double-permeability formulation, the ability to simulate the transport of multiple solutes and daughter products, and established pre- and post-processors.

\section{General Attributes}

\section{Fully Three-Dimensional}

The groundwater flow system is controlled by the distribution of geologic units as well as the location of sources and sinks of water. Additionally, transport properties including source location and strength, porosity, and diffusion may vary in space. The 3-D nature of the groundwater flow system requires that the CAU model will need to be 3-D to adequately simulate migration of the potential contaminants within the CAU-model area.

\section{Large Numbers of Nodes Capability}

For a given formulation, the greater the number of nodes in the CAU model, the greater the detail that can be included. Given the anticipated large geographic area of the Yucca Flat/Climax Mine CAU model, the ability of the CAU model to simulate many nodes will control the amount of detail that can be included. In general, each of the selected codes will only be limited by the capacity of the hardware, not by the software used. 


\section{Multiple Boundary Condition Options}

Options for specified pressure and specified flux boundary conditions for fluids, as well as specified temperature or specified heat flow, may be required in implementing the CAU model.

\section{Transient Capability}

The initial flow simulations for the CAU model will be steady-state with possible transient runs to follow. The contaminant transport simulations will all be performed under transient conditions.

\section{Efficient Solver}

To simulate in sufficient detail, the CAU model will require a large number of nodes as mentioned above. To make a large model practical, the codes must run efficiently. Generally, a code has a selection of solvers available. The solvers must be efficient enough to allow for reasonable simulation times.

\section{Acceptable Numerical Accuracy}

The numerical solution of the transport equation is typically more difficult than the solution of the flow equation. This attribute requires the results of the code for a given test problem to have been checked against analytical solutions and against the results of other numerical codes for the same problem. Documentation of this quality assurance (QA) checking must be available.

\section{Minimal Numerical Dispersion}

Under certain circumstances, the error in the numerical approximation of a value can become as large as the value being approximated. When this occurs, the numerical solution combines an exclusively numerical dispersion with the real hydrodynamic dispersion, producing an overestimate of the actual dispersion. Solution techniques that minimize numerical dispersion are required.

\section{Acceptable Verification and Validation}

The degree of computer code verification and validation varies widely depending on the code being considered. The extent to which this process has been documented for a particular code varies even more. Thoroughly documented testing is required to ensure that the code satisfies requirements specified for its options and features.

\section{Access to Source Code}

Computer codes are initially written by humans in a high-level language such as FORTRAN and then translated into machine language for execution on the computer. The high-level version of the code is called the "source code," and can be read and modified by humans. The machine-language version is called the "executable code," can be deciphered only by the computer. Many distributors of computer codes provide only the executable version of the code to the user. During the course of the development or application of the CAU model, it may be 
necessary to examine or modify the step-by-step procedure implemented in the computer code. To accomplish this, access to the source code will be required.

\section{Groundwater Flow Model Attributes}

\section{Saturated Groundwater Flow}

The codes must be able to simulate saturated groundwater flow.

\section{Heterogeneous and Anisotropic Hydraulic Conductivity}

Aquifer heterogeneity reflects the natural variability in the subsurface. The CAU model must be capable of simulating flow through aquifers in which the hydraulic conductivity may vary from location to location. Anisotropy is a directional dependence of the hydraulic conductivity. In fractured aquifers, it is common for hydraulic conductivity to be larger in a direction parallel to fracturing and smaller perpendicular to fracturing.

\section{Point and Distributed Sources and Sinks of Water}

Recharge may occur over a large spatial area due to precipitation or may be concentrated into washes or craters. Discharge may occur at wells or individual springs or may occur over larger areas such as playas. The CAU model should have the capability to simulate these various cases.

\section{Temperature Dependence}

The flow of groundwater may be influenced by water temperature variations. Warm water is more buoyant than colder water and tends to rise. Additionally, warm water is less viscous and tends to move more easily than cold water. These processes may be important in some portions of the CAU where naturally occurring sources of heat have caused elevated groundwater temperatures. An additional source of warm water may be the underground test cavities. It may be important to account for these temperature effects in the simulations.

\section{Simulate Complex Geology}

The geology of Yucca Flat/Climax Mine area is complex. It consists of multiple stratigraphic units, some of which are truncated by faults and other structural features. Even within units, changes in facies result in spatial variations in material properties. The flow of groundwater (amount and direction) is governed, in large part, by the distribution of geologic units. The code must be able to include important features of the geology such as lateral and vertical changes in material properties. Much of this attribute is similar to earlier general attributes related to the number of grid nodes and simulation speed. The greater the number of nodes, the more detail that can be incorporated into the CAU model.

\section{Transport Model Attributes}

\section{Advection, Dispersion, Sorption, and Matrix Diffusion}

It is expected that advection (via the groundwater flux) and matrix diffusion (via dual porosity) will be the primary factors influencing tritium transport. It is expected that sorption will also be important for reactive contaminants, but this 
may not be the dominant contributor to the location of the contaminant boundary. Dispersion is included because it may be important at smaller scales.

\section{Radioactive Decay}

Most, but not all, of the potential contaminants of interest are radionuclides. The activity per volume of radionuclides decreases via the process of radioactive decay.

\section{Daughter Products}

A radionuclide may decay into another radionuclide (called a daughter product) or into a stable isotope. More accurate estimates of dose can be obtained if the code is capable of simulating the ingrowth and transport of a radionuclide and daughter product(s).

\section{Desirable Attributes}

These are attributes of the computer codes that were considered valuable but not essential to satisfying the CAU-modeling objectives.

\section{Finite Element Formulation}

A finite element formulation allows much more flexibility in representing the geology being modeled. Grids can be developed to represent complex structures such as faults, pinch outs, and layer truncations. In addition, grid refinement allows the grid to be modified to provide more resolution in the area of interest.

\section{Steady-State Capability}

Some of the codes do not include a steady flow option, but rather reach steady-state by leaving parameters fixed in time and performing transient simulations over large periods of time until steady-state is reached. This approach is adequate, but somewhat slower than if a true steady-state option were available.

\section{Double-Porosity/Double-Permeability Formulation}

The double-porosity/double-permeability method is similar to the double-porosity method in that it allows for communication between fractures and matrix material. The term dual porosity/dual permeability is often used in the literature. In this report, dual is used interchangeably with "double" depending on the usage in the model documentation. This feature allows for the modeling of matrix diffusion. The double-porosity/double-permeability method differs in that it allows matrix cells that communicate with fractures to also communicate with other matrix cells. While this method provides a more realistic simulation, its use is more important for unsaturated flow problems.

\section{Multiple Solutes}

Many codes are designed to provide a simulation of the migration of a single solute in a given run. Using a code with the ability to model transport for multiple solutes in a single run may be more efficient. 


\section{Established Pre- and Post-Processors}

The task of creating the input datasets for any model is simplified by having pre-processors take data and put it into a form that is required by the model. Post-processors take model output and typically create graphic images of some simulated parameter such as water level or solute concentration. Pre- and post-processors generally speed up the modeling task. 


\section{A.3.0 Testing Criteria}

The criteria used to assess the codes were defined in the CAIP for Yucca Flat/Climax Mine (DOE/NV, 2000a). These criteria range from a somewhat subjective assessment of ease of use to more quantifiable assessments such as the run time for a sample problem. The testing criteria are as follows:

\section{Portability}

The CAU model may be sent to independent reviewers as well as the State of Nevada. Each of these stakeholders may want to run the code themselves. This requires that the code, when complete, should require minimal special equipment or software in order to make it usable. Additionally, the CAU model will likely need to be run on a classified computer at the NNSA/NSO or another secure location to produce a final estimate of the contaminant boundary (results based on classified data will be reported in a classified report). The code and associated pre- and post-processors must be portable to the selected secure location to allow for efficient classified simulations.

\section{Quality Assurance Evaluation}

The chosen code must have been appropriately verified to ensure the output is accurate. The QA evaluation refers to the level of documentation and testing for a code. The ability of the code to simulate the processes of interest is a function of the formulation of the equations and the quality of the programming. A code meets the QA requirements if its results have been verified against those of other codes as well as compared with analytical solutions. These comparisons must be documented before a code will be used for the Yucca Flat/Climax Mine model.

\section{Ease of Use}

The ease of use is a subjective judgment that assesses the modeler's degree of difficulty in getting the model running. This is, by necessity, a value judgment of the modeler and reflects the modeler's experience and background. A great deal of energy will be spent calibrating the CAU model and setting up sensitivity and uncertainty analyses. A code that is difficult to use makes the job of calibration more difficult and reduces the code's portability. Ease of use includes factors such as the structure of the input datasets used in the model and the flexibility of preand post-processors.

\section{Ability to Represent the CAU Hydrogeology}

The primary geologic features that control flow need to be represented in the CAU model. These features include the hydrostratigraphy, physical boundaries, and structural features such as faults. In addition, the ability to model physical 
processes of concern (e.g., advection, dispersion, matrix diffusion, adsorption, and radioactive decay) is also important. The criteria also include an assessment of the ability of the model to include sufficient detail and stay within the memory limitations of the computer platform chosen for simulation.

\section{Speed of Simulation}

The time required for a solution is also of importance to the evaluation of the codes. The faster the code, the shorter the time to complete each model run. As calibration normally requires many (often greater than 500) model runs, the simulation time becomes a problem if it is too long. To enhance calibration performance, simulation times should be as short as possible. In addition, the ability to carry out model runs in parallel by distributing them across a network can greatly enhance calibration efficiency. 


\section{A.4.0 Finite Element Heat and Mass Transfer Code}

The FEHM code (Zyvoloski et al., 1997b), developed by LANL, simulates 3-D, time-dependent, multiphase, multicomponent, nonisothermal, reactive groundwater flow through porous and fractured media. FEHM's finite element formulation provides an accurate representation of complex 3-D geologic media and structures and their effects on subsurface flow and transport. Specific capabilities include:

- 3-D

- Flow of gas, water, oil, and heat

- Flow of air, water, and heat

- Multiple chemically reactive and sorbing tracers

- Colloid transport

- Finite element/finite volume formulation

- Coupled stress module

- Saturated and unsaturated media

- Preconditioned conjugate gradient solution of coupled nonlinear equations

- Double-porosity and double-porosity/double-permeability capabilities

- Complex geometries with unstructured grids

A number of documents supporting the FEHM code are readily available from LANL. Documentation includes a description of the mathematical models and numerical methods used by FEHM (Zyvoloski et al., 1997a), the user's manual (Zyvoloski et al., 1997b), documentation of the functional and performance requirements for FEHM, description of the FEHM software, the verification and validation plan, and description of the verification and validation activities (Dash et al., 1997; Dash 2000 and 2001). 


\section{A.5.0 Test Problem Location}

Descriptions of the hydrology of the Pahute Mesa-Oasis Valley and the Yucca Flat/Climax Mine areas in DOE/NV (2000) provide a basis for comparison of the important characteristics to be represented in the respective CAU models.

Pahute Mesa is an elongated, east-to-west-oriented volcanic plateau within the Southwestern Nevada Volcanic Field and consists mainly of Miocene rhyolitic rocks that erupted from local calderas (Laczniak et. al., 1996). Its eastern portion occupies the northwestern corner of the NTS, including Areas 19 and 20. The surface of the Pahute Mesa area consists primarily of ash-flow tuffs of the Thirsty Canyon and Timber Mountain Groups that erupted from calderas located just west and south of the area (BN, 2001). These Tertiary volcanics, along with volcanic rocks of the underlying Paintbrush Group, bury an older group of calderas that compose the Silent Canyon caldera complex (BN, 2001). The Silent Canyon Caldera complex along with the Timber Mountain Caldera complex are the dominant geologic features in the Pahute Mesa-Oasis Valley region. The Silent Canyon Caldera complex consists of at least two nested calderas, the Area 20 caldera and the older Grouse Canyon caldera. The Grouse Canyon caldera was formed and then filled by Tertiary eruptions of tuff and lava of the Belted Range Group. The Area 20 caldera was formed by eruptions of tuff of the Crater Flat Group, and then filled by eruptions of tuff and lava of the Crater Flat Group and Volcanics of Area 20. The volcanic rocks of the Belted Range Group, the Crater Flat Group, and Volcanics of Area 20 are underlain by a considerable thickness of older volcanic rocks, which were probably erupted locally from unidentified calderas, some possibly beneath Pahute Mesa. In the eastern portion of Pahute Mesa outside the calderas, the Tertiary volcanic rocks probably overlie an unknown thickness of late Precambrian to Cambrian quartzites and siltstones. Paleozoic carbonates may underlie the volcanic rocks in the western portion of Pahute Mesa (BN, 2001).

Since most tests on Pahute Mesa were conducted below or near the water table, contaminants could potentially migrate from Pahute Mesa to discharge areas in Oasis Valley (DOE/NV, 2000a). As a result, the Pahute Mesa CAU model domain extends to the discharge areas in Oasis Valley. Oasis Valley is a rectangular basin located in the western to southwestern portion of the model domain. The basin includes a moderate thickness of extra-caldera volcanic aquifers. Using the hydrogeologic framework described in DOE/NV (2000), all rocks at the NTS can be categorized using a system of classification consisting of nine hydrogeologic units (HGUs). These nine HGUs include the alluvial aquifer, four volcanic units, two intrusive units, and two units representing the pre-Tertiary rocks. All nine categories of HGUs are represented in the Pahute Mesa area. Structural features considered significant to the hydrology of this area include 
normal faults, transverse faults and structural zones, and calderas (DOE/NV, 2000). Normal faults are generally northwest- to northeast-striking, high-angle faults. Transverse faults and structural zones include generally westto northwest-striking, high-angle normal faults and structural zones oriented transverse to the generally north-striking basin and range normal faults. Calderas are considered hydrologically important features because they are the source of the volcanic rock in the region, and structures associated with the calderas can influence groundwater flow. A total of 47 structural features are included in the Pahute Mesa-Oasis Valley hydrostratigraphic model (Drellack et al., 2002).

From a flow and transport modeling perspective, the hydrogeology of the Yucca Flat/Climax Mine area is less complex than Pahute Mesa. Thus, a flow and transport code that meets the testing criteria for a test problem on Pahute Mesa will also meet the criteria for the Yucca Flat/Climax Mine area.

Yucca Flat is described in DOE/NV (2000) as a topographically closed basin with a playa at its southern end. Low ranges were formed around the basin by faulted and tilted blocks of Tertiary age volcanic rocks and underlying Precambrian and Paleozoic sedimentary rocks. These rocks form the basement of the basin, which is now covered by alluvium. In cross section, the Yucca Flat basin can be conceived of as irregular Precambrian and Paleozoic rocks overlain by the Tertiary volcanic units and the basin-filling alluvium. Eight of the nine HGUs discussed above are represented in the Yucca Flat/Climax Mine area. Volcanic rocks in this area originated from the same source as those on Pahute Mesa. Large-scale normal faulting formed the Yucca Flat basin. These faults may provide conduits between the younger rocks and the underlying regional aquifers. The Climax Mine area is an igneous intrusion in northern Yucca Flat where three tunnel-based tests were conducted above the static water level. Potential pathways from test cavities in the alluvial aquifer to the regional carbonate aquifer were described in DOE/NV (2001). These pathways include:

- High-permeability faults

- Juxtaposition of the alluvial or volcanic aquifers against the regional carbonate aquifer, due to displacement along a fault

- Direct communication from the alluvial and volcanic aquifers to the regional carbonate aquifer, where the alluvial aquifer is in direct contact with the regional carbonate aquifer where volcanic confining units are absent

Similarities between the Pahute Mesa and Yucca Flat/Climax Mine CAUs include: potential contaminants, radionuclide release and transport processes, characteristics of migration paths, geological media, and exposure pathways. Given these similarities and the level of complexity addressed in the TYBO-BENHAM study (Wolfsberg et al., 2002), this study provides a more than adequate test problem to evaluate the suitability of FEHM for the Yucca Flat/Climax Mine CAU model. 


\section{A.6.0 TYBO-BENHAM Study}

The TYBO-BENHAM study integrated field, laboratory, and other modeling data into a modeling process that captured relevant mechanisms affecting radionuclide transport in Pahute Mesa groundwater (Wolfsberg et al., 2002). This study was motivated by the discovery of plutonium and other radionuclides in two groundwater observation wells $1.3 \mathrm{~km}$ from the BENHAM site located in Area 20 of the NTS on Pahute Mesa (Kersting et al., 1999). To accomplish the goals of this study, a number of flow and transport models were developed using the FEHM code.

A sub-CAU scale flow model was developed using FEHM to model flow with depth-dependent thermal properties. The model domain, approximately $10 \mathrm{~km}$ on a side, was discretized using an unstructured finite-element grid that represented the 22 distinct deterministic HSUs in the area. Faults were included as discrete features. The HSU permeabilities were calibrated and the model was used to provide boundary conditions for a site-scale flow model located within the domain of the sub-CAU scale model.

The site-scale flow model developed using FEHM provided steady-state flow in the BENHAM and TYBO vicinity. This model was developed using a structured high-resolution grid and represented a domain 3.2 by $2.6 \mathrm{~km}$. Boundary conditions were provided by the sub-CAU scale flow model. The site-scale flow model was run using the CAU deterministic hydrostratigraphy and 30 geostatistical attribute fields.

A 3-D source model was developed for this study using FEHM. The processes modeled included coupled nonisothermal transient flow, glass dissolution, and particle transport in the BENHAM cavity/chimney system. This model provided mass flux of sorbing and nonsorbing radionuclides into the local aquifers. Linear sorption of radionuclides in the chimney is included in the model. The modeling also considered multiple chimney material properties and thermal conditions in a sensitivity analysis. This model did not include aqueous speciation, rock-water reactions, or $\mathrm{pH}$ variations.

Two site-scale transport models were developed using FEHM, a particle transport model, and a reactive transport model. Reactive, dual-porosity transport in steady-state, 3-D flow fields was modeled using the particle-tracking approach. This model was very computationally efficient, allowing multiple realizations to be run for sensitivity of source term, flow field, and transport parameters. In addition, the CAU deterministic hydrostratigraphy and 30 heterogeneous realizations were run. 
The site scale reactive transport model included more detailed chemical processes. As this model was significantly more complex, only a single heterogeneous realization was run. Processes modeled were reactive, dual-porosity, solute, and colloid-facilitated plutonium transport along steady-state streamtubes in a 3-D flow field.

These component models were combined with others in a system of models to: (1) simulate complex flow in layered, faulted, and fractured volcanic tuff; (2) investigate temperature-dependent processes associated with radionuclide release from melt glass and cavity-chimney systems; and (3) simulate radionuclide transport in fractured media, addressing fracture properties, diffusion, groundwater chemistry, colloids, fracture mineral exposure, and heterogeneity. 


\section{A.7.0 Performance Evaluation}

\section{Portability}

Computational mesh generation tools for this model include the LaGriT (George, 1997) suite of grid meshing tools. LaGriT is a library of user callable tools that provide mesh generation, mesh optimization, and dynamic mesh maintenance in three dimensions for a variety of applications. LaGriT and associated applications require a UNIX-based platform. The software, users manuals, and examples are available at no cost from LANL. A process for transferring hydrogeologic framework model information from an EarthVision ${ }^{\circledR}$ model to inputs required by LaGriT has been developed and tested.

FEHM is available for a number of platforms including Microsoft ${ }^{\circledR}$ Windows-based operating systems. Options can be specified in the FEHM input file to produce output files in a format readable by visualization software such as Tecplot and Surfer.

\section{QA Evaluation}

The FEHM code continues to be subjected to an extensive verification and validation effort and is maintained in a software configuration management system. The verification and validation plan is provided in detail by Dash et al. (1997), and validation tests for recent versions can be found in Dash (2000 and 2001). The objective of the verification is to test the options and features of the code. This is accomplished by comparing the results of simulations with published analytical solutions and results from other codes. Every time a modification is made to the code, it is tested with a suite of verification problems to ensure no errors were introduced or capabilities eliminated. Validation will include modeling of a number of field tests when data become available. The tests considered in the verification effort are described in detail by Dash et al. (1997) and test results are discussed. A number of additional documents supporting the FEHM code are readily available from LANL. These documents include the user's manual (Zyvoloski et al., 1997b), and a description of the mathematical models and numerical methods used by FEHM (Zyvoloski et al., 1997a).

\section{Ease of Use}

Ease of use has been identified as a key code attribute. Since ease of use is often regarded as a subjective judgment, an operational definition of ease of use must be provided to make it a viable measure. This can be accomplished by defining the end-user tasks that the code must satisfy. Ease of use includes factors such as the structure of the input datasets used in the model and the flexibility of pre- and post-processors. Ease of use increases efficiency, reduces likelihood of errors, and makes the work more traceable. 
The user interface consists of input and output files. With the exception of the geometry data file and zone data files developed using LaGriT, as described above, the remaining input files can be built by the user with an ASCII text editor. These files include a control file that contains the names of the input and output files needed by the FEHM code and the input file that contains user-parameter initialization values and problem-control information (Zyvoloski et al., 1997b). The structure of these files is clearly documented (Zyvoloski et al., 1997a) and allows for changes in parameters and problem-control specifications to be easily made using macro control statements.

The output files consist of a number of ASCII files containing values of specified variables such as head, concentration, or temperature among others at user specified times. These output files are in a format easily readable by visualization software such as Tecplot and Surfer.

\section{Ability to Represent the CAU Hydrogeology}

The observed features of the TYBO-BENHAM sub-CAU scale flow system captured by the calibrated model included steep gradients across faults, downward vertical gradients in the shallow units, and upward vertical gradients in the deep units (Wolfsberg et al., 2002). With respect to the TYBO-BENHAM study, Wolfsberg et al. (2002) concluded:

"With these results we are confident that we have generally captured the complex processes of source release and site scale migration."

In addition to the ability of the mesh-generating tools to represent complex geometry, the ability of FEHM to represent other attributes and processes characteristic of the CAU hydrogeology were demonstrated in this evaluation. These are: the capabilities to simulate a 3-D system, heterogeneous and anisotropic hydraulic conductivity, point and distributed sources and sinks of water, advection, dispersion, sorption, matrix diffusion, and temperaturedependent flow.

\section{Speed of Simulation}

The processor times for models of this complexity were considered acceptable. The use of parallel model runs distributed across a network was demonstrated. 


\section{A.8.0 Conclusions}

The TYBO-BENHAM study demonstrated the performance of FEHM with respect to all identified criteria for a site on Pahute Mesa. Given the similarities between the Pahute Mesa and Yucca Flat/Climax Mine CAUs and the simpler hydrostratigraphy of the Yucca Flat/Climax Mine CAU, FEHM is recommended for the Yucca Flat/Climax Mine CAU model. 


\section{A.9.0 References}

BN, see Bechtel Nevada.

Bechtel Nevada. 2001. Nevada Test Site Annual Site Environmental Report for Calendar Year 2000, DOE/NV/11718--605. Las Vegas, NV.

DOE/NV, see U.S. Department of Energy, Nevada Operations Office.

Dash, Z.V. 2000. Validation Test Report (VTR) for the FEHM Application Version 2.10, Yucca Mountain Project Identification Numbers SAN: LANL-1999-046; STN: 10086-2.10-00. Los Alamos, NM: Los Alamos National Laboratory.

Dash, Z.V. 2001. Validation Test Report (VTR) for the FEHM Application Version 2.12, Yucca Mountain Project Identification Numbers SAN: LANL-2001-133; STN: 10086-2.12-00. Los Alamos, NM: Los Alamos National Laboratory.

Dash, Z.V., B.A. Robinson, and G.A. Zyvoloski. 1997. Software Requirements, Design, and Verification and Validation for the FEHM Application - A Finite-Element Heat- and Mass-Transfer Code, LA-13305-MS. Los Alamos, NM: Los Alamos National Laboratory.

Drellack, S.L., L.B. Prothro, and J.L. Gonzales. 2002. A Hydrostratigraphic Model of the Pahute Mesa - Oasis Valley Area, Nye County, Nevada, DOE/NV11718-646. Las Vegas, NV: Bechtel Nevada.

FFACO, see Federal Facility Agreement and Consent Order.

Federal Facility Agreement and Consent Order. 1996 (as amended). Agreed to by the State of Nevada, the U.S. Department of Energy, and the U.S. Department of Defense.

George, D. 1997. Unstructured 3D Grid Toolbox for Modeling and Simulation, LA-UR-97-3052. Los Alamos, NM: Los Alamos National Laboratory.

Kersting, A.B., D.W. Efurd, D.L. Finnegan, D.J. Rokop, D.K. Smith, and J.L. Thompson. 1999. "Migration of Plutonium in Groundwater at the Nevada Test Site.” In Nature, 397. 
Laczniak, R.L., J.C. Cole, D.A. Sawyer, and D.A. Trudeau. 1996. Summary of Hydrogeologic Controls on Ground-Water Flow at the Nevada Test Site, Nye County, Nevada, USGS-WRIR-96-4109. Denver, CO: U.S. Geological Survey.

U.S. Department of Energy, Nevada Operations Office. 2000. Corrective Action Investigation Plan for Corrective Action Unit 97: Yucca Flat/Climax Mine, Nevada Test Site, Nevada, DOE/NV--659. Las Vegas, NV.

Wolfsberg, A., L. Glascoe, G. Lu, A. Olson, P. Lichtner, M. McGraw, T. Cherry, and G. Roemer. 2002. TYBO/BENHAM: Model Analysis for Groundwater Flow and Radionuclide Migration from Underground Nuclear Tests in Southwestern Pahute Mesa, Nevada, LA-13977. Los Alamos, NM: Los Alamos National Laboratory.

Zyvoloski, G.A., B.A. Robinson, Z.V. Dash, and L.L. Trease. 1997a. Summary of Models and Methods for the FEHM Application - A Finite-Element Heatand Mass-Transfer Code, LA-13307-MS. Los Alamos, NM: Los Alamos National Laboratory.

Zyvoloski, G.A., B.A. Robinson, Z.V. Dash, and L.L. Trease. 1997b. User's Manual for the FEHM Application - A Finite-Element Heat- and Mass-Transfer Code, LA-13306-M. Los Alamos, NM: Los Alamos National Laboratory. 


\section{Distribution}

$\underline{\text { Copies }}$

Paul J. Liebendorfer

State of Nevada

Bureau of Federal Facilities

Division of Environmental Protection

333 W. Nye Lane, Room 138

Carson City, NV 89706-0851

Donald R. Elle

State of Nevada

Bureau of Federal Facilities

Division of Environmental Protection

1771 E. Flamingo Rd, Suite 121-A

Las Vegas, NV 89119

Sabrina Lawrence

Environmental Restoration Division

U.S. Department of Energy

National Nuclear Security Administration

Nevada Site Office

P.O. Box $98518, \mathrm{M} / \mathrm{S} 505$

Las Vegas, NV 89193-8518

Robert Bangerter

Environmental Restoration Division

U.S. Department of Energy

National Nuclear Security Administration

Nevada Site Office

P.O. Box 98518, M/S 505

Las Vegas, NV 89193-8518

Ken Ortego

Bechtel Nevada

P.O. Box 98521 MS/NLV 82

Las Vegas, NV 89193

Chuck Russell

Desert Research Institute

755 E. Flamingo

Las Vegas, NV 89119

Ken Wall

Shaw Environmental, Inc.

P.O. Box 93838

Las Vegas, NV 89193 
Jim Aldrich

Los Alamos National Laboratory

Box 1663, MS-J514 CST-7

Los Alamos, NM 87545

Gayle Pawloski

Lawrence Livermore National Laboratory

P.O. Box 808, L-221

Livermore, CA 94551

Tim Rose

Lawrence Livermore National Laboratory

P.O. Box 808, L-221

Livermore, CA 94551

Bonnie Thompson

U.S. Geological Survey

160 Stephanie Street

Henderson, NV 89074

U.S. Department of Energy

National Nuclear Security Administration

Nevada Site Office

Technical Library

P.O. Box 98518, M/S 505

Las Vegas, NV 89193-8518

U.S. Department of Energy

Office of Scientific and Technical Information

P.O. Box 62

Oak Ridge, Tennessee 37831-0062

Southern Nevada Public Reading Facility

c/o Nuclear Testing Archive

P.O. Box 98521, M/S 400

Las Vegas, NV 89193

Manager, Northern Nevada FFACO

Public Reading Room Facility

c/o Nevada State Library \& Archives

Carson City, NV 89701-4285

Rick Waddell

GeoTrans, Inc.

9101 Harlan Street, Suite 210

Westminster, CO 80030
1 (Electronic)

\section{Dist-2}


Andy Wolfsberg

Los Alamos National Laboratory

EES-5, MS F649

Los Alamos, NM 87545

David E. Prudic

U.S. Geological Survey

$333 \mathrm{~W}$. Nye Lane

Carson City, NV 89706

Vefa Yucel

Bechtel Nevada

P.O. Box $98521, \mathrm{M} / \mathrm{S}$ NLV081

Las Vegas, NV 89193

Greg Pohll

Desert Research Institute

2215 Raggio Parkway

Reno, NV 89512

Ken Rehfeldt

GeoTrans, Inc.

P.O. Box 93838

Las Vegas, NV 89193

Shaw Environmental, Inc.

Central Files

P.O. Box 93838

Las Vegas, NV 89193
1 (Electronic)

1 (Electronic)

1 (Electronic)

1 (Electronic)

1 (Paper)

2 (Paper and

Electronic) 